Review

\title{
Two-Dimensional Nanomaterials for the Removal of Pharmaceuticals from Wastewater: A Critical Review
}

\author{
Sergio González-Poggini $(\mathbb{0}$, Andreas Rosenkranz $\mathbb{1}$ and Melanie Colet-Lagrille *
}

check for updates

Citation: González-Poggini, S.; Rosenkranz, A.; Colet-Lagrille, M. Two-Dimensional Nanomaterials for the Removal of Pharmaceuticals from Wastewater: A Critical Review. Processes 2021, 9, 2160. https:// doi.org/10.3390/pr9122160

Academic Editor: Dimitris Zagklis

Received: 20 October 2021

Accepted: 24 November 2021

Published: 29 November 2021

Publisher's Note: MDPI stays neutral with regard to jurisdictional claims in published maps and institutional affiliations.

Copyright: (c) 2021 by the authors. Licensee MDPI, Basel, Switzerland. This article is an open access article distributed under the terms and conditions of the Creative Commons Attribution (CC BY) license (https:// creativecommons.org/licenses/by/ $4.0 /)$.
Department of Chemical Engineering, Biotechnology and Materials, Faculty of Physical and Mathematical Sciences, Universidad de Chile, Beauchef 851, Santiago 8370456, Chile; sergio.gonzalez.p@ug.uchile.cl (S.G.-P.); arosenkranz@ing.uchile.cl (A.R.)

* Correspondence: mcolet@ing.uchile.cl

\begin{abstract}
The removal of pharmaceuticals from wastewater is critical due to their considerable risk on ecosystems and human health. Additionally, they are resistant to conventional chemical and biological remediation methods. Two-dimensional nanomaterials are a promising approach to face this challenge due to their combination of high surface areas, high electrical conductivities, and partially optical transparency. This review discusses the state-of-the-art concerning their use as adsorbents, oxidation catalysts or photocatalysts, and electrochemical catalysts for water treatment purposes. The bibliographic search bases upon academic databases including articles published until August 2021. Regarding adsorption, high removal capacities $\left(>200 \mathrm{mg} \mathrm{g}^{-1}\right)$ and short equilibrium times ( $<30 \mathrm{~min}$ ) are reported for molybdenum disulfide, metal-organic frameworks, MXenes, and graphene oxide/magnetite nanocomposites, attributed to a strong adsorbate-adsorbent chemical interaction. Concerning photocatalysis, MXenes and carbon nitride heterostructures show enhanced charge carriers separation, favoring the generation of reactive oxygen species to degrade most pharmaceuticals. Peroxymonosulfate activation via pure or photo-assisted catalytic oxidation is promising to completely degrade many compounds in less than $30 \mathrm{~min}$. Future work should be focused on the exploration of greener synthesis methods, regeneration, and recycling at the end-of-life of two-dimensional materials towards their successful large-scale production and application.
\end{abstract}

Keywords: two-dimensional nanomaterials; wastewater treatment; pharmaceuticals; adsorption; photocatalytic processes; redox and electrochemical processes

\section{Introduction}

The contamination level of natural water streams has increased in recent decades due to the rapid global industrial development associated with a growing world population. This generates many inorganic contaminants (toxic heavy metals-e.g., arsenic, lead, mercury, cobalt-and toxic gases-e.g., $\mathrm{NO}_{x}, \mathrm{SO}_{\mathrm{x}}, \mathrm{CO}, \mathrm{NH}_{3}-$ ), and organic contaminants including dyes, pesticides, and pharmaceuticals as well as bio-toxics [1-5]. In this scenario, the need for new, highly efficient wastewater treatment processes is compelling considering: (i) the extremely variable composition of the effluents, (ii) the refractory behaviour of several pollutants to conventional chemical and biological remediation methods (coagulation, flocculation, screening, centrifugation, flotation, aerobic and anaerobic treatments), and (iii) the low concentration at which these contaminants are present in wastewater streams.

Particularly in the case of pharmaceuticals, the latter three points are crucial in the design and development of new methods for wastewater treatment. Pharmaceuticals (and personal care products) contain diverse organic groups, such as antibiotics, hormones, and antimicrobial agents, which have a persistent toxic action on microorganisms, thus posing a considerable risk to ecosystems and human health [6-8]. They are regularly detected in natural water streams because of their non-effective elimination in treatment processes. The typical concentrations of pharmaceutical pollutants in wastewater range between 
$1 \mathrm{ng} \mathrm{L}^{-1}$ and $600 \mu \mathrm{g} \mathrm{L} \mathrm{L}^{-1}[9,10]$. They come from varied origins, with industrial, hospital, and domestic wastewaters being the primary sources [11].

Due to the variable nature of pharmaceuticals, there is not a specific treatment that can assure their overall removal. In conventional wastewater treatment plants, carbamazepine, metoprolol, mefenamic acid, and non-steroidal anti-inflammatory drugs such as ketoprofen and diclofenac are poorly eliminated (removal efficiencies lower than $40 \%$ ). The situation is similar for antibiotics such as azithromycin (removal efficiency of $45 \%$ ), clarithromycin (removal efficiency of $43 \%$ ), and erythromycin (removal efficiency of 30\%) [12]. The conventional wastewater treatment processes used for the elimination of persistent pollutants are coagulation-flocculation, adsorption, ozonation, and biological treatment. Coagulationflocculation processes have demonstrated to be ineffective for the elimination of most pharmaceutical micropollutants, ranging from about 0 to 50\% of efficiency. Moreover, adsorption on activated carbon (which is usually employed in drinking water treatment) has proved to remove a higher percentage of pharmaceutical pollutants, with removal efficiencies between 20 and 99\%, but considerably large equilibrium times [11]. Ozonation has shown high degradation efficiencies, high degradation rates, and non-selectivity. However, secondary reactions have been reported in aqueous media leading to the formation of toxic by-products with a detrimental impact on the environment [13]. Lastly, antibiotics are generally non-biodegradable, which explains the high concentrations of ciprofloxacin and tetracycline found in effluents after biological treatment. In this respect, the presence of antibiotics in water sources can contribute to the development of antimicrobial resistance, which is a global health concern since it is annually responsible for more than 23,000 deaths just in the United States [14].

Recently, nanotechnology has appeared as a promising approach to remove or degrade these pollutants in wastewater, due to the unique structural, physicochemical, and electrochemical properties shown by zero-dimensional (0D) nanoparticles, one-dimensional (1D) nanowires/nanorods, two-dimensional (2D) nanoplates/nanosheets, and three-dimensional (3D) nanostructures, as well as their functional composites [15]. Particularly, 2D nanomaterials present the thinnest structures and largest surface-to-volume ratios, which hold great promise towards faster processing times and higher treatment efficiencies than conventional chemical and biological remediation methods (please refer to Section 2 for more details).

A revision of the application of 2D materials in recent years for the removal or degradation of pharmaceuticals from wastewaters (bibliographic search made using academic databases including articles published until August 2021) suggests that they are mostly used as adsorbents, oxidation catalysts or photo-catalysts, and electrochemical catalysts [16-18].

In this regard, adsorption is one of the most widely used approaches for the removal of contaminants from wastewater due to its simplicity and cost-effectiveness. Conventional adsorbents range from granular powdered activated carbon and kaolin to chitosan, which offer high porosity, large specific surface area, and suitable functionalities for the effective capture of pollutants under optimal operating conditions (adsorbent dose, pollutant initial concentration, temperature, $\mathrm{pH}$, ionic strength, mixing speed, and contact time). Recently, 2D nanomaterials, such as graphene or MXenes, have gained attention as emerging adsorbents due to their unique surface properties compared to conventional bulk adsorbents $[19,20]$. Particularly for the removal of antibiotics such as, tetracycline, doxycycline, and ciprofloxacin, graphene and its nanocomposites have reached removal ratios of about $100 \mathrm{mg}$ of contaminant per gram of adsorbent, which can be further enhanced by modifying their degree of functionalization, or electric/magnetic properties [21]. MXenes and their nanocomposites have shown comparable removal ratios in the case of metal ions and dyes, which can be tailored by the same routes than graphene-based nanomaterials $[22,23]$.

Heterogeneous photocatalytic processes also attract considerable attention as an effective approach for the degradation of persistent contaminants, since they represent a green route for wastewater treatment based on inexhaustible solar energy as driving force. Particularly, 2D carbon-based nanomaterials, such as graphitic carbon nitride $\left(\mathrm{g}-\mathrm{C}_{3} \mathrm{~N}_{4}\right)$ 
and graphene-based nanomaterials, synthesized by various routes and modified by different metals/metal oxides—such as $\mathrm{Ag}, \mathrm{Au}, \mathrm{Ni}, \mathrm{Zn}, \mathrm{Sn}$, and $\mathrm{Fe}$ - have shown unique photoelectronic properties, high chemical stability, and good light absorption in the visible range (approximately between 450 and $460 \mathrm{~nm}$ ) [24,25]. This type of catalysts promotes the generation of highly reactive radical species such as hydroxyl radicals $\left(\mathrm{OH}^{\bullet}\right)$, superoxide radicals $\left(\mathrm{O}_{2}{ }^{-}\right)$, and holes $\left(\mathrm{h}^{+}\right)$at their surface via photo-assisted water decomposition, which oxidize a large variety of pharmaceuticals such as ciprofloxacin, venlafaxine, sulfamethoxazole, carbamazepine, and dexamethasone. In some cases, pharmaceuticals can be even completely mineralized, as demonstrated at laboratory and pilot scale. Moreover, other type of contaminants such as dyes, petroleum hydrocarbons, and phenolic compounds have been treated with outstanding results [26-28].

Redox and electrochemical processes offer the possibility of degrading a wide range of organic compounds, such as phenols, dyes, pharmaceuticals, and personal care products, via the generation of highly reactive radical species induced through the redox or electrochemical activation of intermediate species (hydrogen peroxide $\left(\mathrm{H}_{2} \mathrm{O}_{2}\right)$ or peroxymonosulfate $\left.\left(\mathrm{HSO}_{5}{ }^{-}\right)\right)$on the surface of a catalyst or electrocatalyst $[29,30]$. Fenton and Fenton-like processes are the most widely studied and applied advanced oxidation processes (AOPs) for the degradation of these contaminants due to their simple operation, mild operating conditions, and fast formation rates of $\mathrm{OH}^{\bullet}$ radicals compared with other AOPs such as ultrasound, ozonation, and radiolysis. In conventional Fenton processes, the $\mathrm{Fe}^{3+} / \mathrm{Fe}^{2+}$ redox couple is used as intermediary for the activation of added or in-situ produced $\mathrm{H}_{2} \mathrm{O}_{2}$. However, recently other metal redox couples such as $\mathrm{Co}^{3+} / \mathrm{Co}^{2+}, \mathrm{Ce}^{4+} / \mathrm{Ce}^{3+}$, or $\mathrm{Mo}^{6+} / \mathrm{Mo}^{4+}$ have been tested in Fenton-like processes with increased degradation rates when compared to iron [31,32]. The integration of this approach into electrochemical systems and the introduction of 2D nanomaterials for the fabrication of electrodes are expected to allow for successful scaling up of continuous operation processes, since their combination permits the rapid degradation of a diversity of contaminants due to the enhanced oxidation efficiencies established under an applied current or potential [33-36].

This article aims to summarize the key properties of 2D nanomaterials for wastewater treatment (Section 2), and their most recent applications for the removal of pharmaceuticals from wastewater via adsorption (Section 3.1), photocatalytic (Section 3.2), redox, and electrochemical processes (Section 3.3). As a result of a critical analysis of the articles revised the most promising alternatives of 2D nanomaterials for the removal of pharmaceuticals are identified, as well as the challenges they face for their future large-scale fabrication and application.

\section{2D Nanomaterials: General Aspects}

Initiated by graphene discovery [37], a one-atom-thick layer of carbon atoms with honeycomb structure, the successful synthesis of 2D nanomaterials rapidly expanded from graphene derivates (graphene oxide (GO) and reduced graphene oxide (rGO)) [38] to transition metal dichalcogenides (TMDs) [39,40] and MXenes [41-44]. Their unique physicochemical, mechanical, electrical, and thermal properties suggest their usage for advanced water purification purposes such as the removal of pharmaceutical contaminants from wastewater $[45,46]$. In this regard, three approaches including adsorption, photocatalytic, and electrocatalytic degradation (or combinations of them), can be identified. The first approach seems to be interesting since it is easily applicable, cheap, and efficient [47]. Photocatalytic degradation using sunlight as energy source is environmentally friendly, cost-effective and efficient [48-50], while electrochemical processes (particularly combined with photocatalytic degradation) are promising to be up-scaled for continuous operation applications [4,32].

The use of 2D nanomaterials for these purposes is promising since they have a unique property combination involving high surface areas, high thermal and electrical conductivities, and partially an optical transparency. Moreover, the layer thickness of 2D nanomaterials (z-dimension) becomes adjustable by synthesis and/or mechanical/chemical delamination. 
Another striking factor of 2D nanomaterials is that they have functional groups on their surface, which makes their surface chemistry intentionally tunable [43,51-53].

Regarding adsorption, single- or few-layered nanosheets provide many active sites, which can be easily accessed and contacted from both sides. Their high specific surface area and pore size are advantageous, thus enabling fast diffusion processes and surface reactions, which result in fast adsorption kinetics. The existing surface terminations on 2D nanomaterials can be used to induce specific interfacial reactions such as hydrogen bonding or $\pi-\pi$ interactions. The overall dimensions of the used 2D nanomaterials (reduced z-dimensions) enables a fast mass transfer rate between the adsorbent and the contaminants, which results in fast equilibrium processes [47-49].

However, due to the overall purpose to remove pharmaceuticals from wastewater, the used 2D nanomaterials need to form stable dispersions in water. Their nanoscopic size induces the tendency for agglomeration, thus forming bigger clusters. This reduces not only the specific surface area, but also decreases the number of available active reaction sites and decreases the overall adsorption capacity $[54,55]$. In this regard, this reagglomeration tendency needs to be suppressed to ensure beneficial adsorption properties over time. The existing surface groups can be used to chemically functionalize the nanomaterials, which can help to reduce their agglomeration tendency and improve their dispersion stability. Besides chemical functionalization, the assembly of 2D and 3D structures including heterojunctions, hybrid nanocomposites, hydro- and aerogels has shown the potential to circumvent the critical agglomeration tendency [54,55]. Furthermore, the combination of different 2D nanomaterials can intentionally manipulate the specific surface area as well as the resulting interaction with the pollutants, thus increasing the respective adsorption capacity and accelerating the underlying kinetics. Similar outcomes can be achieved by doping or defect-engineering of 2D nanomaterials such as the creation of additional vacancies. Another advantage of 2D nanomaterials is that they can be easily combined with other 2D nanomaterials or 1D nanoparticles to create multifunctional hybrids. Frequently, 2D nanomaterials are self-assembled with magnetic $\mathrm{Fe}_{3} \mathrm{O}_{4}$ nanoparticles without any further crosslinking agent. Besides beneficial adsorption properties, the designed hybrid nanocomposites enable an easy solid-liquid separation, which is essential for their repetitive usage and recycling.

Regarding photocatalytic degradation, the underlying processes rely on the adsorption of light, thus exciting electrons and shifting them from the valence to the conduction band. This process produces the same amount of positively charged holes in the valence band. By adjusting the respective potential differences correctly, radical oxygen species (ROS) such as $\mathrm{OH}^{\bullet}$ and $\mathrm{O}_{2}{ }^{\bullet-}$ can be formed. ROS are molecules consisting of oxygen atoms with unsaturated electron pairs, which are highly reactive and of short lifetime $[24,37]$. Four important species, namely superoxide anion radicals $\left(\mathrm{O}_{2}{ }^{\bullet-}\right)$, hydrogen peroxide $\left(\mathrm{H}_{2} \mathrm{O}_{2}\right)$, singlet oxygen $\left({ }^{1} \mathrm{O}_{2}\right)$ and hydroxyl radicals $\left(\mathrm{OH}^{\bullet}\right)$ need to be distinguished. ROS are generated in oxygen- and/or water-containing environments by complex redox reactions, while the necessary respective activation energy typically comes from the absorption of light. Superoxide anion radicals and hydrogen peroxide are generated by stepwise reduction processes or the addition of an electron to the $\pi^{*}$ orbitals with subsequent protonation processes [37]. When further reducing hydrogen peroxide, the dissociation of the oxygen bond generates hydroxyl radicals. It is important to mention that the oxidation of water in aqueous environments induces the formation of ROS in the following order: hydroxyl radicals, hydrogen peroxide, superoxide anion radicals and singlet oxygen. In contrast, complex reduction processes of $\mathrm{O}_{2}$ generate ROS in the respective order of superoxide anion radicals, hydrogen peroxide and hydroxyl radicals [37]. The important influence of ROS regarding photocatalytic properties has been also recently demonstrated for few- and multi-layer MXenes nanosheets. Rosales et al. showed that active $\mathrm{TiO}_{2}$ sites on the surface of few-layer $\mathrm{Ti}_{3} \mathrm{C}_{2} \mathrm{~T}_{\mathrm{X}}$ nanosheets, which were verified by XPS, are capable to form electron/hole pairs under UVA irradiation. As aforementioned, the electrons experience a transfer from the conduction band of $\mathrm{TiO}_{2}$ to the nanosheets surface thus 
helping to separate the photogenerated carriers [56]. The existing surface terminations and MXenes outstanding electrical conductivity reduce the probability for recombination, thus notably boosting photocatalytic processes. It can be assumed that complex redox reactions (-OH surface terminations and oxygen or water) are likely to induce the generation of ROS. Few-layer $\mathrm{Ti}_{3} \mathrm{C}_{2} \mathrm{~T}_{\mathrm{x}}$ nanosheets have shown a higher capability to generate ROS due to an increased amount of superficial $\mathrm{TiO}_{2}$ compared to multi-layer nanosheets [57].

In this regard, the key properties of $2 \mathrm{D}$ nanomaterials for the successful usage in photocatalytic degradation are their specific surface area, respective bandgap energy, electron mobility and electrical conductivity [57]. Particular emphasis needs to be put on the respective bandgap engineering to match the respective energy input by visible light with the bandgap of the 2D nanomaterial [58-60]. To manipulate the bandgap and optical transparency, doping and defect engineering (vacancies) of 2D nanomaterials are well-explored approaches. In this context, doping can be realized by non-metal and metal doping with the overall purpose to improve light adsorption. Vacancies can trap electrons or holes thus manipulating the diffusion length of the respective carriers or changing the electronic structure, which potentially increases light adsorption. Electron-hole separation and migration properties can be defined by a specific interfacial design such as homo- or heterojunction interfaces, Schottky interfaces, and double heterojunctions.

In the case of pure or photo-assisted redox and electrochemical processes the same properties benefiting the photocatalytic degradation of contaminants in wastewater (namely, enhanced specific surface area, electron mobility, and charge transfer) explain the promising performance of 2D nanomaterials as oxidation catalysts and electrode materials. Particularly, titanium and carbon-based 2D nanomaterials are prospective options to conventional environmentally unfriendly and toxic catalysts and electrode materials such as cobalt and lead.

\section{2D Nanomaterials for the Removal of Pharmaceuticals in Wastewater}

\subsection{Adsorption Processes}

2D nanomaterials have been frequently used to efficiently remove pharmaceuticals from wastewater via direct adsorption processes on the adsorbent surface suspended in the polluted liquid. In this regard, two main approaches can be identified including the direct use of as-synthesized or as-modified 2D nanomaterials or the application of binary or ternary nanocomposites.

\subsubsection{Pure 2D Nanomaterials}

In this group, different 2D nanomaterials including $\mathrm{MoS}_{2}$, boron nitride (BN), $\mathrm{GO}$ and $\mathrm{Ti}_{3} \mathrm{C}_{2} \mathrm{~T}_{\mathrm{x}}$ MXenes have been studied [61]. Yalei et al. fabricated flower-like, wrinkled $\mathrm{MoS}_{2}$ nanosheets via hydrothermal processing and studied their adsorption capability for diclofenac in aqueous solutions [62]. Hydrothermal processing at $210^{\circ} \mathrm{C}$ led to the formation of single-layer flower-like $\mathrm{MoS}_{2}$ with lateral dimensions of about $1.5 \mu \mathrm{m}$ and a specific superficial area of about $23.9 \mathrm{~m}^{2} \mathrm{~g}^{-1}$. The sorption behaviour of the as-fabricated flowerlike, single-layer $\mathrm{MoS}_{2}$ was studied in batch experiments depending on the interaction time (2-120 $\mathrm{min}$ ) and diclofenac concentration (2-200 $\left.\mathrm{mg} \mathrm{L}^{-1}\right)$. Compared to commercial $\mathrm{MoS}_{2}$, the flower-like $\mathrm{MoS}_{2}$ showed notably improved removal characteristics with a faster overall removal using less material. This behaviour was connected to the structure and surface properties of the fabricated flower-like $\mathrm{MoS}_{2}$. The maximum, theoretical sorption capacity of the flower-like $\mathrm{MoS}_{2}$ was about $217 \mathrm{mg} \mathrm{g}^{-1}$. This value is approximately 4 times larger than that of commercially available $\mathrm{MoS}_{2}$ and outperforms activated carbon and rGO having removal capacities of about 63 and $59 \mathrm{mg} \mathrm{g}^{-1}$, respectively. Regarding the sorption kinetics, a fast process with short reactions times was demonstrated thus adsorbing more than $90 \%$ of the contaminant in the first $5 \mathrm{~min}$ and reaching equilibrium conditions after $10 \mathrm{~min}$. The experimental data were fitted with a pseudo-second order model, which implies that chemical sorption is the underlying mechanism, while the respective capacity is related to the number of active sites available. 
Liu et al. optimized the synthesis of $\mathrm{BN}$ nanosheets using boric acid and urea as starting materials to obtain few-layered BN with a high surface area of about $900 \mathrm{~m}^{2} \mathrm{~g}^{-1}$ and a pore volume of about $0.76 \mathrm{~cm}^{3} \mathrm{~g}^{-1}$ [63]. Few-layer BN nanosheets were used to study their adsorption capability for estrone. The adsorption experiments were conducted in batch experiments dependent on temperature and concentration of BN. In the first $10 \mathrm{~min}$ of the adsorption experiments, about $80 \%$ of the initial concentration $\left(500 \mu \mathrm{g} \mathrm{L}^{-1}\right)$ were adsorbed. After a reaction time of $2 \mathrm{~h}$ (equilibrium conditions), a contaminant removal of $95 \%$ was achieved (Figure 1a,b)). Materials characterization, together with the adsorption experiments, confirmed that thinner nanosheets with fewer layers provided more accessible adsorption sites, thus inducing enhanced adsorption capabilities. The data were best fitted with a pseudo-second order kinetic model and the main mechanism was identified to be chemical adsorption (further confirmed by X-ray photoelectron spectroscopy (XPS) after the adsorption experiments). The adsorption capability depended on the initial concentration of estrone and tended to increase with concentration. Data fitted with a Langmuir model verified a maximum adsorption capacity of $250 \mathrm{mg} \mathrm{g}^{-1}$ for estrone. A careful thermodynamic consideration demonstrated that the involved processes are spontaneous with negative $\Delta G$ values and entropy-driven.

Chao et al. used diboron trioxide and urea to synthesize BN nanosheets, while $\mathrm{KOH}$ was used to controllably induce nitrogen defects in the nanosheets structure [64]. The authors verified by X-ray diffraction (XRD) a defective structure with reduced crystallinity and weakened interlayer interaction after the use of $\mathrm{KOH}$. The specific surface area was determined to be about $533 \mathrm{~m}^{2} \mathrm{~g}^{-1}$, with a pore size of about $2.74 \mathrm{~nm}$ for the defective nanosheets. Adsorption experiments for tetracycline verified an $18 \%$ increase in the maximum adsorption capacity for the defective nanosheets. The adsorption kinetics demonstrated a fast initial adsorption before reaching equilibrium conditions after $6 \mathrm{~h}$. The experimental data were best fitted with a pseudo-second order model, which implies that strong intermolecular forces controlled the adsorption process. The Freundlich isotherm fitted the kinetic data in the most appropriate way, which pointed towards a multi-layer adsorption behaviour. The introduction of defects in the nanosheets changed their electronic distribution thus enhancing $\pi-\pi$ interactions between the nanosheets and tetracycline. Chao et al. compared the adsorption capability of pristine $\mathrm{BN}$ with engineered $\mathrm{BN}$ having highly active boron vacancies and a hierarchical pore structure [65]. In this context, $\mathrm{ZnCl}_{2}$, which is known to be a pore-forming agent, was utilized during the polymerization of boric oxide $\mathrm{B}_{2} \mathrm{O}_{3}$ and urea, which led to the formation of few-layered $\mathrm{BN}$ nanosheets with embedded $\mathrm{Zn}$ nanoparticles. These nanoparticles can be evaporated using high calcination temperatures, thus creating the mentioned boron vacancies and porous structure. This, in turn, helped to manipulate the electronic structure and enriched the nanosheets with active sites. The adsorption properties of these engineered nanosheets for tetracycline were studied in batch experiments as a function of the used concentration and temperature. The specific surface area was shown to increase significantly, thus reaching a value of $1104 \mathrm{~m}^{2} \mathrm{~g}^{-1}$ for the engineered nanosheets, which may be beneficial for the involved mass transfer in adsorption processes. The adsorption capability of the created nanomaterial was determined to be about $438 \mathrm{mg} \mathrm{g}^{-1}$, which reflects an increase by $38 \%$ compared to pristine $\mathrm{BN}$. This clearly demonstrated that the precise addition of boron vacancies and creation of a porous structure helped to enhance the adsorption ability. In this regard, boron vacancies were made responsible to manipulate the electronic structure and create more active reaction sites, while the porous structure greatly increased the available surface area, both beneficially contributing towards enhanced adsorption characteristics. The obtained data were best fitted with a pseudo-second order model, which implies that the underlying mechanism relates to chemical adsorption. The authors speculated that intermolecular forces are important for the adsorption process and that the amount of adsorbed material correlated with the available active sites. The sorption isotherms were fitted with the Freundlich model, which is representative for multi-layer sorption on heterogeneous surfaces, which matches well with the characteristics of the few-layer, engineered BN. Adsorption, 
which was spontaneous in all cases considered, was more favourable at lower temperatures and showed negative $\Delta \mathrm{H}$ values (exothermic reaction). Related to the respective conditions, the adsorption capability for tetracycline was shown to be $\mathrm{pH}$-dependent, with an improved performance for the acidic regimes. The coexistence of other ions (especially, $\mathrm{PO}_{4}{ }^{3-}$ and $\mathrm{SO}_{4}{ }^{2-}$ ) in solution showed an inhibition effect with decreased adsorption capabilities of about $78 \%$. This demonstrated that electrostatic interactions are important in the overall adsorption process.

Few-layer $\mathrm{g}-\mathrm{C}_{3} \mathrm{~N}_{4}$ nanosheets were synthesized in a simple two-step thermal process based upon different precursors such as thiourea, dicyanamide or melamine to study their adsorption and photocatalytic activity towards tetracycline removal [66]. The produced nanosheets have an average thickness of $10 \mathrm{~nm}$ with a hierarchical morphology. Adsorption batch experiments to study the removal of tetracycline were conducted as a function of the nanomaterial loading, while keeping the temperature and $\mathrm{pH}$ constant throughout all experiments. $\mathrm{g}-\mathrm{C}_{3} \mathrm{~N}_{4}$ nanosheets adsorbed about $41 \%$ of the tetracycline in solution, which is 10 times higher than the value for conventional nanomaterials. Besides efficient adsorption capabilities, the nanomaterials showed excellent photocatalytic properties with about $38 \%$ of tetracycline being degraded under illumination (further revision of this sort of process is presented in Section 3.2). Adsorption and photocatalytic activity were shown to be stable over time with insignificant changes after three complete cycles. The beneficial properties of $g-\mathrm{C}_{3} \mathrm{~N}_{4}$ nanosheets were related to their increased specific surface area, which increased the contact area for the adsorption of tetracycline molecules. Moreover, XPS reveals a significant content of $\mathrm{sp}^{2}$-hybridized carbon on the surface of the nanomaterials, which implies the existence of superficial delocalized $\pi$ bonds. Consequently, more tetracycline molecules were able to interact with the nanosheets surface via $\pi-\pi$ interactions. The kinetic data of the tetracycline adsorption demonstrated a maximum adsorbed quantity under equilibrium conditions of about $40 \mathrm{mg} \mathrm{g}^{-1}$. The kinetic data were best fitted with a pseudo-second order model, which implies that chemical adsorption is the underlying mechanism.

Zhao et al. used a microwave-assisted hydrothermal approach to synthesize 2D copper-meso-tetra(4-carboxylphenyl)porphine (Cu-TCPP) and studied their adsorption behaviour as well as photocatalytic activity for different dyes and conventional antibiotics [67]. The synthesized Cu-TCPP nanosheets showed an average size of about $500 \mathrm{~nm}$, a high crystallinity, a specific surface area of $342 \mathrm{~m}^{2} \mathrm{~g}^{-1}$, and an average pore size of about $12 \mathrm{~nm}$. The respective adsorption behaviour was studied for three different antibiotics (oxytocin, tetracycline, and norfloxacin) as a function of the adjusted $\mathrm{pH}$. For oxytocin, a maximum removal rate of $47 \%$ was shown for a $\mathrm{pH}$ equal to 9 , while the highest removal efficiency for tetracycline $(72 \%)$ was found for a $\mathrm{pH}$ equal to 5 . The adsorption kinetics verified that equilibrium conditions were reached quickly, and the overall data followed a pseudo-second order model. The maximum adsorption capacities for oxytocin and tetracycline were determined to be around $130 \mathrm{mg} \mathrm{g}^{-1}$ and $150 \mathrm{mg} \mathrm{g}^{-1}$ under equilibrium conditions. The data were fitted by Langmuir isotherms, which implies that the underlying processes for the adsorption of different antibiotics rely on the existence of different functional groups on the surface of $\mathrm{Cu}$-TCPP.

Tang et al. synthesized two fluorescent, chemically and thermally stable covalent triazine frameworks via condensation reactions using aldehydes or amidines thus creating nanosheets with specific surface areas of $565 \mathrm{~m}^{2} \mathrm{~g}^{-1}$ and an average pore size of $1.5 \mathrm{~nm}$ (Figure 1c,d) [68]. The nanosheets showed pronounced adsorption capabilities for different antibiotics, including nitrofurazone, nitrofurantoin, and furazolidone. The maximum adsorption capacity of $351 \mathrm{mg} \mathrm{g}^{-1}$ was found for nitrofurazone. The kinetic data were best fitted with the Langmuir model, which implies that the underlying mechanism is based upon monolayer adsorption. After having reached equilibrium conditions, the nanosheets were capable to adsorb more than $99 \%$ of the different antibiotics (Figure 1e). The underlying kinetics followed a pseudo-second order kinetic model, while the adsorption capacity correlated with the respective pore size and specific surface area. 
Jiang et al. fabricated few-layered, zwitterionic covalent organic frameworks (5-7 layers) with sulfonic acids and amines evenly distributed over the nanosheets surface via solvothermal processing (specific surface area of around $187 \mathrm{~m}^{2} \mathrm{~g}^{-1}$ ) (Figure 1f) [69]. The existing functional groups induced some repulsive interactions between the layers, thus leading to self-exfoliation, which increased the number of active sites available. The adsorption kinetics were best fitted with a pseudo-second order model. For norfloxacin, an ultrafast adsorption with a $99.4 \%$ removal after $30 \mathrm{~s}$ was verified (Figure $1 \mathrm{~g}$ ). The speed was explained by nanochannels and zwitterionic sites available. The Langmuir isotherm fitting represented the kinetic data best, which implies that the underlying mechanisms can be best described as monolayer adsorption. The maximum adsorption capacity for norfloxacin was determined to be $824 \mathrm{mg} \mathrm{g}^{-1}$, which was explained by the improved accessibility of active sites and their zwitterionic character.
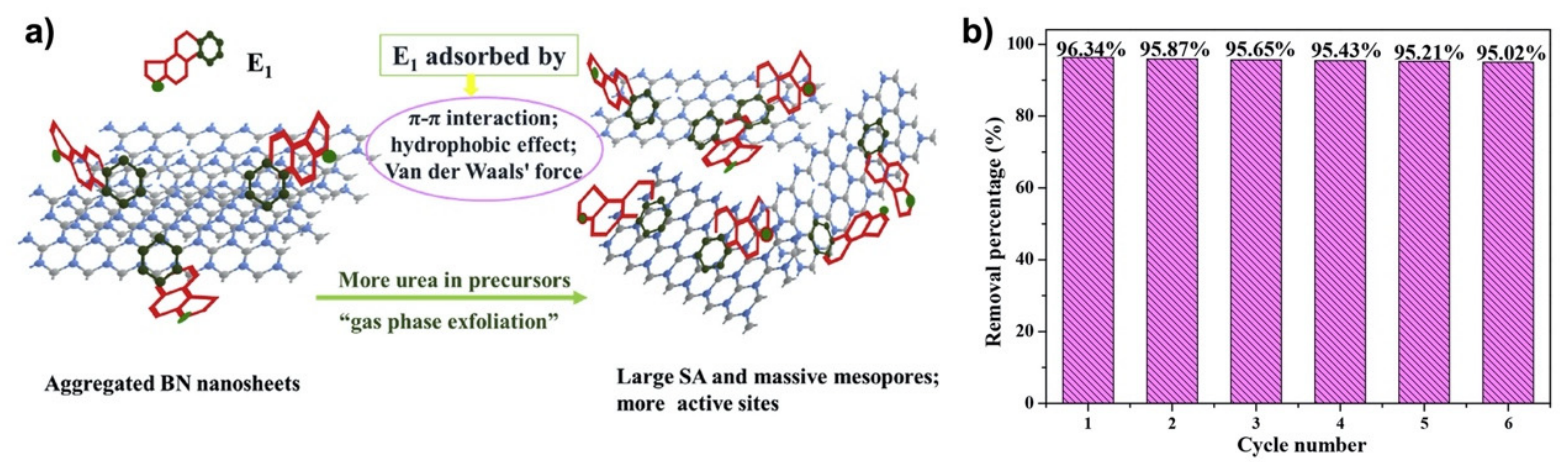
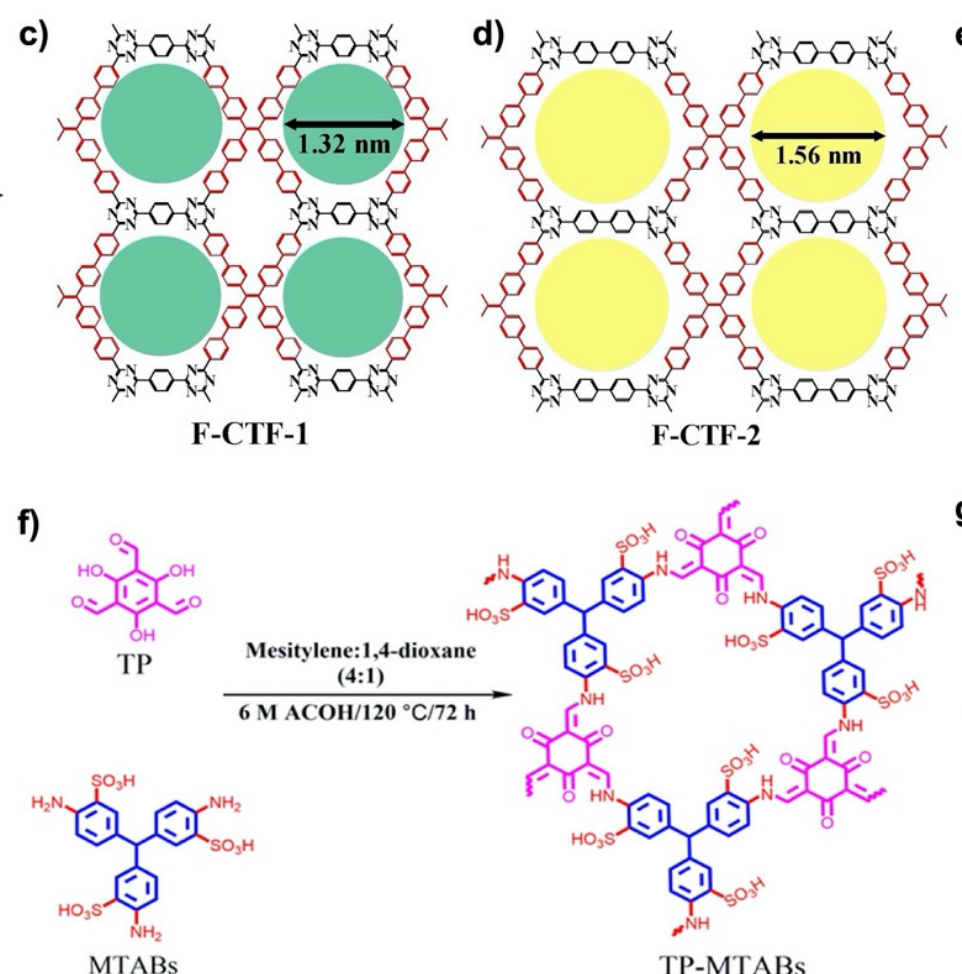

e)

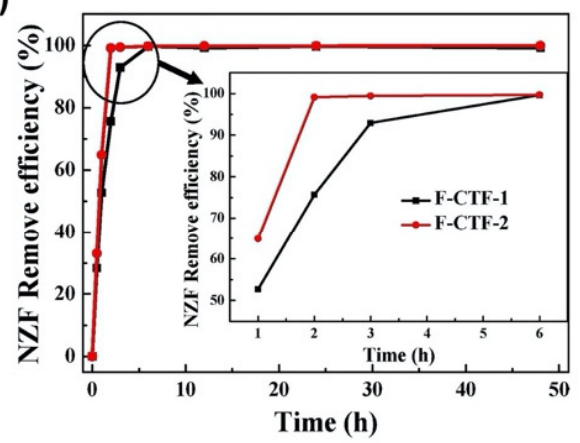

g)

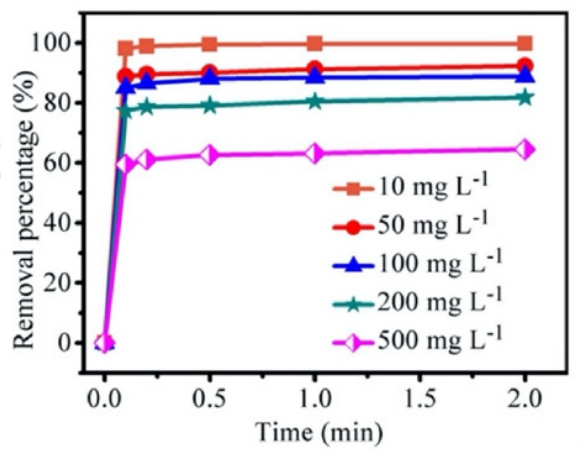

Figure 1. As-synthesized and as-modified 2D nanomaterials and their removal efficiency: (a,b) BN nanosheets and estrone removal after several cycles (reproduced with permission [63]), (c-e) 2D porous covalent triazine framework nanosheets and nitrofurazone removal by adsorbents synthesized from different precursors (reproduced with permission [68]), and (f,g) zwitterionic covalent organic frameworks and norfloxacin removal at different initial concentrations of the contaminant (reproduced with permission [69]).

Ghani et al. used sodium-intercalated, multi-layer $\mathrm{Ti}_{3} \mathrm{C}_{2} \mathrm{~T}_{\mathrm{x}}$ nanosheets to study their adsorption behaviour and electrochemical regeneration for the removal of ciprofloxacin [70]. 
The sodium-intercalated nanosheets were synthesized by simply immersing multi-layer MXenes in a $\mathrm{NaOH}$ solution, which led to a $25 \%$ increase of the d-spacing due to the intercalated ions. The increased d-spacing was speculated to be essential for the adsorption capability due to easier accessibility for the active sites. Compared to the pristine MXenes, the sodium-intercalated MXenes showed a 2-fold enhancement in the adsorption capability. Since the superficial area was constant for both nanosheets, the improved adsorption behaviour was traced back to the increased d-spacing and more accessible -O and -OH groups of the sodium-intercalated nanosheets. The highest removal rate for ciprofloxacin was found for a $\mathrm{pH}$ equal to 6 , while $\mathrm{pH}$ values above and below led to a considerable decrease of the removal. This can be well connected with the electronic states of ciprofloxacin, which largely depend on the respective $\mathrm{pH}$ of the solution. Kinetic data showed the adsorption of more than $80 \%$ of ciprofloxacin in the first $30 \mathrm{~s}$ of the experiment resembling superfast diffusion kinetics. The kinetic data were best fitted with the Elovich model, which determines chemisorption processes as the dominant processes. The post-characterization of the nanosheets after the adsorption experiments led to the assumption that the electrostatic interaction between the positively charged surface of ciprofloxacin ( $\mathrm{pH}$ around 5.5-6) and negatively charged surface terminations may be the main underlying reason. Moreover, the successful electrochemical regeneration of the sodium-intercalated MXenes was demonstrated by immersing the loaded nanosheets in a $\mathrm{NaOH}$ solution.

Figure 1 summarizes the structures and performances of the pure 2D nanomaterials with the highest adsorption removal efficiencies reported, which correspond to: few-layered BN nanosheets, covalent triazine frameworks, and zwitterionic covalent organic frameworks.

\subsubsection{Binary and Ternary Nanocomposites}

2D nanomaterials such as $\mathrm{MoS}_{2}$ or GO are frequently combined with ferritic $\mathrm{Fe}_{3} \mathrm{O}_{4}$ nanoparticles to create hybrid nanomaterials with a certain adsorption capability for pharmaceuticals. Wu et al. used solvothermal synthesis to create magnetic $\mathrm{rGO} /$ ferrite $\left(\mathrm{Fe}_{3} \mathrm{O}_{4}\right)$ hybrids to study their removal performance for antibiotics from wastewater [71]. In this context, GO, Fe(III) and hydrazine hydrate (reduction of GO) were mixed under alkaline conditions and temperatures below $100{ }^{\circ} \mathrm{C}$ thus anchoring $\mathrm{Fe}_{3} \mathrm{O}_{4}$ nanoparticles on rGO. The presence of $\mathrm{Fe}_{3} \mathrm{O}_{4}$ in the nanocomposite made it magnetic, which is beneficial for the subsequent separation after wastewater treatment, while the remaining surface groups on rGO ensured a good dispersion in water. Extraction experiments for different sulfonamide antibiotics verified a concentration-dependent behaviour with increased recovery for higher amounts of nanohybrids used. The removal depended on the adjusted $\mathrm{pH}$ with the highest values obtained for a $\mathrm{pH}$ equal to 6 . The excellent extraction performance of $\mathrm{rGO} / \mathrm{Fe}_{3} \mathrm{O}_{4}$ hybrids, which outperformed $\mathrm{rGO}, \mathrm{Fe}_{3} \mathrm{O}_{4}$ and $\mathrm{GO} / \mathrm{MWCNT}$ hybrids, was traced back to the enlarged surface area of $\mathrm{rGO}$ and the pronounced $\pi-\pi$ interactions between the nanohybrid and the contaminant.

$\mathrm{Li}$ et al. fabricated GO via a modified Hummers approach before using co-precipitation to generate magnetic $\mathrm{GO}\left(\mathrm{Fe}_{3} \mathrm{O}_{4}-\mathrm{GO}\right)$ [72]. Subsequently, magnetic $\mathrm{GO}$ was surface grafted with nitrilotriacetic acid (NTA) to create magnetic, functionalized $\mathrm{Fe}_{3} \mathrm{O}_{4} / \mathrm{GO}$ nanocomposites having a specific surface area of $249 \mathrm{~m}^{2} \mathrm{~g}^{-1}$ and an average pore diameter of $4.3 \mathrm{~nm}$. The adsorption capacity of these nanocomposites for tetracycline was studied as a function of the $\mathrm{pH}$, time, temperature, concentration, and ionic strength. Related to the $\mathrm{pH}$ value, the highest adsorption capability was verified for a $\mathrm{pH}$ equal to 4 with a maximum adsorption capacity of $212 \mathrm{mg} \mathrm{g}^{-1}$. The enhanced adsorption capacity of the nanocomposite was traced back to the ionic characteristics of tetracycline at the respective $\mathrm{pH}$ and the available surface groups on the nanocomposite. Although showing a fast initial uptake in the first $20 \mathrm{~min}$, equilibrium conditions were just reached after $600 \mathrm{~min}$. The data were best fitted by a pseudo-second order model, which implies that the rate-limiting step is related to chemisorption. The adsorption mechanism was mainly related to the amino groups in the tetracycline molecule, which interacted with the $\pi$ electrons of the nanocomposite as well as hydrogen bonds. Also, $\mathrm{Li}$ et al. fabricated homogenous $\mathrm{Fe}_{3} \mathrm{O}_{4} / \mathrm{GO}$ nanocomposites with different $\mathrm{Fe}_{3} \mathrm{O}_{4} / \mathrm{GO}$ 
ratios between 2.5 and 20 to study their adsorption capability for chlorpheniramine [73]. The kinetics of the chlorpheniramine adsorption showed a high initial rate, which implies a fast removal. The experimental results were fitted with a pseudo second-order model, which inferred that the adsorption occurred via chemical adsorption. Regarding the effect of the $\mathrm{Fe}_{3} \mathrm{O}_{4} / \mathrm{GO}$ ratio, an increased amount of $\mathrm{Fe}_{3} \mathrm{O}_{4}$ reduced the number of adsorption sites on GO thus decreasing the total amount of adsorbed chlorpheniramine from 300 to $138 \mathrm{mg} \mathrm{g}^{-1}$. The authors demonstrated that the micropore volume correlated with the adsorbed chlorpheniramine concentrations, which held especially true for low $\mathrm{Fe}_{3} \mathrm{O}_{4} / \mathrm{GO}$ ratios. The adsorption behaviour was also shown to be $\mathrm{pH}$ dependent with the greatest removal for a $\mathrm{pH}$ equal to 8 . This effect related to the stronger electrostatic interaction between the positive chlorpheniramine and the negative nanocomposite.

Xiao et al. fabricated ternary nanocomposites consisting of GO, $\mathrm{MoS}_{2}$ and $\mathrm{Fe}_{3} \mathrm{O}_{4}$ nanoparticles [74]. In this regard, $\mathrm{GO}$ was synthesized via a modified Hummers process before producing $\mathrm{GO}-\mathrm{Fe}_{3} \mathrm{O}_{4}$ nanocomposites via chemical solvothermal processing. The obtained nanocomposites were solution-processed to obtain ternary nanocomposites by precipitation. The fabricated ternary nanocomposites had a specific surface area of $135.14 \mathrm{~m}^{2} \mathrm{~g}^{-1}$, which was significantly higher than the values of the pure nanomaterials or the binary nanocomposites. The adsorption behaviour of these ternary nanocomposites was studied for different antibiotics including lecofloxacin, pazcofloxacin, and gatifloxacin. The ternary nanocomposite containing $50 \% \mathrm{MoS}_{2}$ showed the best adsorption capability for all antibiotics, thus outperforming the pure nanomaterials and binary nanocomposites. The ternary nanocomposite showed a fast adsorption behaviour and reached its maximum adsorption capacity after only $2 \mathrm{~min}$. Regarding the influence of the $\mathrm{pH}$, the highest adsorption was verified for a $\mathrm{pH}$ equal to 7 , which related to the available surface terminations on GO. The underlying mechanism for the enhanced adsorption observed for the ternary nanocomposite was related to enhanced hydrogen bonding and electrostatic interactions.

Park et al. generated ternary nanocomposites consisting of supports of rGO decorated with silver and $\mathrm{Fe}_{3} \mathrm{O}_{4}$ nanoparticles via a simple nucleation and crystallization process [75]. The overall purpose of this nanocomposite was to activate peroxydisulfate (PDS), thus producing $\mathrm{SO}_{4}{ }^{\bullet-}$ radicals which can catalytically remove phenol (further revision of these processes is presented in Section 3.3.1). This, in turn, was utilized to study the degradation and catalytical removal of different pharmaceutics including acetaminophen, ibuprofen, naproxen, among others. To characterize the underlying adsorption characteristics of these ternary nanocomposites, $\mathrm{pH}$-dependent batch experiments were conducted. Reference experiments verified that PDS and $\mathrm{H}_{2} \mathrm{O}_{2}$ were not capable to degrade phenol. The highest removal efficiency was shown for the ternary nanocomposite (with binary composites and pure materials as references) with $k_{\text {ini }}$ values of $0.67,0.46$, and $0.23 \mathrm{~h}^{-1}$ for $\mathrm{pH} 4,7$, and 10, respectively. This effect was traced back to an increased adsorption of phenol and enhanced catalytic activity of PDS, which induced synergistic effects. The pH-dependency was explained based upon a competing reaction between $\mathrm{SO}_{4}{ }^{\bullet-}$ and $\mathrm{OH}^{\bullet}$ radicals, which may be converted into each other depending on the predominant $\mathrm{pH}$ milieu. The increased $k_{\text {ini }}$ value for a $\mathrm{pH}$ equal to 4 verifies the dominant role of $\mathrm{SO}_{4}{ }^{\bullet-}$ radicals in the degradation of phenol under the conditions studied. The kinetic data were fitted with a pseudosecond order model and demonstrated the greatest adsorption capacity for the ternary nanocomposites. The beneficial behaviour induced by the ternary nanocomposites was explained by the fact that the deposition of silver and $\mathrm{Fe}_{3} \mathrm{O}_{4}$ nanoparticles on $\mathrm{rGO}$ helped to reduce the nanosheets agglomeration. This made more reactive sites available for the adsorption of phenol. Moreover, more epoxy and hydroxyl groups were verified by XPS for the ternary nanocomposites, which can act as Lewis base sites with the possibility to chemically bond with phenolic hydroxyl groups. Subsequently, the authors studied the degradation kinetics for selective organic compounds. In the case of a $\mathrm{pH}$ equal to 4 , a degradation of more than $90 \%$ in one hour reaction time was verified for acetaminophen, ibuprofen, $17 \beta$-estradiol, and $17 \alpha$-ethinyl estradiol, while a $50-90 \%$ degradation was shown 
for naproxen and bisphenol A. The observed results imply that non-radical oxidation plays a dominant role in the PDS/nanocomposite system.

Zeng et al. generated via hydrothermal synthesis biochar decorated with g-MoS nanosheets for the removal of tetracycline [76]. Nitrogen adsorption/desorption experiments revealed for g-MoS - -biochar composites a specific surface area of $176.8 \mathrm{~m}^{2} \mathrm{~g}^{-1}$ and an averaged pore diameter of about $3 \mathrm{~nm}$. The produced nanocomposites exhibited a good thermal stability up to $450{ }^{\circ} \mathrm{C}$ as verified by TGA. Adsorption experiments as a function of the $\mathrm{pH}$ value revealed an increase of the adsorption capacity when $\mathrm{pH}$ increases from 2 to 4 . Afterwards, it remained rather stable before dropping for $\mathrm{pH}$ values above 8 . The beneficial effect for low $\mathrm{pH}$ values was correlated with the present surface charges and reduced repulsive interactions between the adsorbent and tetracycline, thus favouring adsorption. Surface charges may not be responsible for the adsorption capacity observed for medium $\mathrm{pH}$ values as there is only little electrostatic interaction. In this regime, it is more likely that hydrogen bonds, $\pi-\pi$ or hydrophobic interactions contribute towards the beneficial behaviour observed. Additional ions present in the solution tended to induce a downgraded adsorption behaviour due to reduced electrostatic interaction between tetracycline and g-MoS 2 . A detailed consideration of the kinetic data suggests a three-step process for the adsorption of tetracycline onto g-MoS 2 biochar composites. In an initial fast adsorption step (more than $80 \%$ adsorption in the first $4 \mathrm{~h}$ ), the tetracycline molecules overcome the liquid resistance and are transferred to the exterior surface of the composite, which is governed by film diffusion. Subsequently, the molecules migrate from the surface to pores (intraparticle diffusion) before reaching the active sites on the interior of the composites thus being adsorbed (equilibrium conditions). Like the multiple diffusion steps necessary to reach equilibrium conditions, the underlying mechanism needs to be subdivided in different contributions including hydrogen bonding, $\pi-\pi$ interactions, pore filling and electrostatic interactions thus inducing the beneficial adsorption ability of g-MoS 2 biochar nanocomposites for tetracycline.

González et al. generated chitin/GO nanocomposites (3:1 weight ratio) by wetspinning to study their adsorption performance for ciprofloxacin in batch experiments by assessing the effect of the flow rate, $\mathrm{pH}$ value and sodium as well as calcium concentrations (water quality parameters) [77]. Scanning electron micrographs of the as-synthesized nanocomposites revealed a very broad pore size distribution with micro-, sub-microand nanoscopic pore sizes ranging from $10 \mathrm{~nm}$ up to $10 \mu \mathrm{m}$. A detailed analysis of the adsorption characteristics demonstrated a rather heterogeneous sorption, which may be correlated to the molecular structure of ciprofloxacin having three nitrogen atoms and two unsaturated rings. The existence of these structural features makes the interaction with functional groups on the GO nanosheets possible (electrostatic or $\pi-\pi$ interactions). The dynamic adsorption behaviour was shown to be sensitive towards the $\mathrm{pH}$ adjusted, which is triggered by the respective surface charge of different surface features of ciprofloxacin. These surface charges can induce attractive or repulsive interactions with the surface terminations of GO, thus determining the adsorption behaviour.

\subsubsection{Conclusions on Adsorption Processes}

Adsorption is a conventional wastewater treatment process for which the use of 2D nanomaterials represents an innovation due to the enhanced surface properties they offer. In principle, their unprecedent surface area and porosity (such as in the case of $\mathrm{MoS}_{2}$ nanosheets and covalent triazine frameworks) would explain their remarkable removal efficiencies and kinetics due to a higher amount of accessible adsorption sites as compared to conventional adsorbents (such as activated carbon). However, it has been observed that the generation of superficial delocalized $\pi$ bonds during synthesis is essential for the enhancement of the adsorbent-adsorbate interaction due to the formation of strong $\pi-\pi$ interactions (chemisorption). Furthermore, the weakening of the interlayer interaction in $2 \mathrm{~d}$ nanomaterials such as $\mathrm{g}-\mathrm{C}_{3} \mathrm{~N}_{4}$ nanosheets and MXenes also contributes to strengthen the electrostatic surface-contaminant interaction due to the increased amount of superficial 
$-\mathrm{O}$ and $-\mathrm{OH}$ groups accessible. Therefore, future synthesis approaches should be designed to produce surfaces with well distributed and accessible active sites of these types.

Enlarged surface area, $\pi-\pi$ interactions and electrostatic interactions can also be induced by the usage of binary or ternary composites instead of pure 2D nanomaterials. In fact, $\mathrm{rGO} / \mathrm{Fe}_{3} \mathrm{O}_{4}$ nanoparticles showed a pronounced $\pi-\pi$ interaction with contaminants when compared to both nanomaterials separately, while $\mathrm{MoS}_{2} / \mathrm{GO} / \mathrm{Fe}_{3} \mathrm{O}_{4}$ composites presented an enhanced $\mathrm{H}$ bonding with the adsorbate and electrostatic interactions when compared to the pure nanomaterials or the binary nanocomposites. Moreover, g- $\mathrm{MoS}_{2} /$ biochar composites showed a mixture of these three adsorbate-adsorbent interactions although their kinetics were reduced when compared to $\mathrm{rGO} / \mathrm{Fe}_{3} \mathrm{O}_{4}$ and $\mathrm{MoS}_{2} / \mathrm{GO} / \mathrm{Fe}_{3} \mathrm{O}_{4}$. Therefore, another interesting future research area is the development of new composites based on 2D nanomaterials.

Finally, it is worth to discuss about the recyclability of adsorbents since it is a key aspect to be considered when determining its potential for application at large scale. The regeneration of MXene-based materials is usually performed by treatment with $\mathrm{HCl}, \mathrm{HNO}_{3}$, or $\mathrm{Ca}\left(\mathrm{NO}_{3}\right)_{2}$. The regeneration mechanism is based upon the competition between the cations and the adsorbed pollutants at the surface-active sites [19,78]. In this regard, Khan et al. reported a sustained pollutant removal efficiency (over 90\%) after five regeneration cycles and no significant changes in morphology [79]. Acid or alkaline solutions are used to separate ions from GO and $\mathrm{rGO}$, where the $\mathrm{pH}$ of the solution plays an important role in the regeneration mechanism. Oxygen-containing functional groups on $\mathrm{GO}$ and $\mathrm{rGO}$ display different protonation at different $\mathrm{pH}$, thus the ionization of pollutants can be easily modified by the $\mathrm{pH}$ in solution [21]. Kexin et al. studied the regeneration of $\mathrm{GO} / \mathrm{NiO}$ nanocomposites loaded with $\mathrm{Cr}(\mathrm{VI})$ using a $0.1 \mathrm{M} \mathrm{HCl}$ solution. In their experiments, it was found that the uptake capacity slightly decreased with increasing regeneration cycles, demonstrating a steady removal efficiency (around 83\%) after five cycles. Additionally, hydrophobic solutions such as ethanol and methanol can act as effective eluents for the removal of organic molecules from adsorbents. Soleimani et al. regenerated GOcellulose nanowhiskers using ethanol, with a reduction of the efficiency about $5-10 \%$ after 3 cycles [80].

\subsection{Photocatalytic Processes}

Photocatalytic degradation processes are heterogeneous catalytic reactions, which typically comprise five steps: (i) mass transfer of pollutants from the bulk to the surface of the photocatalyst, (ii) adsorption of the molecules onto its surface, (iii) photocatalytic degradation reaction, (iv) desorption of products, and (v) removal of reaction product from the interphase. The working principle of photocatalytic degradation reactions by a semiconductor in an aqueous medium is based on its band structure. A semiconductor material is capable of absorbing radiation with an energy $(h v)$ equal to or greater than its bandgap. The photons absorbed by the semiconductor induce the promotion of electrons from the valence band to its conduction band, generating holes $\left(\mathrm{h}^{+}\right)$in the valence band. These charge carriers can either directly react with pollutants molecules adsorbed on the surface of the material or with water and oxygen molecules to form ROS. Figure 2 illustrates the possible reaction pathways that can take place after the light excitation of a photocatalyst. 


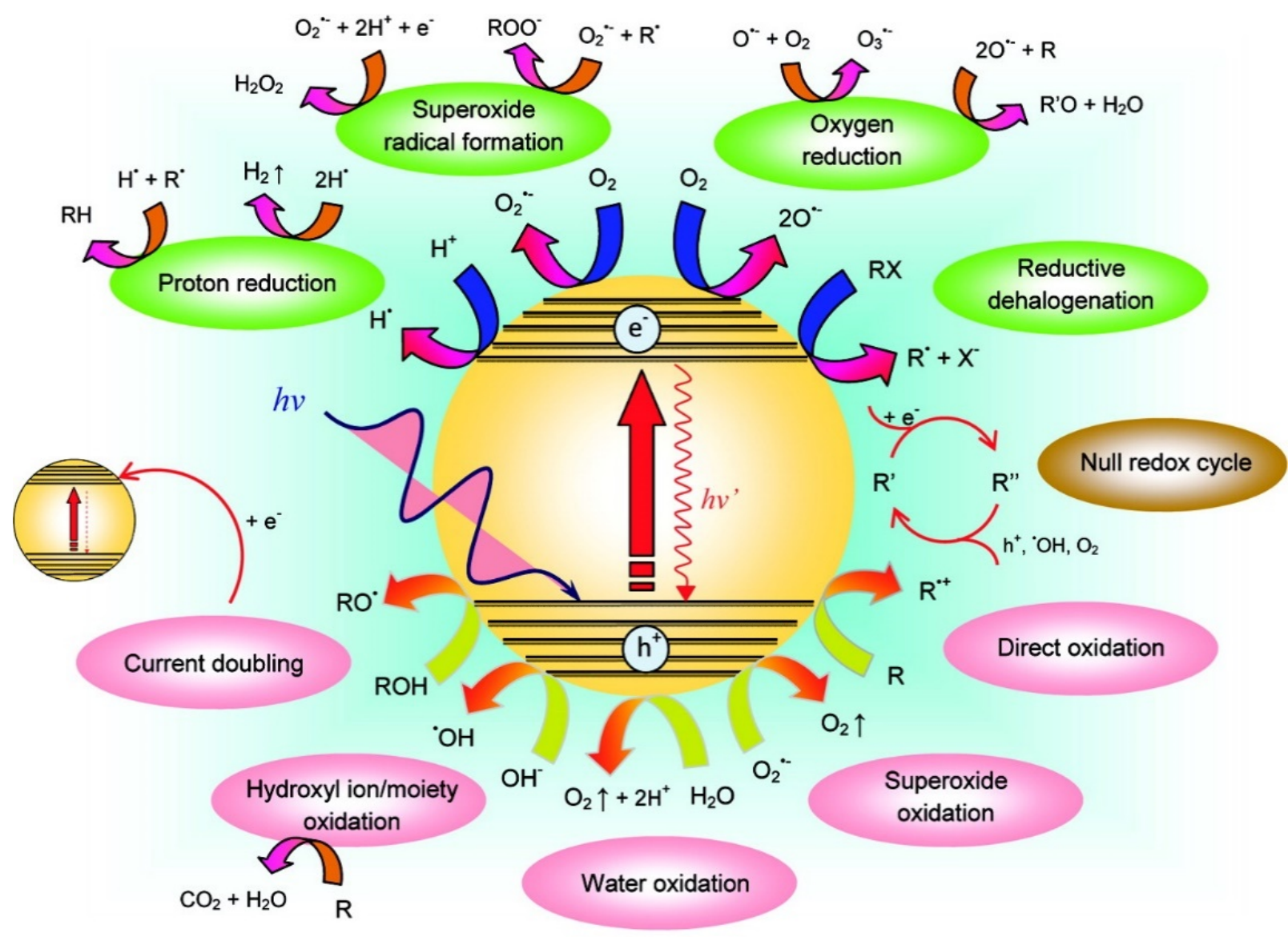

Figure 2. Possible reaction pathways arising from the excitation of photocatalysts. R denotes the general organic electron donor molecule (reproduced with permission [81]).

The efficiency of a photocatalytic degradation reaction depends on factors such as photon absorption, and photo-induced charge carrier concentration and separation. Charge carriers have the potential to recombine in the material bulk or at the surface, thus decreasing their concentration in the material and limiting the degradation efficiency. This recombination processes can occur due to a small bandgap energy, low electronic conductivity, or a high charge transfer resistance at the surface [82].

\subsubsection{Graphitic Carbon Nitride-Based Materials}

Graphitic carbon nitride $\left(\mathrm{g}-\mathrm{C}_{3} \mathrm{~N}_{4}\right)$ has emerged as a new photocatalyst due to its bandgap energy of $2.7 \mathrm{eV}$, which can effectively absorb solar irradiation [24], and its excellent physicochemical stability. $\mathrm{g}-\mathrm{C}_{3} \mathrm{~N}_{4}$ is a metal-free semiconductor with a $2 \mathrm{D}$ layered structure with graphitic planes constructed from tri-s-trizazine units connected by planar amino groups, which can be synthesized via an one-step polymerization reaction using precursors such as cyanamide, urea, thiourea, melamine, or dicyandiamide [83]. The band structure of $\mathrm{g}-\mathrm{C}_{3} \mathrm{~N}_{4}$ consists of $p$ orbitals from nitrogen forming the valence band, while the conduction band is mainly composed of the $p_{\mathrm{z}}$ orbitals of carbon [84]. Although g- $\mathrm{C}_{3} \mathrm{~N}_{4}$ presents light absorption in the visible light spectrum, its performance as a photocatalyst is limited due to a reduced charge migration and a low electronic conductivity, which cause a fast recombination of the photogenerated charge carriers [24,85]. Recently, several strategies have been employed to enhance the photocatalytic performance of g- $\mathrm{C}_{3} \mathrm{~N}_{4}$ including surface modification, doping, and the formation of heterostructures.

The photocatalytic activity strongly depends on the morphology, crystalline structure, and surface composition of the catalyst. This implies that materials with similar chemical composition can yield drastically different photocatalytic activity. Shi et al. prepared a 
supramolecular carbon nitride (MCU- $\mathrm{C}_{3} \mathrm{~N}_{4}$ ) by dissolving melamine, cyanuric acid, and urea in dimethyl sulfoxide (DMSO), followed by a thermal treatment at $550{ }^{\circ} \mathrm{C}$ [86]. The resulting material showed a 2D morphology with a smooth surface. It was observed that after the addition of cyanuric acid and urea, a thin nanosheet structure was obtained with randomly distributed mesopores (average pore size of $6.48 \mathrm{~nm}$ ). The bandgap energy was estimated from UV-vis diffuse reflectance spectra (UV-vis DRS) and compared with the value of pure $\mathrm{g}-\mathrm{C}_{3} \mathrm{~N}_{4}$, which was synthesized only from melamine. The bandgap energies were estimated to be 2.50 and $2.79 \mathrm{eV}$ for $\mathrm{g}-\mathrm{C}_{3} \mathrm{~N}_{4}$ and MCU-C $\mathrm{C}_{3} \mathrm{~N}_{4}$, respectively. An increased bandgap energy and a blue-shift in MCU-C $\mathrm{C}_{3} \mathrm{~N}_{4}$ absorption spectra were observed, which was ascribed to the quantum confinement effect derived from the smaller size and mesoporous structures of MCU-C ${ }_{3} \mathrm{~N}_{4}$. The photocatalytic activity of MCU-C ${ }_{3} \mathrm{~N}_{4}$ was evaluated by the degradation of $10 \mathrm{mg} \mathrm{L}^{-1}$ of tetracycline and ciprofloxacin under visible light irradiation ( $420 \mathrm{~nm}$ cut-off filter), with a catalyst load of $0.7 \mathrm{~g} \mathrm{~L}^{-1}$. MCU-C ${ }_{3} \mathrm{~N}_{4}$ showed a degradation efficiency of $81.6 \%$ ( $80 \mathrm{~min}$ ) and $65.80 \%$ (90 $\mathrm{min}$ ) for tetracycline and ciprofloxacin, respectively. The reported degradation mechanism demonstrates the direct oxidation of the antibiotic molecules by $\mathrm{h}^{+}$and $\mathrm{O}_{2}{ }^{\bullet-}$ in the bulk.

Liu et al. demonstrated the degradation of sulfadiazine, a sulfonamide widely used as antibiotic in veterinary medicine, using a catalyst consisting of carbon nitride nanosheets with carbon vacancies ( $\mathrm{Cv}$-CNNs) synthesized by mixing pure carbon nitride nanosheets (CNNs) with $\mathrm{NH}_{4} \mathrm{Cl}$ and a subsequent thermal treatment at $550{ }^{\circ} \mathrm{C}$ for $2 \mathrm{~h}$ [87]. The fabricated catalyst exhibited a thin few-layered sheet structure with in-plane pores of 5-7 nm. UV-vis DRS analysis revealed that $\mathrm{Cv}-\mathrm{CNNs}$ presented a bandgap of $2.83 \mathrm{eV}$, slightly higher than that of the pristine CNNs $(2.81 \mathrm{eV})$. Degradation experiments were performed under visible light (420 nm cut-off filter) with a catalyst load of $0.02 \mathrm{~g} \mathrm{~L}^{-1}$ and a sulfadiazine concentration of $10 \mathrm{mg} \mathrm{L}^{-1}$. Sulfadiazine was completely degraded by $\mathrm{Cv}-\mathrm{CNNs}$ in $90 \mathrm{~min}$, in contrast to CNNs that showed an efficiency of $64.94 \%$. This increased photocatalytic activity was attributed to an improved charge separation in $\mathrm{Cv}$ $\mathrm{CNNs}$, which was confirmed by photoluminescence. Furthermore, it has been reported that the formation of $\mathrm{C}$ vacancies led to a conversion of $\mathrm{N}$ exposed atoms into $-\mathrm{NH}_{2}$ groups, which can act as hole-stabilizers and increase the charge separation in the material.

The incorporation of a different element into a semiconductor structure can tailor the electronic and optical properties and, therefore, the material photocatalytic activity [88]. A recent work by Guo et al. showcases the effects of oxygen substitution on the resulting photocatalytic performance of g- $\mathrm{C}_{3} \mathrm{~N}_{4}$ [89]. Oxygen-substituted ultrathin porous g- $\mathrm{C}_{3} \mathrm{~N}_{4}$ nanosheets (OCN-24-550) were prepared by a two-step hydrothermal-recalcination treatment of bulk g- $\mathrm{C}_{3} \mathrm{~N}_{4}$ at $160{ }^{\circ} \mathrm{C}$ in deionized water for $24 \mathrm{~h}$. The produced catalyst presented a sheet-like structure with a planar size of $2.2 \mu \mathrm{m}$, an average thickness of $6.8 \mathrm{~nm}$ with many in-plane pores, and $\mathrm{O}$ atoms partially incorporated into the lattice by substituting the $\mathrm{C}-\mathrm{N}=\mathrm{C}$ coordinated nitride atom. The optical bandgap was determined to be 2.54 and $2.49 \mathrm{eV}$ for $\mathrm{OCN}-24-550$ and pure $\mathrm{g}-\mathrm{C}_{3} \mathrm{~N}_{4}$, respectively. The photocatalytic performance of these nanosheets was studied under visible light irradiation ( $420 \mathrm{~nm}$ cut-off filter) in a $20 \mathrm{mg} \mathrm{L}^{-1}$ tetracycline solution with a catalyst load of $1 \mathrm{~g} \mathrm{~L}^{-1}$. OCN-24-550 efficiently degraded $85.76 \%$ of tetracycline within $120 \mathrm{~min}$, while pristine $\mathrm{g}-\mathrm{C}_{3} \mathrm{~N}_{4}$ only degraded $17.19 \%$. The enhanced photocatalytic activity was ascribed to the synergetic effects of a larger surface area and the $\mathrm{O}$ substitution. This facilitated the diffusion of reactants and optimized the electronic structure by creating a local electronic polarization effect resulting in a boosted exciton dissociation and improved charge migration.

Wenjun et al. proposed an alkali metal-assisted synthesis method for the fabrication of g- $\mathrm{C}_{3} \mathrm{~N}_{4}$ nanosheets with a tuneable bandgap [90]. In this regard, a novel potassium-doped porous ultrathin $\mathrm{g}-\mathrm{C}_{3} \mathrm{~N}_{4}(\mathrm{KMCN}(0.05))$ photocatalyst was synthesized by hydrothermal treatment of ultrathin $\mathrm{g}_{-} \mathrm{C}_{3} \mathrm{~N}_{4}$ nanosheets in the presence of $\mathrm{KOH}(0.05 \mathrm{M})$, followed by a recalcination treatment at $550{ }^{\circ} \mathrm{C}$ for $4 \mathrm{~h}$. The as-synthesized catalyst exhibited a nanosheet morphology with micro-pores having sizes between 5 and $40 \mathrm{~nm}$. Moreover, the addition of potassium cations $\left(\mathrm{K}^{+}\right)$into $g-\mathrm{C}_{3} \mathrm{~N}_{4}$ nanosheets increased the pore size and 
specific surface area by 1.4 and 3.9 times, respectively. The calculated bandgap energy of g- $\mathrm{C}_{3} \mathrm{~N}_{4}$ and $\mathrm{KMCN}(0.05)$ was 2.65 and $2.33 \mathrm{eV}$, respectively. The photocatalytic activity of $\mathrm{KMCN}(0.05)$ was evaluated under visible light irradiation using tetracycline $\left(20 \mathrm{mg} \mathrm{L}^{-1}\right)$ as target pollutant and a catalyst load of $1 \mathrm{~g} \mathrm{~L}^{-1}$. $\mathrm{KMCN}(0.05)$ demonstrated an excellent tetracycline degradation capability, exhibiting a degradation efficiency of $85.13 \%$, while pure g- $\mathrm{C}_{3} \mathrm{~N}_{4}$ showed an efficiency of only $29.60 \%$. The authors attributed the improved photocatalytic activity to a lower charge transfer resistance, and a reduced recombination rate of the photogenerated charge carriers.

Yi et al. constructed a binary photocatalyst using few-layer $\mathrm{Ti}_{3} \mathrm{C}_{2} \mathrm{~T}_{\mathrm{x}}$ embedded into alkalized $C_{3} \mathrm{~N}_{4}$ [91]. The catalyst was prepared via co-calcinating urea and $\mathrm{Ti}_{3} \mathrm{C}_{2} \mathrm{~T}_{\mathrm{x}}$ precursors in the presence of alkali. The resulting material was composed of $\mathrm{Ti}_{3} \mathrm{C}_{2} \mathrm{~T}_{\mathrm{x}}$ encapsulated and well-blended in alkalized $\mathrm{C}_{3} \mathrm{~N}_{4}$ nanosheets. Due to the generation of $\mathrm{NH}_{3}$ gas during urea polymerization, the etched $\mathrm{Ti}_{3} \mathrm{C}_{2} \mathrm{~T}_{\mathrm{x}}$ lamellas were exfoliated into thinner lamellas and the interlayer spacing expanded from 1.017 to $1.249 \mathrm{~nm}$. The bandgap energy of alkalized $\mathrm{C}_{3} \mathrm{~N}_{4}$ was estimated to be $2.39 \mathrm{eV}$. The photocatalytic performance of the photocatalyst was tested through the degradation of tetracycline under visible light irradiation (420 nm cut-off filter) with a concentration of $20 \mathrm{mg} \mathrm{L}^{-1}$ of tetracycline and $0.2 \mathrm{~g} \mathrm{~L}^{-1}$ of catalyst. Alkalized $\mathrm{C}_{3} \mathrm{~N}_{4}$ showed degradation efficiency of $77 \%$, which was significantly higher compared to pure $\mathrm{C}_{3} \mathrm{~N}_{4}(10 \%)$. The authors associated this enhanced photocatalytic activity with the formation of a Schottky junction, which prevented charge recombination of charge carriers with $\mathrm{Ti}_{3} \mathrm{C}_{2} \mathrm{~T}_{\mathrm{x}}$ acting as an electron acceptor. When reusing the catalyst for 4 times, no changes were observed between each cycle of tetracycline removal. Additionally, radical scavenging experiments indicated that $\mathrm{h}^{+}$was the most significant active species during the degradation of tetracycline.

\subsubsection{Bismuth Oxyhalides-Based Materials}

In recent decades, bismuth oxyhalides ( $\mathrm{BiOX}$ with $\mathrm{X}=\mathrm{Cl}, \mathrm{Br}, \mathrm{I}$ ) have gained great attention due to their photocatalytic activity towards the removal of contaminants in wastewaters. $\mathrm{BiOX}$ possess a layered structure composed of a $\left[\mathrm{Bi}_{2} \mathrm{O}_{2}\right]^{2+}$ layer and two halogen ions layers. BiOX photocatalysts are chemically inert, non-hazardous, and corrosion-resistant in aqueous environments. These catalysts absorb visible light radiation having bandgap energies of 3.22, 2.64, and 1.77, for $\mathrm{BiOCl}, \mathrm{BiOBr}$, and $\mathrm{BiOI}$, respectively [92]. The valence band of BiOX crystals is composed of $p$ orbitals of $X$, while the conduction band is comprised of Bi $6 p$ orbitals [93]. Previous studies have reported the degradation of several pharmaceutical molecules using BiOX materials such as $171 \alpha$-ethinyl estradiol, estriol, carbamazepine, and levofloxacin [92,94-96]. However, the degradation performance of BiOX is still restricted by a poor light harvesting ability and a reduced charge transfer efficiency related to its low conductivity.

Yingying et al. reported the synthesis of $\mathrm{BiOBr}$ nanosheets employing L-cysteine as a directing agent (Cyst-BiOBr) by a hydrothermal method at $180^{\circ} \mathrm{C}$ for $24 \mathrm{~h}$. [97]. Cyst$\mathrm{BiOBr}$ nanosheets showed an even distribution with a size range of 0.05 to $0.5 \mu \mathrm{m}$, an interplanar lattice distance of $0.277 \mathrm{~nm}$, a high surface area and oriented growth in the (110) direction. It was found that Cyst-BiOBr exhibited a bandgap energy of $2.30 \mathrm{eV}$, which was smaller compared to the bandgap energy of $\mathrm{BiOBr}$ nanosheets synthesized using the amino acids arginine and glycine ( 2.51 and $2.62 \mathrm{eV}$, respectively). The reduced bandgap of Cyst-BiOBr was attributed to its smaller particle size, which altered the band structure. The introduction of cysteine into the precursor solution promoted the complexation of $\mathrm{Bi}^{3+}$ with the amino acid, which controlled the release of these ions to form $\mathrm{BiOBr}$ crystallites when adding $\mathrm{Br}^{-}$to the solution. The evaluation of the photocatalytic activity of Cyst-BiOBr was performed through the degradation of cefazolin, a first-generation cephalosporin, under visible light irradiation ( $420 \mathrm{~nm}$ cut-off filter) with a catalyst load of $0.2 \mathrm{~g} \mathrm{~L}^{-1}$ and a cefazolin concentration of $10 \mathrm{mg} \mathrm{L}^{-1}$. After $3 \mathrm{~h}$ of irradiation, a degradation efficiency of $87 \%$ was attained. 
The studies of Chu-Ya et al. provided an insight on the impact of thickness on the photocatalytic activity of bismuth oxybromide $\mathrm{Bi}_{24} \mathrm{O}_{31} \mathrm{Br}_{10}$ nanosheets (BOB) [98]. These nanosheets were synthesized via hydrothermal method at $160{ }^{\circ} \mathrm{C}$ for $12 \mathrm{~h}$, controlling the thickness by adjusting the concentration of $\mathrm{NH}_{4} \mathrm{Br}$ during synthesis. The resulting material showed a uniform 2D sheet structure, with nanosheets size between 0.5 and $1.0 \mu \mathrm{m}$ and different thicknesses, noted as BOB-S (40 nm), BOB-M (85 nm) and BOB-L (130 nm). The estimated optical bandgap energies were 2.30, 2.33, and $2.35 \mathrm{eV}$ for BOB-S, BOB-M, and BOB-L, respectively. The photocatalytic performance was tested by the degradation of tetracycline under visible light (420 nm cut-off filter) with a catalyst load of $0.34 \mathrm{~g} \mathrm{~L}^{-1}$ and $10 \mathrm{mg} \mathrm{L}^{-1}$ of tetracycline. After a reaction time of $90 \mathrm{~min}$, a degradation efficiency of 95 , 70 , and $45 \%$ was achieved for BOB-S, BOB-M, and BOB-L, respectively. The increment in the degradation rate for BOB-S was ascribed to its higher charge transfer efficiency, which was supported by electrochemical impedance spectroscopy analyses, and a higher concentration of $\mathrm{h}^{+}$due to an increased valence band potential with an energy top of $-0.06 \mathrm{eV}$ (in contrast to -0.51 and $-0.42 \mathrm{eV}$ for BOB-M and BOB-S, respectively).

Wang et al. synthesized $\mathrm{BiOCl}_{0.75} \mathrm{I}_{0.25}$ nanospheres via precipitation method, followed by calcination at $200{ }^{\circ} \mathrm{C}$ for $2 \mathrm{~h}$. BiOCl ${ }_{0.75} \mathrm{I}_{0.25}$ showed a flower-like hierarchical nanosphere structure consisting in globular nanosheets about $0.5 \mu \mathrm{m}$ in size [99]. Compared to the pure materials, $\mathrm{BiOCl}_{0.75} \mathrm{I}_{0.25}$ exhibited a smaller size and a bandgap energy of $2.12 \mathrm{eV}$, which was lower than $\mathrm{BiOCl}(3.31 \mathrm{eV})$ but higher compared to $\mathrm{BiOI}(1.73 \mathrm{eV})$. The degradation of acetaminophen, an analgesic and antipyretic drug, was performed under visible light employing a reactor with a catalyst load of $0.6 \mathrm{~g} \mathrm{~L}^{-1}$ and acetaminophen concentration of $20 \mathrm{mg} \mathrm{L}^{-1}$. After $3 \mathrm{~h}$ of constant stirring, a degradation efficiency of $80 \%$ was accomplished, which was superior to that obtained for pure $\mathrm{BiOCl}(34 \%)$ and $\mathrm{BiOI}(54 \%)$. The increase was attributed to a greater generation of $\mathrm{O}_{2}{ }^{\bullet-}$.

The photocatalytic performance of a semiconductor can also be enhanced by creating heterostructures. Heterostructures are composed of combinations of different semiconductors in a multilayer arrangement, which can induce an efficient charge separation, enhance light absorption, and generate band alignments that favour the separation of electrons and holes [82]. In this regard, novel $\mathrm{Bi}_{5} \mathrm{O}_{7} \mathrm{Br} / \mathrm{BiOBr} 2 \mathrm{D} / 3 \mathrm{D}$ heterojunctions were prepared by Lulu et al. by a one-step hydrolysis [100]. The fabricated material displayed a morphology consisting of $\mathrm{Bi}_{5} \mathrm{O}_{7} \mathrm{Br}$ nanosheets well dispersed on the surface of $\mathrm{BiOBr}$ nanospheres. The photocatalytic activity was studied by the degradation of carbamazepine under visible light irradiation using a catalyst load of $0.5 \mathrm{mg} \mathrm{mL}^{-1}$ and a carbamazepine concentration of $10 \mathrm{mg} \mathrm{L}^{-1}$. Pristine $\mathrm{BiOBr}$ and $\mathrm{Bi}_{5} \mathrm{O}_{7} \mathrm{Br}$ showed a moderated activity after $90 \mathrm{~min}$ of irradiation, reaching a 25.8 and $40 \%$ degradation efficiency, respectively. In contrast, $\mathrm{Bi}_{5} \mathrm{O}_{7} \mathrm{Br} / \mathrm{BiOBr}$ achieved a degradation efficiency of $92 \%$. This behaviour was ascribed to an increase of the charge carriers separation efficiency within the material, while $\mathrm{h}^{+}$was the dominant active species in the degradation mechanism.

A recent study by Haibo et al. revealed the effects of coupling BiOX with metallic $\mathrm{Bi}$ and carbon [101]. Ultrathin $\mathrm{Bi} / \mathrm{C} / \mathrm{BiOX}(\mathrm{X}=\mathrm{Cl}, \mathrm{Br})$ nanosheets were prepared by a solvothermal method followed by a calcination with Ar protection. This process resulted in microspheres with a diameter of $2 \mu \mathrm{m}$, which were decorated with several nanosheets with a thickness of 30 and $40 \mathrm{~nm}$ for $\mathrm{BiOCl}$ and $\mathrm{BiOBr}$, respectively. Tetracycline degradation experiments were performed under visible light (420 nm cut-off filter) with a catalyst load of $0.2 \mathrm{~g} \mathrm{~L}^{-1}$ and a tetracycline concentration of $10 \mathrm{mg} \mathrm{L}^{-1}$. Bi/C/BiOCl and $\mathrm{Bi} / \mathrm{C} / \mathrm{BiOBr}$ demonstrated a degradation efficiency of 80 and $56.3 \%$, respectively, while the pure catalysts $\mathrm{BiOCl}$ and $\mathrm{BiOBr}$ degraded only 45.3 and $24 \%$, respectively. The enhanced photocatalytic activity of $\mathrm{Bi} / \mathrm{C} / \mathrm{BiOCl}$ was explained by synergetic contributions originating from the surface plasmon resonance effect of $\mathrm{Bi}$ and the presence of oxygen vacancies.

Guodong et al. developed a novel $\mathrm{Bi}_{4} \mathrm{Ti}_{3} \mathrm{O}_{12} / \mathrm{BiOBr}$ p-n junction. $\mathrm{Bi}_{4} \mathrm{Ti}_{3} \mathrm{O}_{12}$ was synthesized via a solid state (diffusion) method followed by an in-situ growth of $\mathrm{BiOBr}$ [102]. The obtained $\mathrm{Bi}_{4} \mathrm{Ti}_{3} \mathrm{O}_{12} / \mathrm{BiOBr}$ heterojunction consisted of $\mathrm{Bi}_{4} \mathrm{Ti}_{3} \mathrm{O}_{12}$ particles evenly decorated with round $\mathrm{BiOBr}$ nanosheets (diameter of 100-200 nm). The photocatalytic activity 
of $\mathrm{Bi}_{4} \mathrm{Ti}_{3} \mathrm{O}_{12} / \mathrm{BiOBr}$ was studied by the degradation of ciprofloxacin and tetracycline with concentrations of $20 \mathrm{mg} \mathrm{L}^{-1}$ under visible light (400 nm cut-off filter). After a reaction time of $210 \mathrm{~min}, \mathrm{Bi}_{4} \mathrm{Ti}_{3} \mathrm{O}_{12} / \mathrm{BiOBr}$ achieved a degradation efficiency of 96 and $97 \%$ for ciprofloxacin and tetracycline, respectively. This value was more than 1.5 times increased compared to the degradation efficiency of pristine $\mathrm{Bi}_{4} \mathrm{Ti}_{3} \mathrm{O}_{12}$ and $\mathrm{BiOBr}$. This enhanced performance was traced back to the increased photoactivity of the p-n junction structure, which decreased the recombination rate of the charge carriers.

\subsection{3. $\mathrm{TiO}_{2}$-Based Materials}

$\mathrm{TiO}_{2}$ is a widely studied semiconductor with a bandgap energy around 3.0 to $3.2 \mathrm{eV}$. The band structure of $\mathrm{TiO}_{2}$ is comprised of $\mathrm{O} 2 p$ orbitals forming the valence band and a conduction band composed of Ti $3 d$ orbitals [103]. Since a semiconductor can absorb photons with energies equal or greater than its bandgap, $\mathrm{TiO}_{2}$ can only absorb the light in the UV region, which accounts for only $5 \%$ of the solar spectrum. Moreover, $\mathrm{TiO}_{2}$ suffers from recombination of charge carriers, which prohibits surface reactions to occur. Coupling $\mathrm{TiO}_{2}$ with other semiconductors has been proven an efficient way to reduce the charge carriers recombination rate and to extend the light absorption edges of the material [82]. In this regard, Lin et al. synthesized $\mathrm{TiO}_{2}$ nanofibers enfolded with $\mathrm{BN}$ nanosheets $\left(\mathrm{TiO}_{2}-\mathrm{BN}\right)$ via electrospinning [104]. XPS analysis of $\mathrm{BN}$ nanosheets and $\mathrm{TiO}_{2}$ nanofibers indicated the existence of B-O-Ti bonds. The optical properties of the fabricated catalyst showed that the absorption of visible light was improved with the addition of BN nanosheets, which could be a result of an energy rearrangement stemming from the formation of B-O-Ti bonds. The photodegradation of ibuprofen $\left(5 \mathrm{mg} \mathrm{L}^{-1}\right)$ by $\mathrm{TiO}_{2}-\mathrm{BN}$ was tested under visible light irradiation with a catalyst load of $0.2 \mathrm{~g} \mathrm{~L}^{-1}$. $\mathrm{TiO}_{2}-5 \mathrm{wt} . \% \mathrm{BN}$ exhibited a $100 \%$ degradation efficiency after $2 \mathrm{~h}$ under light irradiation, while pure $\mathrm{TiO}_{2}$ showed an efficiency of $60 \%$. Furthermore, the photocatalytic degradation increased with increasing BN content. This behaviour was attributed to an improved charge carriers separation produced by BN nanosheets wrapping onto $\mathrm{TiO}_{2}$. Moreover, negatively charged $\mathrm{BN}$ nanosheets increased the dispersion of holes.

$\mathrm{Xu}$ et al. reported the fabrication of $\mathrm{CF} / \mathrm{TiO}_{2} / \mathrm{Bi}_{2} \mathrm{WO}_{6}$ nanostructured heterojunctions by coating carbon fibres (CF) with $\mathrm{TiO}_{2}$ nanorods by a dip-coating hydrothermal technique, followed by an in-situ growth of $\mathrm{Bi}_{2} \mathrm{WO}_{6}$ nanosheets [105]. The fabricated catalyst consisted of carbon fibres coated by $\mathrm{TiO}_{2}$ nanorods (diameter of about $200 \mathrm{~nm}$ ), which were decorated with $\mathrm{BiWO}_{6}$ nanosheets with diameters ranging from 350 to $500 \mathrm{~nm}$ and a thickness of about $15 \mathrm{~nm}$. $\mathrm{CF} / \mathrm{TiO}_{2} / \mathrm{Bi}_{2} \mathrm{WO}_{6}$ exhibited a long-wavelength absorption edge at $440 \mathrm{~nm}$ and photocatalytic activity towards the degradation of tetracycline. Degradation experiments using $10 \mathrm{mg} \mathrm{L}^{-1}$ of tetracycline and $3 \mathrm{~g} \mathrm{~L}^{-1}$ of catalyst under solar light irradiation showed that $\mathrm{CF} / \mathrm{TiO}_{2} / \mathrm{Bi}_{2} \mathrm{WO}_{6}$ can degrade $95.1 \%$ of tetracycline in $60 \mathrm{~min}$, a significantly higher efficiency compared to $\mathrm{CF} / \mathrm{TiO}_{2}$ (29.6\%). Additionally, radical trapping experiments revealed that $\mathrm{O}_{2}{ }^{\bullet-}$ and $\mathrm{h}^{+}$can be regarded as the main active species during the degradation of tetracycline.

Leong et al. synthesized $\mathrm{Ni}(\mathrm{OH})_{2}$-modified coral-like rutile $\mathrm{TiO}_{2}\left(\mathrm{Ni}(\mathrm{OH})_{2}-\mathrm{TiO}_{2}\right)$ via hydrolysis of $\mathrm{TiCl}_{4}$ followed by hydrothermal crystallization [106]. The synthesized catalysts showed a coral-like loops morphology consisting of $\mathrm{TiO}_{2}$ nanorod aggregates decorated with $\mathrm{Ni}(\mathrm{OH})_{2}$ nanosheets clusters. UV-vis DRS revealed that pure rutile $\mathrm{TiO}_{2}$ exhibits a light absorption edge at $410 \mathrm{~nm}$ with the deposition of $\mathrm{Ni}(\mathrm{OH})_{2}$ generating additional light absorption in the range from 600 to $800 \mathrm{~nm}$, which was ascribed to $d-d$ transitions of $\mathrm{Ni}(\mathrm{II})$. Tetracycline photodegradation experiments were performed to assess the photocatalytic activity of $\mathrm{Ni}(\mathrm{OH})_{2}-\mathrm{TiO}_{2}$ under visible light irradiation $(420 \mathrm{~nm}$ cut-off filter) using a solution with $10 \mathrm{~g} \mathrm{~L}^{-1}$ catalyst and $100 \mathrm{mg} \mathrm{L}^{-1}$ tetracycline. After $2 \mathrm{~h}$ of irradiation, a $74 \%$ of tetracycline was degraded by $\mathrm{Ni}(\mathrm{OH})_{2}-\mathrm{TiO}_{2}$, which was slightly higher than pristine $\mathrm{TiO}_{2}(65 \%)$. The greater efficiency was connected with a higher adsorption ability induced by $\mathrm{Ni}(\mathrm{OH})_{2}$ incorporation and the extended light absorption range exhibited by $\mathrm{Ni}(\mathrm{OH})_{2}-\mathrm{TiO}_{2}$. 


\subsubsection{Conclusions on Photocatalytic Processes}

Compared to adsorption, for which processes focus mainly on the interaction between the pollutant molecules and the material surface, photocatalytic processes comprise charge separation/transfer mechanisms and the formation of ROS, which ultimately interact with pollutants. To develop effective photocatalysts, the design of the band structure is crucial for the generation of charge carries $\left(\mathrm{h}^{+}\right.$and electrons) with adequate energy levels that allow for their interaction with the target pollutants. In this respect, bandgap energies are commonly reported in the literature, but detailed band structure characterizations are required to properly study charge transfer and photocatalytic degradation mechanisms. These studies might include band positions and composition, as well as the study of potential mid-gap states.

It has been demonstrated that the bandgap energy can be modulated by controlling the morphology and size of two-dimensional nanomaterials. Photocatalysts $\mathrm{Cyst}-\mathrm{BiOBr}$ $(2.30 \mathrm{eV})$ and BOB-S (2.30 eV) exhibited smaller bandgap energies compared to control catalysts produced by alternative methods. Even though these catalysts exhibit bandgap energies that allows them to absorb a large spectrum of light, the degradation rates exhibited during photocatalytic degradation experiments ( 27.17 and $31.05 \mathrm{mg}$ pollutant (g catalyst $\mathrm{min})^{-1}$ ) were significantly lower than that calculated for catalysts with larger bandgaps such as $\mathrm{Cv}$-CNNs (555.6 $\mathrm{mg}$ pollutant (g catalyst $\mathrm{min})^{-1}$ ). In addition to bandgap energy, charge separation and charge transfer have a great influence on the degradation rate, since the higher rate exhibited by $\mathrm{Cv}-\mathrm{CNNs}$ was attributed to the incorporation of carbon vacancies, which increase electronic conductivity and improves charge separation.

Moreover, the synthesis of heterostructures (binary and tertiary systems) has proven to enhance charge separation, producing photocatalysts with higher degradation activities. In this regard, $\mathrm{Ti}_{3} \mathrm{C}_{2} \mathrm{~T}_{\mathrm{x}}$ embedded into alkalized $\mathrm{C}_{3} \mathrm{~N}_{4}\left(\mathrm{Ti}_{3} \mathrm{C}_{2} \mathrm{~T}_{\mathrm{x}} / \mathrm{C}_{3} \mathrm{~N}_{4}\right)$ exhibited a degradation rate of $128.33 \mathrm{mg}$ tetracycline (g catalyst $\mathrm{min})^{-1}$, nearly 8 times higher than that of other $\mathrm{g}-\mathrm{C}_{3} \mathrm{~N}_{4}$-based materials such as $\mathrm{MCU}-\mathrm{C}_{3} \mathrm{~N}_{4}$. This high degradation rate is ascribed to the presence of $\mathrm{Ti}_{3} \mathrm{C}_{2} \mathrm{~T}_{\mathrm{x}}$, which act as an electron acceptor and increase the charge separation. Similarly, $\mathrm{Bi} / \mathrm{C} / \mathrm{BiOCl}$ displayed a degradation rate of $266.67 \mathrm{mg}$ tetracycline (g catalyst $\mathrm{min})^{-1}$, related to synergetic contributions from surface plasmon resonance effects of $\mathrm{Bi}$ and the presence of oxygen vacancies in the structure.

With respect to heterostructure engineering, the fabrication of binary and ternary photocatalysts can be considered as an effective modification method and further research should be done on coupling two-dimensional materials with metal nanoparticles, inorganic semiconductors, and conducting materials with the overall aim of enhancing charge carriers separation.

\subsection{Redox and Electrochemical Processes}

Heterogeneous catalysis based on redox and electrochemical processes has been widely applied for the degradation of organic contaminants, particularly pharmaceuticals, in water [33-36,107]. Conventionally, highly oxidizing hydroxyl $\left(\mathrm{OH}^{\bullet}\right)$ and superoxide $\left(\mathrm{O}_{2}{ }^{\bullet-}\right)$ ROS are produced via direct activation of $\mathrm{H}_{2} \mathrm{O}_{2}$ at the surface of a catalyst containing redox metallic active sites, such as $\mathrm{Fe}^{3+} / \mathrm{Fe}^{2+}$ or $\mathrm{Co}^{3+} / \mathrm{Co}^{2+}$ (Fenton or Fenton-like reactions), or via electrochemical activation of oxygen and water molecules at the surface of metal-based electrocatalysts (electrochemical processes). Additionally, photo-electrocatalytic generation of electron-holes $\left(\mathrm{h}^{+}\right)$can take place together with the generation of ROS, if photoactive semiconductors are used as electrodes. More recently, sulfate radical $\left(\mathrm{SO}_{4}{ }^{-\boldsymbol{}}\right)$-based advanced oxidation processes via peroxymonosulfate $\left(\mathrm{HSO}_{5}{ }^{-}\right)$activation on the surface of catalysts containing transition metals have gained attention to remove toxic and refractory pollutants from water due to the significant oxidation activity of this radical.

The degradation efficiency of all these processes strongly depends on the properties of the catalytic materials employed. Particularly, an increase in the catalyst (support) surface area, catalyst active centers dispersion, and charge transfer properties have a significant impact on the materials performance, which is reflected by superior degradation kinetics of the pollutants. 2D nanomaterials offer these enhanced properties, as discussed in Section 2, and 
recently have been started to be explored as catalysts and/or catalyst supports for redox and (photo-)electrochemical degradation of organic pollutants with promising results.

In this section, the most recent works on peroxymonosulfate activation, Fenton and Fenton-like reactions, and (photo-)electrochemical processes using 2D catalysts are discussed. This includes a description of the catalysts main properties, their degradation efficiency, optimal operating conditions (temperature, $\mathrm{pH}$, catalyst dosage, pollutant concentration, activated species concentration), and catalysts stability.

\subsubsection{Peroxymonosulfate (PMS) Activation}

Ma et al. prepared hollow structure cobalt hydroxide $\left(\mathrm{h}-\mathrm{Co}(\mathrm{OH})_{2}\right)$ through a modified solvothermal-hydrothermal process using $\mathrm{Co}\left(\mathrm{NO}_{3}\right)_{2} \cdot 6 \mathrm{H}_{2} \mathrm{O}$ dissolved in isopropanol and glycerine (solvothermal stage) followed by redissolution of the precipitate obtained in water (hydrothermal stage). They compared its effectiveness for PMS activation and ibuprofen degradation with that of neat $\mathrm{Co}(\mathrm{OH})_{2}$ prepared via a conventional precipitation method $\left(\mathrm{p}-\mathrm{Co}(\mathrm{OH})_{2}\right)$ [108]. Unlike $\mathrm{p}-\mathrm{Co}(\mathrm{OH})_{2}$ which generally exhibits a broken and uneven flat nanostructure $\left(100-500 \mathrm{~nm}\right.$ in size), h- $\mathrm{Co}(\mathrm{OH})_{2}$ represented hollow microscale spheres (about $1 \mu \mathrm{m}$ diameter) with a thin nanosheets shell. In this regard, it was observed that $\mathrm{p}$ $\mathrm{Co}(\mathrm{OH})_{2}$ and $\mathrm{h}-\mathrm{Co}(\mathrm{OH})_{2}$ correspond to the $\beta-\mathrm{Co}(\mathrm{OH})_{2}$ and $\alpha-\mathrm{Co}(\mathrm{OH})_{2}$ phase, respectively. Both presented $\mathrm{Co}^{3+}$ on its surface due to oxidation of $\mathrm{Co}^{2+}$. The specific surface area and total pore volume of $\mathrm{p}-\mathrm{Co}(\mathrm{OH})_{2}$ were $23.9 \mathrm{~m}^{2} \mathrm{~g}^{-1}$ and $0.088 \mathrm{~cm}^{3} \mathrm{~g}^{-1}$, respectively, while these for h-Co(OH) 2 were $132.36 \mathrm{~m}^{2} \mathrm{~g}^{-1}$ and $0.57 \mathrm{~cm}^{3} \mathrm{~g}^{-1}$, respectively. Control tests for ibuprofen (initial concentration: $10 \mu \mathrm{mol} \mathrm{L}{ }^{-1}$ ) degradation indicated that almost no removal of the contaminant was reached by contact with PMS $\left(0.2 \mathrm{mmol} \mathrm{L}^{-1}\right.$ at $\mathrm{pH}$ equal to 7.0) in the absence of catalyst. However, the addition of $\mathrm{p}-\mathrm{Co}(\mathrm{OH})_{2}$ or $\mathrm{h}-\mathrm{Co}(\mathrm{OH})_{2}$ to the previous solution $\left(0.2 \mathrm{~g} \mathrm{~L}^{-1}\right)$ promoted a fast (within about $10 \mathrm{~min}$ ) and efficient degradation of the contaminant (83.6 and 98.6\%, respectively, following a pseudo-first order kinetic model). This was promoted by the effective PSM activation on the surface of these catalysts considering that the adsorption of ibuprofen was negligible $(<0.2 \%)$. The better performance of $\mathrm{h}-\mathrm{Co}(\mathrm{OH})_{2}$ over $\mathrm{p}-\mathrm{Co}(\mathrm{OH})_{2}$ in terms of degradation efficiency was explained by its higher specific surface area and pore volume, as well as its different crystalline phase, which would enhance the interaction of PMS with the catalyst. The formation of superficial $\mathrm{Co}(\mathrm{OH})^{+}$has been reported as the rate-limiting step for radical production, and also it is the key cobalt species to activate PMS. PMS can also consume $\mathrm{Co}^{3+}$ to regenerate $\mathrm{Co}^{2+}$, which is a critical process to maintain the chain reactions at relative low cobalt concentrations. The generated sulfate radicals $\left(\mathrm{SO}_{4}^{\bullet-}\right)$, as well as $\mathrm{OH}^{\bullet}$ radicals, attack the organic molecules for their degradation or mineralization $\left(\mathrm{CO}_{2}+\mathrm{H}_{2} \mathrm{O}\right.$ as products). When h- $\mathrm{Co}(\mathrm{OH})_{2}$ was used as catalyst $6.3 \%$ of the ibuprofen decomposition can be attributed to $\mathrm{OH}^{\bullet}$ radicals, while $75.7 \%$ can be attributed to $\mathrm{SO}_{4}{ }^{\bullet-}$ radicals. After the degradation process a dissolution of $2.36 \%$ of cobalt was observed for this catalyst.

On the search of cobalt-free PMS activators due to the high toxicity and scarcity of this metal, Ding et al. prepared an $\alpha-\mathrm{Fe}_{2} \mathrm{O}_{3} / \mathrm{MXene}$ nanocomposite (FM) through hydrothermal processing using $\mathrm{FeCl}_{3} \cdot 6 \mathrm{H}_{2} \mathrm{O}$ aqueous solutions of concentrations $0.5 \mathrm{M}, 1 \mathrm{M}$, and $2 \mathrm{M}$ (FM-1, FM-2, and FM-3, respectively). They compared its effectiveness for PMS activation and salicylic acid degradation with that of pure MXenes and $\alpha-\mathrm{Fe}_{2} \mathrm{O}_{3}$ prepared by the same hydrofluoric acid etching and hydrothermal processing, respectively [109]. XRD verified the characteristic peaks of $\mathrm{MXene}$ and $\alpha-\mathrm{Fe}_{2} \mathrm{O}_{3}$ in the composite, with the latter gradually intensified as the content of $\alpha-\mathrm{Fe}_{2} \mathrm{O}_{3}$ increased. Infrared spectroscopy revealed the interfacial contact between $\mathrm{MXenes}$ and $\alpha-\mathrm{Fe}_{2} \mathrm{O}_{3}$, which indicated that the iron oxide particles were successfully grafted onto MXene nanosheets. SEM and TEM micrographs demonstrated that $\alpha-\mathrm{Fe}_{2} \mathrm{O}_{3}$ nanoparticles with smaller size were well-dispersed on the surface of MXene nanosheets, which hold especially true for the FM-2 nanocomposite, while some agglomerations were found for the FM-3 nanocomposite. ICP-OES showed that the FM-1, FM-2, and FM-3 nanocomposites contained 8.9, 17.1, and $26.6 \mathrm{wt} . \%$ of $\alpha-\mathrm{Fe}_{2} \mathrm{O}_{3}$, respectively, while XPS indicated that $\mathrm{Fe}^{3+}$ is the predominant oxidation state of iron on 
the fresh catalyst surface. The BET specific surface areas of as-prepared MXene, $\alpha-\mathrm{Fe}_{2} \mathrm{O}_{3}$, and the FM-2 nanocomposite were 19.3, 22.4, and $37.2 \mathrm{~m}^{2} \mathrm{~g}^{-1}$, respectively. Control tests for the degradation of salicylic acid (initial concentration: $20 \mathrm{mg} \mathrm{L}^{-1}$ ) indicated that almost no removal of the contaminant was reached by contact with PMS $\left(200 \mathrm{mg} \mathrm{L}^{-1}\right.$ at $\mathrm{pH}$ equal to 7.0) in the absence of catalyst or in the presence of as-prepared MXenes $\left(0.2 \mathrm{~g} \mathrm{~L}^{-1}\right)$. The maximum degradation was obtained for the FM-2 nanocomposite $\left(0.2 \mathrm{~g} \mathrm{~L}^{-1}\right)$, which allowed for a decomposition of $96.7 \%$ of salicylic acid in $120 \mathrm{~min}$ (following a pseudo-first order kinetic model). This was promoted by the effective PSM activation on the surface of this catalyst with negligible adsorption of salicylic acid $(<2.5 \%)$. The superior activity of FM nanocomposites over pure $\alpha-\mathrm{Fe}_{2} \mathrm{O}_{3}$ was cross-correlated with the smaller size of $\alpha-\mathrm{Fe}_{2} \mathrm{O}_{3}$ on the MXenes surface, which supressed the nanoparticles agglomeration, as well as the higher specific surface areas of the nanocomposites. However, an excess of $\alpha-\mathrm{Fe}_{2} \mathrm{O}_{3}$ on the surface of MXene (as in the case of FM-3) resulted in a decreased degradation rate, probably due to the overlap of the active sites. The negative effect that an increase in the catalyst dosage (over $0.3 \mathrm{~g} \mathrm{~L}^{-1}$ ) has on the degradation rate of salicylic acid can be explained by the accelerated consumption of PMS for the generation of $\mathrm{SO}_{5}{ }^{\bullet-}$ radicals, leading to lower availability of PMS to produce $\mathrm{SO}_{4}{ }^{\bullet-}$ radicals. The $\mathrm{SO}_{5}{ }^{\bullet-}$ radicals possess a weaker oxidation capacity than $\mathrm{SO}_{4}{ }^{\bullet-}$ radicals, which results in a decreased degradation rate. The results of quenching analyses demonstrated that the principal radical species controlling the oxidation reaction was $\mathrm{SO}_{4}{ }^{\bullet-}$. It was observed that the degradation capacity of the FM-2 catalyst decreased from 97.2 to $87.9 \%$ after five cycles, which was related to the adsorption of intermediate products on the surface of the catalyst and leaching of active constituents.

Similarly, looking for the replacement of cobalt as catalyst material, Yang et al. synthesized a Cu-incorporated $\mathrm{Mo}_{2} \mathrm{C}\left(\mathrm{Cu}-\mathrm{Mo}_{2} \mathrm{C}\right)$ catalyst with an exposed (002) facet and different copper contents (1 to $10 \mathrm{wt} . \%$ ) through a one-step calcination method using aqueous solutions of ammonium molybdate tetrahydrate $\left(\left(\mathrm{NH}_{4}\right)_{6} \mathrm{Mo}_{7} \mathrm{O}_{24} \cdot 4 \mathrm{H}_{2} \mathrm{O}\right)$ and cupric acetate monohydrate $\left(\mathrm{Cu}\left(\mathrm{C}_{2} \mathrm{H}_{3} \mathrm{O}_{2}\right)_{2} \cdot \mathrm{H}_{2} \mathrm{O}\right)$. They studied its effectiveness for PMS activation and antibiotics degradation [110]. The XRD patterns of the $\mathrm{Cu}-\mathrm{Mo}_{2} \mathrm{C}$ catalysts showed the characteristic peaks of the hexagonal $\beta-\mathrm{Mo}_{2} \mathrm{C}$ phase and the metallic copper phase, while XPS verified the incorporation of $\mathrm{Cu}$ on the $\mathrm{Mo}_{2} \mathrm{C}$ surface. SEM and TEM images present the pristine $\mathrm{Mo}_{2} \mathrm{C}$ as highly aggregated hexagonal nanosheets with a thickness of $28.7 \mathrm{~nm}$, while the incorporation of copper reduced the particle size and promoted the particles disaggregation. HRTEM-SAED indicated that the hexagonal $5 \% \mathrm{Cu}-\mathrm{Mo}_{2} \mathrm{C}$ had a pure crystalline structure with a (002) lattice plane. HAADF-EDS confirmed that copper was evenly distributed on the surface of the $\mathrm{Mo}_{2} \mathrm{C}$ nanosheets. Control tests for tetracycline (initial concentration: $40 \mathrm{ppm}$ ) degradation indicated that a low removal of the contaminant (around $18 \%$ in $60 \mathrm{~min})$ was reached by contact with PMS $\left(0.3 \mathrm{~g} \mathrm{~L}^{-1}\right.$ at $\mathrm{pH}$ equal to 5.0) in the absence of catalyst or in the presence of pristine $\mathrm{Mo}_{2} \mathrm{C}, \mathrm{Co}_{3} \mathrm{O}_{4}$, and $\alpha-\mathrm{Fe}_{2} \mathrm{O}_{3}\left(34,28\right.$, and $46 \%$, respectively, in $60 \mathrm{~min}$ when $0.2 \mathrm{~g} \mathrm{~L}^{-1}$ of catalyst was added). A degradation efficiency of almost $100 \%$ in only 20 min was obtained in the presence of $5 \%$ $\mathrm{Cu}-\mathrm{Mo}_{2} \mathrm{C}$ catalyst $\left(0.2 \mathrm{~g} \mathrm{~L}^{-1}\right)$, which was promoted by the effective PSM activation on the surface of this catalyst (Figure 3a,b). A further copper addition ( $>5 \mathrm{wt} . \%$ ) decreased the catalyst efficiency probably due its agglomeration on the surface of the $\mathrm{Mo}_{2} \mathrm{C}$ nanosheets. Degradation kinetics verified a pseudo-first order kinetic model for all cases studied. The results of quenching analyses demonstrated that the principal radical species controlling the oxidation reaction was $\mathrm{SO}_{4}{ }^{\bullet-}$, followed by $\mathrm{OH}^{\bullet}$ and $\mathrm{O}_{2}{ }^{\bullet-}$ radicals. Additionally, electrochemical impedance spectroscopy showed that the incorporated copper might facilitate the interfacial charge transfer, which is beneficial for the valence transition and PMS activation. It was observed that the degradation capacity of the $5 \% \mathrm{Cu}-\mathrm{Mo}_{2} \mathrm{C}$ catalyst decreased from $100 \%$ to $91 \%$ after six cycles, which was associated with leaching of $\mathrm{Cu}$ (0.78 wt.\%) and Mo (0.12 wt.\%) after the stability experiment. 


\subsubsection{Fenton and Fenton-like Reactions}

Nie et al. prepared ultrathin iron-cobalt oxide nanosheets (CoFe-ONSs) through a surfactant-aided co-reduction process using $\mathrm{Fe}\left(\mathrm{NO}_{3}\right)_{3} \cdot 9 \mathrm{H}_{2} \mathrm{O}, \mathrm{Co}\left(\mathrm{NO}_{3}\right)_{2} \cdot 6 \mathrm{H}_{2} \mathrm{O}$, and cetyl trimethyl ammonium bromide (CTAB) aqueous solutions with $\mathrm{NaBH}_{4}$ as reducing agent. They investigated their effectiveness for $\mathrm{H}_{2} \mathrm{O}_{2}$ activation and tetracycline degradation, and compared with that of $\mathrm{CoFe}_{2} \mathrm{O}_{4}$ nanoparticles [111]. SEM micrographs of the CoFeONSs revealed hierarchical structures assembled by ultrathin nanosheets with wrinkles, while TEM confirmed the interconnection between the nanosheets and lateral sizes of the nanosheets of about 300-500 $\mathrm{nm}$. The XRD patterns of the CoFe-ONSs were associated to the standard structure of $\mathrm{CoFe}_{2} \mathrm{O}_{4}$, while EDS verified that the major elements are $\mathrm{Fe}, \mathrm{Co}$, and $\mathrm{O}$, which were evenly distributed in the material structure. XPS confirmed that superficial $\mathrm{Fe}$ and Co presented oxidation states of +2 and +3 . AFM demonstrated that the height of nanosheets was $4.6 \mathrm{~nm}$. The specific surface area of CoFe-ONSs was $144.1 \mathrm{~m}^{2} \mathrm{~g}^{-1}$, while the pore volume accounted for $0.638 \mathrm{~cm}^{3} \mathrm{~g}^{-1}$ with an average pore size of $16.6 \mathrm{~nm}$. Control tests for tetracycline (initial concentration: $50 \mathrm{mg} \mathrm{L}^{-1}$ ) degradation indicated that a low contaminant removal (around 16.8\% in $50 \mathrm{~min}$ ) was obtained by contact with $\mathrm{H}_{2} \mathrm{O}_{2}$ (20 mM at pH equal to 7.0) in the absence of catalyst or in the presence of $\mathrm{CoFe}_{2} \mathrm{O}_{4}$ nanoparticles (around $59 \%$ in $50 \mathrm{~min}$ when $0.3 \mathrm{~g} \mathrm{~L}^{-1}$ of catalyst was added). A degradation efficiency of $83.5 \%$ within 50 min was reached for the CoFe-ONSs catalyst, which was promoted by synergistic effects induced by the nanostructures and $\mathrm{H}_{2} \mathrm{O}_{2}\left(\mathrm{H}_{2} \mathrm{O}_{2}\right.$ direct degradation + adsorption of the contaminant on the CoFe-ONSs surface $+\mathrm{H}_{2} \mathrm{O}_{2}$ activation on the surface of the catalyst). The degradation kinetics showed a pseudofirst order kinetic model for all cases studied. The better performance of CoFe-ONSs over $\mathrm{CoFe}_{2} \mathrm{O}_{4}$ was attributed to its distinctive hierarchical structure with interconnected wrinkled nanosheets, which contributed with an extensive specific surface area and an ultrathin nature offering numerous active sites and fast electron transport that benefit the contaminant adsorption and its degradation via Fenton-like reaction. The results of quenching analyses demonstrated that the principal radical species controlling the oxidation reaction was $\mathrm{OH}^{\bullet}$. The efficiency of tetracycline degradation after five succeeding cycles slightly decreased (from 83.5 to $74.4 \%$ ) probably due to intermediate products occupying active sites and leaching of the active metals from CoFe-ONSs $\left(0.045 \mathrm{mg} \mathrm{Fe} \mathrm{L}^{-1}\right.$ and $0.016 \mathrm{mg} \mathrm{Co} \mathrm{L}^{-1}$ after each cycle).

On the search of an enhanced iron-based catalyst for Fenton and Fenton-like reactions, Xing et al. prepared a 2D $\pi$-d conjugated metal-organic framework (MOF) $\mathrm{Fe}_{3}$ (hexaiminotriphenylene $)_{2}\left(\mathrm{Fe}_{3}(\mathrm{HITP})_{2}\right)$ through an ammonia-assisted precipitation method using $\mathrm{FeCl}_{3}$ and HITP. $6 \mathrm{HCl}$ aqueous solutions. They studied its efficiency for $\mathrm{H}_{2} \mathrm{O}_{2}$ activation and tetracycline degradation under dark conditions and under visible light illumination, and compared with that of $\mathrm{Fe}_{2} \mathrm{O}_{3}$ and $\mathrm{Fe}_{3} \mathrm{O}_{4}$ in dark [112]. XRD of $\mathrm{Fe}_{3}(\mathrm{HITP})_{2}$ revealed a poor crystallinity, but high purity. TEM indicated that $\mathrm{Fe}_{3}(\mathrm{HITP})_{2}$ displayed an irregular nanosheet structure with a smooth surface and hexagonal pores (MOF honeycomb arrangement), while HAADF-STEM verified a homogeneous distribution of Fe, $\mathrm{N}$, and $\mathrm{C}$ within the nanosheets (an average iron content of $19.3 \mathrm{wt} . \%$ as measured by ICP and XPS). XPS, XAFS, FTIR, and Raman confirmed the formation of $\pi$-d conjugated 2D structures with $\mathrm{Fe}-\mathrm{N}_{4}$ active sites and mixed iron oxidation states $(+2$ and +3$)$. Finally, the BET specific surface area of $\mathrm{Fe}_{3}(\mathrm{HITP})_{2}$ was $260.2 \mathrm{~m}^{2} \mathrm{~g}^{-1}$. By UV-vis diffuse reflectance, it was verified that $\mathrm{Fe}_{3}(\mathrm{HITP})_{2}$ absorbed light over the entire UV-vis range and part of the infrared range. Control tests for tetracycline (initial concentration: $20 \mathrm{mg} \mathrm{L}^{-1}$ ) degradation indicated that its adsorption on the $\mathrm{Fe}_{3}(\mathrm{HITP})_{2}$ surface $\left(0.4 \mathrm{~g} \mathrm{~L}^{-1}\right.$ at $\mathrm{pH}$ equal to 4.5) under dark was negligible ( $3 \%$ in $30 \mathrm{~min}$ ), while low degradation ( $17.3 \%$ in $30 \mathrm{~min}$ ) was reached in the presence of $\mathrm{H}_{2} \mathrm{O}_{2}(20 \mathrm{mM}$ at $\mathrm{pH}$ equal to 4.5). The degradation efficiency did not improve under visible light illumination in the presence of the catalyst (13\% in $30 \mathrm{~min}$ ) or in the presence of $\mathrm{H}_{2} \mathrm{O}_{2}(2.7 \%$ in $30 \mathrm{~min})$, respectively. However, in the presence of $\mathrm{Fe}_{3}(\mathrm{HITP})_{2}$ and $\mathrm{H}_{2} \mathrm{O}_{2}$ under visible illumination, a degradation efficiency of around $96.7 \%$ was reached in $30 \mathrm{~min}$, which suggests a synergistic effect of the catalyst, $\mathrm{H}_{2} \mathrm{O}_{2}$, and visible 
light in a photo-Fenton-like reaction (Figure $3 c$,d). The $\mathrm{Fe}_{3}(\mathrm{HITP})_{2}$ and $\mathrm{H}_{2} \mathrm{O}_{2}$ system under visible light illumination outperformed $\mathrm{Fe}_{2} \mathrm{O}_{3}(31.5 \%$ of degradation in $30 \mathrm{~min})$ and $\mathrm{Fe}_{3} \mathrm{O}_{4}$ (41.8\% of degradation in $30 \mathrm{~min}$ ), which was connected to the catalyst remarkable high specific surface area, high density of $\mathrm{Fe}^{-} \mathrm{N}_{4}$ active sites, and superior light absorption. The results of quenching analyses demonstrated that the principal radical species controlling the oxidation reaction was $\mathrm{O}_{2}^{\bullet-}$, rather than $\mathrm{OH}^{\bullet}$ radicals observed in traditional Fenton or Fenton-like reactions. Electron paramagnetic resonance spectroscopy results suggest that light illumination promotes the dynamic cycle $\mathrm{Fe}^{2+} / \mathrm{Fe}^{3+}$. DFT calculations indicated that $\mathrm{Fe}_{3}^{3+}(\mathrm{HITP})_{2}$ and $\mathrm{Fe}_{3}^{2+}(\mathrm{HITP})_{2}$ possess narrow band gaps of 0.37 and $0.33 \mathrm{eV}$, respectively. No decay of the degradation efficiency was observed after 8 cycles, even though $0.037 \mathrm{mg} \mathrm{L}^{-1}$ of iron were leached from the catalyst after each cycle, demonstrating its high stability.

\subsubsection{Electrochemical Processes}

$\mathrm{Mi}$ et al. prepared stable reduced graphene oxide ( $\mathrm{rGO}) / \mathrm{Ce}-\mathrm{WO}_{3}$ nanosheets to modify carbon felt (CF) as an electro-Fenton cathode through a hydrothermal method using aqueous solutions of rGO synthesized by the Hummers method, $\mathrm{Na}_{2} \mathrm{WO}_{3} \cdot 2 \mathrm{H}_{2} \mathrm{O}$, and $\mathrm{CeCl}_{3} \cdot 7 \mathrm{H}_{2} \mathrm{O}$ with variable mass ratio of $\mathrm{rGO}$ and $\mathrm{Ce}-\mathrm{WO}_{3}$. Subsequently, they compared their effectiveness for $\mathrm{H}_{2} \mathrm{O}_{2}$ production and activation, and ciprofloxacin degradation [113]. $\mathrm{SEM}$ micrographs of $\mathrm{CF} / \mathrm{rGO} / \mathrm{Ce}-\mathrm{WO}_{3}$ cathodes showed nanosheets randomly loaded on the rough surface of CF fibres, while TEM confirmed the plate-like morphologies of $\mathrm{rGO} / \mathrm{Ce}-\mathrm{WO}_{3}$ nanoparticles with diameters of about 8-12 nm with $\mathrm{Ce}-\mathrm{WO}_{3}$ nanosheets distributed on the surface of rGO. HR-TEM showed that $\mathrm{rGO} / \mathrm{Ce}-\mathrm{WO}_{3}$ nanoparticles presented good crystallinity with $\mathrm{WO}_{3}$ planes clearly exposed and $\mathrm{CeO}_{2}$ crystallites highly dispersed. XPS revealed the presence of $\mathrm{C}, \mathrm{O}, \mathrm{W}$, and $\mathrm{Ce}$, with the addition of $\mathrm{RGO}$ on the surface of $\mathrm{CF}$ greatly increasing the degree of oxidation, abundance of superficial active oxygen species, and $\mathrm{Ce}^{4+}, \mathrm{Ce}^{3+}, \mathrm{W}^{6+}$, and $\mathrm{W}^{5+}$ coexisting on the surface. The specific surface area of $\mathrm{rGO} / \mathrm{Ce}-\mathrm{WO}_{3}$ was $69.71 \mathrm{~m}^{2} \mathrm{~g}^{-1}$, while its pore volume and average pore size were $0.120 \mathrm{~cm}^{3} \mathrm{~g}^{-1}$ and $14.084 \mathrm{~nm}$, respectively. EIS tests showed that $\mathrm{CF} / \mathrm{rGO} / \mathrm{Ce}-$ $\mathrm{WO}_{3}$ electrodes presented lower electron transfer impedance than $\mathrm{CF} / \mathrm{Ce}-\mathrm{WO}_{3}$. This indicates that rGO could promoted the electron transfer between the electrode surface and the solution. Degradation tests were carried out at room temperature with an electrolyte solution containing $50 \mathrm{mg} \mathrm{L}^{-1}$ of ciprofloxacin, $0.05 \mathrm{~mol} \mathrm{~L}-1$ of $\mathrm{Na}_{2} \mathrm{SO}_{4}$, and $0.1 \mathrm{mmol} \mathrm{L}^{-1}$ of $\mathrm{FeSO}_{4} \cdot 7 \mathrm{H}_{2} \mathrm{O}$ at a $\mathrm{pH}$ equal to 3.0. The anode (counter electrode) was a platinum plate of $1 \times 0.5 \mathrm{~cm}^{2}$, and the cathode was the $\mathrm{CF} / \mathrm{rGO} / \mathrm{Ce}-\mathrm{WO}_{3}$ fabricated using a $6 \times 3 \times 0.5 \mathrm{~cm}^{3}$ $3 \mathrm{D}$ carbon felt. Oxygen was bubbled into the solution at a flow rate of $100 \mathrm{~mL} \mathrm{~min}^{-1}$ up to $30 \mathrm{~min}$ prior to each degradation experiment. It was determined that the optimal $\mathrm{rGO} / \mathrm{Ce}-\mathrm{WO}_{3}$ mass ratio, $\mathrm{Ce} / \mathrm{W}$ molar ratio, and $\left(\mathrm{RGO} / \mathrm{Ce}-\mathrm{WO}_{3}\right) / \mathrm{CF}$ loading amount in the cathode were $1: 3,0.05$, and $4.5 \mathrm{wt} . \%$, respectively, which exhibited a degradation efficiency of $100 \%$ in $60 \mathrm{~min}$ at an applied current of $400 \mathrm{~mA}$. This high degradation efficiency can be explained by the effective generation of $\mathrm{H}_{2} \mathrm{O}_{2}$ and radical species on the high specific surface of the electrode, while its activity was enhanced by addition of $\mathrm{Ce}$ as a dopant. The results of quenching analyses suggest that oxygen $\left(\mathrm{O}_{2}\right)$ is reduced in the presence of protons $\left(\mathrm{H}^{+}\right)$on the surface of the cathode to produce $\mathrm{H}_{2} \mathrm{O}_{2}$ via a two-electron transfer process. This gives rise to the generation of $\mathrm{O}_{2}{ }^{\bullet-}$ radicals, which can produce further $\mathrm{H}_{2} \mathrm{O}_{2}$ (via $\mathrm{OH}^{\bullet}$ and $\mathrm{OOH}^{\bullet}$ radicals) or oxidize the organic pollutant (Figure 3e,f). Therefore, ciprofloxacin degradation occurs via $\mathrm{OH}^{\bullet}$ radicals generated by $\mathrm{H}_{2} \mathrm{O}_{2}$ through a Fenton-like process and $\mathrm{O}_{2}{ }^{\bullet-}$ radicals generated via $\mathrm{O}_{2}$ reduction and Fenton-like processes. The degradation of ciprofloxacin marginally reduced (by $5.1 \%$ ) after five cycles due to mechanical wearing of the cathode coating.

Tang et al. prepared $\mathrm{g}-\mathrm{C}_{3} \mathrm{~N}_{4}$ nanosheets supported on $\mathrm{TiO}_{2}$ nanotube arrays (TCNs) as photo-electrocatalytic anodes through direct calcination of melamine $(0.2,0.5$ and $1 \mathrm{~g}$ in $15 \mathrm{~mL}$ of ethyl alcohol) onto $\mathrm{TiO}_{2}$ nanotube arrays (TNAs). They investigated their effectiveness for the degradation of tetracycline compared with bare TNAs anodes [114]. 
SEM and TEM micrographs showed well-ordered and highly dense, pure TNAs with tube diameters between 100 and $125 \mathrm{~nm}$, while the added g- $\mathrm{C}_{3} \mathrm{~N}_{4}$ nanosheets were uniformly anchored on the TNAs. The tube walls of $\mathrm{TiO}_{2}$ nanotubes tend to thicken with increasing g- $\mathrm{C}_{3} \mathrm{~N}_{4}$ content due to their attachment to the tube surfaces. XRD identified anatase $\mathrm{TiO}_{2}$ and increasing peaks intensities for $\mathrm{g}-\mathrm{C}_{3} \mathrm{~N}_{4}$ with increasing amount of melamine in the precursor solution. EDX confirmed that $\mathrm{g}-\mathrm{C}_{3} \mathrm{~N}_{4}$ was evenly distributed over the entire TNAs. XPS verified the interaction between electron-rich nitrogen in $\mathrm{g}^{-} \mathrm{C}_{3} \mathrm{~N}_{4}$ and the electron deficient $\mathrm{Ti}^{4+}$ in $\mathrm{TiO}_{2}$, which would benefit charge separation and transfer at their interface. UV-visible diffuse reflection spectroscopy revealed a stronger light absorption of TCNs compared with pure TNAs and g- $\mathrm{C}_{3} \mathrm{~N}_{4}$, while photoluminescence measurements showed that TCN-2 (TCNs prepared with $0.5 \mathrm{~g}$ of melamine) presented the most stable separation of photogenerated charge carriers. Degradation tests were carried out in an aqueous electrolyte containing $10 \mathrm{mg} \mathrm{L}^{-1}$ of tetracycline and $0.1 \mathrm{M}^{\mathrm{N}} \mathrm{Na}_{2} \mathrm{SO}_{4}$. The anode was the as-prepared TNAs or TCNs photoelectrode with an active area of 4 $\mathrm{cm}^{2}$, while a platinum plate was used as cathode (counter electrode) and an $\mathrm{Ag} / \mathrm{AgCl}$ electrode was used as reference. The system was kept under dark conditions for $30 \mathrm{~min}$ to reach adsorption-desorption equilibrium prior to photo-electrochemical measurements under simulated solar light irradiation. The photo-electrochemical degradation process showed a higher efficiency than electrochemical and photocatalytic processes for both TNAs and TCNs anodes. In the case of TCN-2 electrodes, a degradation efficiency of $95 \%$ within $60 \mathrm{~min}$ was reached when a potential of $1.0 \mathrm{~V}$ vs. $\mathrm{Ag} / \mathrm{AgCl}$ was applied. The results of quenching analyses demonstrate that the electron holes $\left(\mathrm{h}^{+}\right)$, generated under simulated solar light irradiation at the $\mathrm{TiO}_{2} / \mathrm{g}-\mathrm{C}_{3} \mathrm{~N}_{4}$ heterojunction are the main radical species acting in the degradation of tetracycline. The $\mathrm{OH}^{\bullet}$ and $\mathrm{O}_{2}{ }^{--}$radicals produced at the cathode showed a lower degradation effect than $\mathrm{h}^{+}$, although it was not negligible. Finally, tests under continuous flow $\left(0.84 \mathrm{~mL} \mathrm{~min}^{-1}\right)$ were conducted using a real water source electrolyte reaching a degradation of tetracycline of $80 \%$ in $60 \mathrm{~min}$ with unchanged morphology and structure of the TCN-2 anode.

Recently, Wang et al. prepared 2D Ni-MOF derived NiO@C nanosheet arrays modified $\mathrm{Ti} / \mathrm{TiO}_{2} \mathrm{NTs} / \mathrm{PbO}_{2}$ anodes through a solvothermal process using $\mathrm{NiCl}_{2} \cdot 6 \mathrm{H}_{2} \mathrm{O}$ and 1,4-dicarboxybenzene acid dissolved in a solution containing water, ethanol and N,Ndimethylformamide, in which $\mathrm{TiO}_{2} \mathrm{NTs}$ were immersed. This process was followed by a carbonization stage of the produced electrode in highly pure $\mathrm{N}_{2}$ for the effective generation of the NiO@C nanosheet arrays. Finally, $\beta-\mathrm{PbO}_{2}$ active layers were electrodeposited on $\mathrm{Ti} / \mathrm{TiO}_{2} \mathrm{NTs} / \mathrm{NiO} @ \mathrm{C}$, $\mathrm{Ti} / \mathrm{TiO}_{2} \mathrm{NTs}$, and bare Ti plate electrodes using an electrolyte containing $\mathrm{Pb}\left(\mathrm{NO}_{3}\right)_{2}$ and $\mathrm{HNO}_{3}$, and different electrodeposition times $(15,20,30$ and $45 \mathrm{~min}$ ) [115]. SEM images showed well-ordered and highly dense $\mathrm{TiO}_{2} \mathrm{NTs}$ with a tube diameter of around $140 \mathrm{~nm}$. The tubes were covered by highly dispersed NiO@C petal-like nanosheets with an average thickness of $30 \mathrm{~nm} . \mathrm{PbO}_{2}$-electroplated Ti/ $/ \mathrm{TiO}_{2} \mathrm{NTs} / \mathrm{NiO} @ \mathrm{C}$ electrodes showed smaller metal oxide particles, which were uniformly dispersed on their surface and increased the availability of active sites. XRD demonstrated the presence of anatase $\mathrm{TiO}_{2}$, cubic $\mathrm{NiO}$, and $\beta-\mathrm{PbO}_{2}$ phases as well as smaller grain sizes for the latter in the case of $\mathrm{Ti} / \mathrm{TiO}_{2} \mathrm{NTs} / \mathrm{NiO} @ \mathrm{C} / \mathrm{PbO}_{2}$ electrodes. XPS confirmed $\mathrm{Ni}$ oxidation states of 0 and +2 , which implies the presence of $\mathrm{Ni}$ metal and $\mathrm{NiO}$ in the structure. The electrochemical performance was tested using Ti/ $\mathrm{TiO}_{2} \mathrm{NTs} / \mathrm{NiO} @ \mathrm{C} / \mathrm{PbO}_{2}, \mathrm{Ti} / \mathrm{TiO}_{2} \mathrm{NTs} / \mathrm{PbO}_{2}$ or bare $\mathrm{Ti} / \mathrm{PbO}_{2}$ plate electrodes as anode, a platinum plate as cathode (counter electrode), and $\mathrm{KCl}$-saturated calomel electrode as reference, immersed in a $2 \mathrm{~mol} \mathrm{~L}^{-1} \mathrm{H}_{2} \mathrm{SO}_{4}$ solution at $60{ }^{\circ} \mathrm{C}$. It was observed that the $\mathrm{Ti} / \mathrm{TiO}_{2} \mathrm{NTs} / \mathrm{NiO} @ \mathrm{C} / \mathrm{PbO}_{2}$ electrode with electrodeposition time of $20 \mathrm{~min}$ showed the largest electrochemical active area and the fastest electron transfer rate. In addition, the electrode showed: (i) a high oxygen evolution potential that favours the formation of more reactive oxygen species (particularly, $\mathrm{OH}^{\bullet}$ radicals), and (ii) a service life larger than $40 \mathrm{~h}$ (in accelerated life tests). Both aspects are desirable for the degradation of organic pollutants. The degradation tests were carried out in an electrolyte aqueous solution containing $10 \mathrm{mg} \mathrm{L}^{-1}$ of salicylic acid and $0.1 \mathrm{~mol} \mathrm{~L}^{-1} \mathrm{of} \mathrm{Na}_{2} \mathrm{SO}_{4}$ 
at a $\mathrm{pH}$ equal to 5. The prepared electrodes were tested as anode and a titanium plate $\left(2 \mathrm{~cm}^{2}\right)$ was used as cathode. A current density of $70 \mathrm{~mA} \mathrm{~cm}^{-2}$ was applied for $3 \mathrm{~h}$. The $\mathrm{Ti} / \mathrm{TiO}_{2} \mathrm{NTs} / \mathrm{NiO} @ \mathrm{C} / \mathrm{PbO}_{2}$ electrode showed the highest degradation rate (pseudo-first order kinetics) due to its enhanced electrochemical performance, reaching a removal of around $96.29 \%$ of salicylic acid even after 8 cycles. The degradation of salicylic acid was attributed to indirect electrochemical oxidation via mediating $\mathrm{OH}^{\bullet}$ radicals generated at the $\mathrm{Ti} / \mathrm{TiO}_{2} \mathrm{NTs} / \mathrm{NiO} @ \mathrm{C} / \mathrm{PbO}_{2}$ electrode surface.

Figure 3 summarizes the structure and performance of the 2D nanomaterials with the highest degradation efficiencies reported for PMS activation $\left(\mathrm{Mo}_{2} \mathrm{C}\right.$ nanosheets), Fenton and Fenton-like reactions (2D $\pi$-d conjugated metal organic framework $\mathrm{Fe}_{3}(\mathrm{HITP})_{2}$ ), and electrochemical processes ( $\mathrm{rGO}-\mathrm{Ce} / \mathrm{WO}_{3}$ nanosheets).

\subsubsection{Conclusions on Redox and Electrochemical Processes}

PMS activation and Fenton or Fenton-like reactions are redox processes which greatly depend on the generation of active species such as $\mathrm{SO}_{4}{ }^{\bullet-}$ or $\mathrm{ROS}\left(\mathrm{OH}^{\bullet}, \mathrm{O}_{2}{ }^{\bullet-}\right)$ for the degradation of pharmaceuticals. In this regard, the results reported in Sections 3.3.1 and 3.3.2 indicate that 2D nanomaterials are promising catalysts for these processes due to their enhanced surface area and charge transfer properties. Additionally, as observed for $\mathrm{Cu}-\mathrm{Mo}_{2} \mathrm{C}$ in PMS activation and $\mathrm{Fe}_{3}(\mathrm{HITP})_{2}$ in Fenton-like reactions, high disaggregation and density of active sites is crucial for obtaining high degradation rates and efficiencies. Therefore, the improvement of the synthesis methods towards intelligent materials design appears as an important aspect to be considered in future studies for their successful application in wastewater treatment.

Together with structure and surface design of 2D nanomaterials to obtain increased surface areas and highly dispersed active centres, the ability to control their optical transparency via bandgap engineering is an effective method to enhance their degradation properties. As observed for $\mathrm{Fe}_{3}(\mathrm{HITP})_{2}$ in Fenton-like reactions and TCNs in electrochemical processes, the photogenerated electron holes $\left(\mathrm{h}^{+}\right)$can also act as oxidation agents together with ROS, showing even higher degradation yields. Considering that PMS activation seems to be the most effective degradation method of pharmaceuticals in wastewater due to the lower degradation times and the variety of degraded compounds reported, it is thought that the development of new 2D nanomaterials for PMS activation with enhanced optical properties is a promising research area.

Finally, electrochemical processes offer a more straightforward path for the design of continuous operation devices than conventional heterogeneous catalysis methods (PMS activation and Fenton reactions), which is attractive in terms of large-scale wastewater treatment. Electrochemical cells allow for the ad-hoc and facile control of the reduction and oxidation kinetics, which is important in real operations where wastewater composition can be variable over time. This combined with the use of improved photocatalytic electrode materials (as shown for TCNs) and the integration of PMS electro-activation can also be an interesting area for future research.

It is worth to highlight that the replacement of scarce and/or toxic metals, such as cobalt and lead, as part of catalyst or electrocatalyst is of great importance for the success of the methods reported in Section 3.3. The environmental and health impact that these technologies might have at the end of their life is an aspect to be studied to promote real, sustainable alternatives with a positive impact on environment. In this regard, recycling processes of catalysts or electrocatalysts should be developed aiming to reduce the impact of waste worldwide. This aspect is critical considering the instability reported for several materials after a small number of cycles (up to 8 cycles), which should be further reduced in the future. 
a)

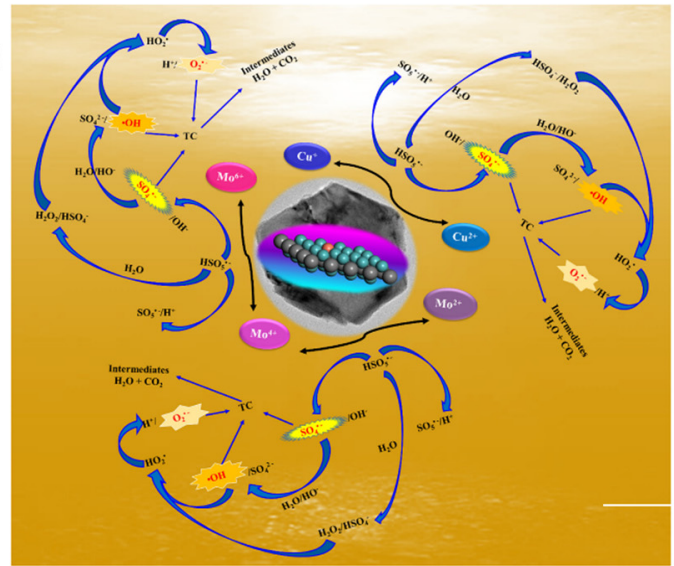

c)

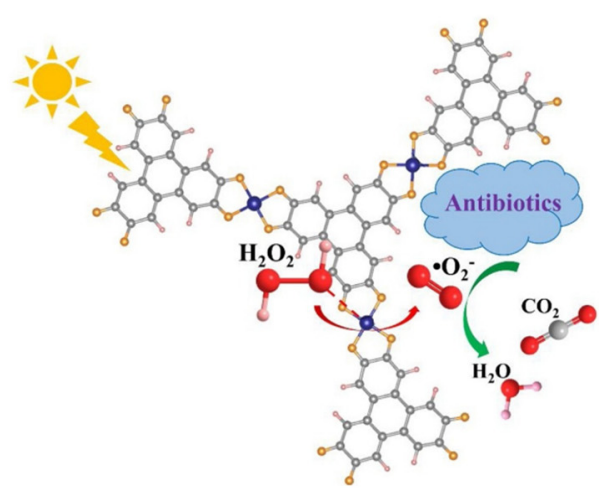

e)

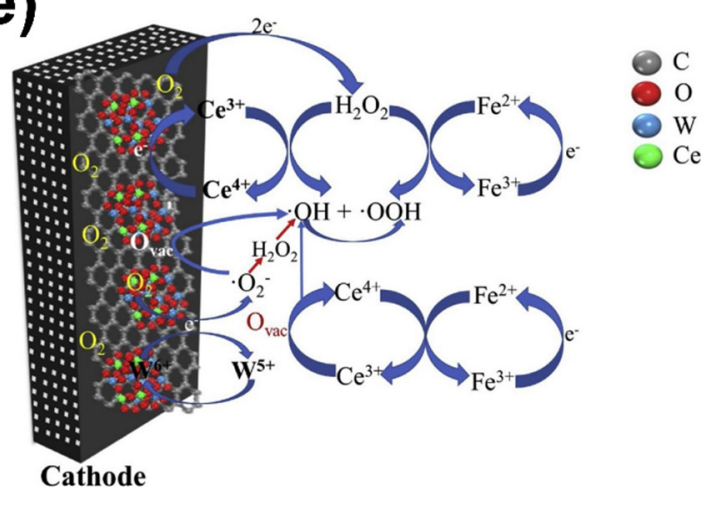

b)

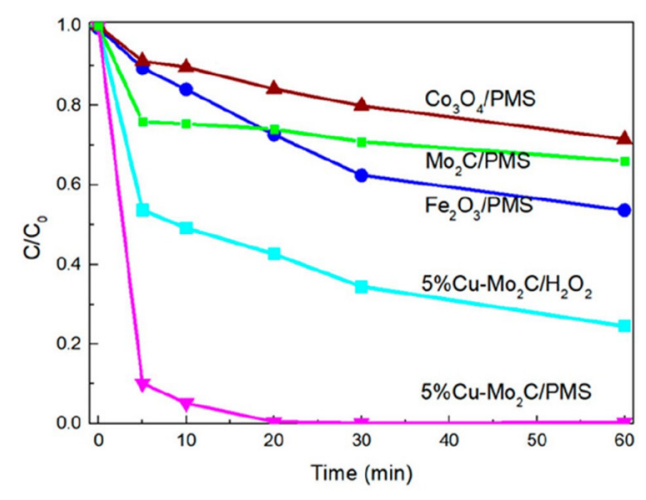

d)

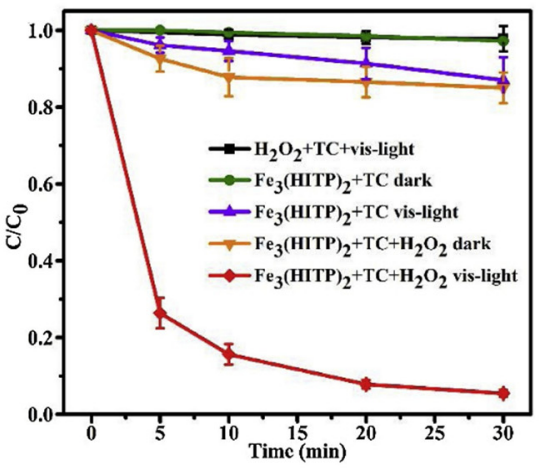

f)

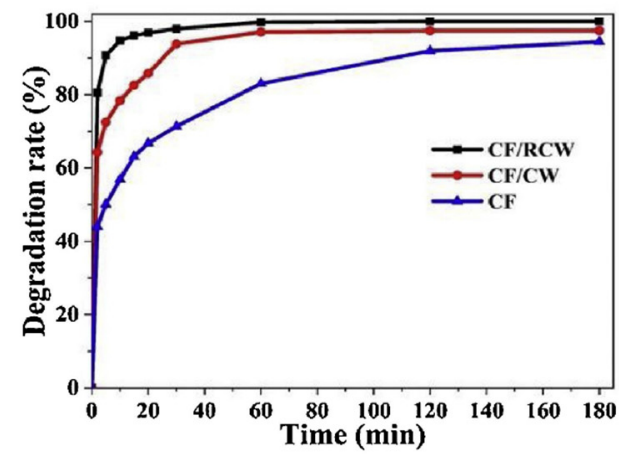

Figure 3. 2D nanomaterials for redox and electrochemical processes and their removal efficiency: $(\mathbf{a}, \mathbf{b})$ hexagonal $\mathrm{Mo}_{2} \mathrm{C}$ nanosheets with (002) facets and $\mathrm{Cu}$ incorporation for tetracycline removal via PMS activation (reproduced with permission [110]), (c,d) 2D $\pi$-d conjugated metal-organic framework $\mathrm{Fe}_{3}(\mathrm{HITP})_{2}$ and tetracycline removal via photo-Fenton like reaction (reproduced with permission [112]), and (e,f) $\mathrm{rGO}-\mathrm{Ce} / \mathrm{WO}_{3}$ nanosheets modified carbon felt cathode and ciprofloxacin removal via electro-Fenton process (reproduced with permission [113]).

\section{Overview and Outlook}

In this review, the state-of-the-art regarding the ability of 2D nanomaterials to remove pharmaceutical pollutants from wastewater is summarized and critically discussed. In this regard, adsorption, photocatalytic, and redox/electrochemical processes have been identified as main approaches. Current trends in 2D nanomaterials development for wastewater treatment tend to the research of materials composed of earth-abundant elements (e.g., C, $\mathrm{Bi}, \mathrm{Ti}, \mathrm{Mo}$, and $\mathrm{Fe}$ ), the design of rational material-pollutant interactions, and the fabrication of diverse morphologies for a superior removal or degradation of pollutants.

Table 1 summarizes the performance of pure 2D nanomaterials and binary/ternary nanocomposites as adsorbents of pharmaceutical contaminants in wastewater. The results suggest that materials based on $\mathrm{MoS}_{2}, \mathrm{MOF}$, and MXenes are the most promising for 
the removal of many compounds, showing a fast uptake within a few minutes or even seconds, short equilibrium times, and maximum adsorption capacities between 200 and $800 \mathrm{mg} \mathrm{g}^{-1}$. The exceptional adsorption capacity of these nanomaterials is associated with a superior specific surface area (in the range of 10 to $100 \mathrm{~m}^{2} \mathrm{~g}^{-1}$ ), and a surface structure which offers an increased number of active sites (such as -OH and -O) that promote chemisorption of the pollutants. Moreover, $\mathrm{GO} / \mathrm{Fe}_{3} \mathrm{O}_{4}$ binary nanocomposites demonstrated fast uptakes within $10 \mathrm{~min}$, equilibrium times of $30 \mathrm{~min}$, and maximum adsorption capacities around $250 \mathrm{mg} \mathrm{g}^{-1}$ due to pronounced $\pi-\pi$ interactions between the nanohybrid and the contaminant.

Table 2 summarizes the reviewed studies regarding photocatalytic processes. To compare different material performances, the degradation rate normalized by the catalyst load is used as an indicator for the degradation capacity. This parameter is found suitable since it considers the initial concentration, efficiency, reaction time, and catalyst load. In this context, the fabrication of heterostructures appears as a promising strategy to obtain highly active photocatalysts, allowing for the enhancement of visible light absorption, thus increasing the charge carriers separation and reducing charge recombination. $\mathrm{Ti}_{3} \mathrm{C}_{2} \mathrm{~T}_{\mathrm{x}}$ embedded into alkalized $\mathrm{C}_{3} \mathrm{~N}_{4}$ $\left(\mathrm{Ti}_{3} \mathrm{C}_{2} \mathrm{~T}_{\mathrm{x}} / \mathrm{C}_{3} \mathrm{~N}_{4}\right)$ exhibited a degradation rate of $128.33 \mathrm{mg}$ tetracycline ( $\mathrm{g}$ catalyst min $)^{-1}$, which is nearly 8 times higher than that of other $g-C_{3} N_{4}$-based materials such as $M C U-C_{3} N_{4}$. This enhanced photodegradation activity was ascribed to its binary structure, which prevents the recombination of charge carriers, while $\mathrm{Ti}_{3} \mathrm{C}_{2} \mathrm{~T}_{\mathrm{x}}$ acted as an electron acceptor. Similarly, the high photocatalytic activity achieved by $\mathrm{Bi} / \mathrm{C} / \mathrm{BiOCl}$ (266.67 $\mathrm{mg}$ tetracycline (g catalyst $\mathrm{min})^{-1}$ ) was connected to synergetic contributions from surface plasmon resonance effects of $\mathrm{Bi}$ and the presence of oxygen vacancies. Additionally, carbon nitride nanosheets catalysts with carbon vacancies ( $\mathrm{Cv}-\mathrm{CNNs}$ ) exhibited a degradation rate of $555.56 \mathrm{mg}$ sulfadiazine (g

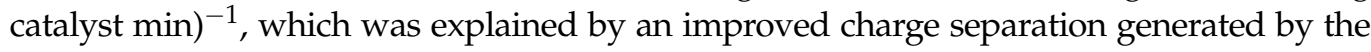
incorporated carbon vacancies.

Table 3 summarizes the performance of the 2D nanomaterials used for redox and electrochemical degradation of pharmaceuticals in wastewater. The results suggest that oxidation processes based on peroxymonosulfate activation are the most promising method for degradation, reaching degradation rates of nearly $100 \%$ in less than $30 \mathrm{~min}$. This is associated with the high activity of $\mathrm{SO}_{4}{ }^{\bullet-}$ radicals, as well as their capacity to enhance the generation of $\mathrm{OH}^{\bullet}$ radicals in water, which seems to be favoured by metal carbide nanomaterials such as $\mathrm{Cu}-\mathrm{MoC}_{2}$ nanosheets. Furthermore, this nanomaterial showed a strong ability to degrade many contaminants under natural $\mathrm{pH}$ and temperature conditions in different water sources. In the case of Fenton-like processes, it is worth to highlight the performance of the metal-organic framework $\mathrm{Fe}_{3}(\mathrm{HITP})_{2}$ and its ability to absorb visible light, which enhanced the degradation rate for a wide range of contaminants when compared with conventional iron-based Fenton catalysts.

Table 1. 2D nanomaterials reported for the removal of pharmaceuticals in wastewater via adsorption processes.

\begin{tabular}{|c|c|c|c|c|c|c|c|}
\hline \multicolumn{8}{|c|}{ Pure 2D Nanomaterials } \\
\hline Material & Pollutant & $\begin{array}{c}\text { Specific } \\
\text { area } / \mathrm{m}^{2} \\
\mathrm{~g}^{-1}\end{array}$ & $\begin{array}{l}\text { Concentration } \\
\text { (pollutant/adsorbent) }\end{array}$ & $\begin{array}{l}\text { Wastewater } \\
\text { characteristics }\end{array}$ & $\begin{array}{c}\text { Optimal } \\
\text { adsorption } \\
\text { characteristics }\end{array}$ & $\begin{array}{l}\text { Maximum } \\
\text { adsorption } \\
\text { capacity }\end{array}$ & Ref. \\
\hline $\begin{array}{l}\text { Flower-like } \\
\text { single-layer } \\
\mathrm{MoS}_{2}\end{array}$ & diclofenac & 23.9 & $\begin{array}{c}10 \mathrm{mg} \mathrm{L}^{-1} / \\
0.2-0.8 \mathrm{~g} \mathrm{~L}^{-1} \\
\text { (optimal: } 0.5 \mathrm{~g} \\
\mathrm{~L}^{-1} \text { ) }\end{array}$ & $\begin{array}{c}\text { Synthetic, } \\
\text { temperature: } 25^{\circ} \mathrm{C}\end{array}$ & $\begin{array}{l}>90 \%(\text { in } 5 \mathrm{~min}) / \\
\text { equilibrium time: } \\
\qquad 10 \mathrm{~min}\end{array}$ & $217 \mathrm{mg} \mathrm{g}^{-1}$ & [62] \\
\hline $\begin{array}{l}\text { Few-layer } \\
\text { boron- } \\
\text { nitride } \\
\text { nanosheets }\end{array}$ & estrone & 900 & $\begin{array}{c}500 \mu \mathrm{g} \mathrm{L}^{-1} / \\
0.05 \mathrm{~g} \mathrm{~L}^{-1}\end{array}$ & $\begin{array}{c}\text { Synthetic, } \\
\text { temperature: } 25^{\circ} \mathrm{C}\end{array}$ & $\begin{array}{c}>80 \% \text { (in } 10 \\
\text { min)/ } \\
\text { equilibrium time: } \\
2 \mathrm{~h}\end{array}$ & $249 \mathrm{mg} \mathrm{g}^{-1}$ & [63] \\
\hline
\end{tabular}


Table 1. Cont.

\begin{tabular}{|c|c|c|c|c|c|c|c|}
\hline \multicolumn{8}{|c|}{ Pure 2D Nanomaterials } \\
\hline $\begin{array}{l}\text { Defective } \\
\text { boron- } \\
\text { nitride } \\
\text { nanosheets }\end{array}$ & tetracycline & 533 & $\begin{array}{c}\text { 200-250 mg L } \\
\text { (optimal: } 250 \mathrm{mg} \\
\mathrm{L}^{-1} \text { )/ } \\
0.2-2 \mathrm{~g} \mathrm{~L}^{-1} \\
\text { (optimal: } 2 \mathrm{~g} \mathrm{~L}^{-1} \text { ) }\end{array}$ & $\begin{array}{c}\text { Synthetic, } \\
\text { temperature: } 25^{\circ} \mathrm{C}\end{array}$ & $\begin{array}{c}\text { Fast uptake } \\
\text { within } 50 \mathrm{~min} / \\
\text { equilibrium time: } \\
6 \mathrm{~h}\end{array}$ & $1101 \mathrm{mg} \mathrm{g}^{-1}$ & [64] \\
\hline $\begin{array}{l}\text { Defective } \\
\text { boron- } \\
\text { nitride } \\
\text { nanosheets } \\
\text { with boron } \\
\text { vacancies }\end{array}$ & tetracycline & 1104 & $\begin{array}{c}200 \mathrm{mg} \mathrm{L}^{-1} / \\
0.2 \mathrm{~g} \mathrm{~L}^{-1}\end{array}$ & $\begin{array}{l}\text { Synthetic, } \mathrm{pH}=3.2, \\
\text { temperature: } 25^{\circ} \mathrm{C}\end{array}$ & $\begin{array}{c}\text { Fast uptake } \\
\text { within } 50 \mathrm{~min} / \\
\text { equilibrium time: } \\
3 \mathrm{~h}\end{array}$ & $438 \mathrm{mg} \mathrm{g}^{-1}$ & [65] \\
\hline $\begin{array}{l}\text { Few-layer } \\
\mathrm{g}^{-C_{3} \mathrm{~N}_{4}}\end{array}$ & tetracycline & 178 & $\begin{array}{l}20 \mathrm{mg} \mathrm{L}^{-1} / \\
0.2 \mathrm{~g} \mathrm{~L}^{-1}\end{array}$ & $\begin{array}{c}\text { Synthetic, } \mathrm{pH}= \\
6.5-7.5, \\
\text { temperature: } 25^{\circ} \mathrm{C}\end{array}$ & $\begin{array}{c}>75 \% \text { (in } 60 \\
\text { min) } / \\
\text { adsorption }+ \\
\text { photocatalytic } \\
\text { process }\end{array}$ & $40 \mathrm{mg} \mathrm{g}^{-1}$ & [66] \\
\hline $\begin{array}{l}\text { Copper- } \\
\text { porphyrin }\end{array}$ & tetracycline & 342 & $\begin{array}{l}10 \mathrm{mg} \mathrm{L}^{-1} / \\
0.2 \mathrm{~g} \mathrm{~L}^{-1}\end{array}$ & Synthetic, $\mathrm{pH}=5$ & $\begin{array}{c}>85 \% \text { (in } 6 \mathrm{~h} \text { )/ } \\
\text { equilibrium time: } \\
30 \mathrm{~min} / \\
\text { adsorption }+ \\
\text { photocatalytic } \\
\text { process }\end{array}$ & $150 \mathrm{mg} \mathrm{g}^{-1}$ & [67] \\
\hline $\begin{array}{l}\text { Covalent } \\
\text { triazine } \\
\text { framework } \\
\text { nano- } \\
\text { sheets }\end{array}$ & nitrofurazone & 565 & $\begin{array}{l}50 \mathrm{ppm} /^{-1} \\
0.5 \mathrm{~g} \mathrm{~L}^{-1}\end{array}$ & Synthetic, $\mathrm{pH}=6$ & $\begin{array}{c}\text { Fast uptake } \\
\text { within } 60 \mathrm{~min} / \\
\text { equilibrium time: } \\
2 \mathrm{~h}\end{array}$ & $351 \mathrm{mg} \mathrm{g}^{-1}$ & [68] \\
\hline $\begin{array}{l}\text { Few-layer, } \\
\text { zwitter- } \\
\text { ionic } \\
\text { COFs }\end{array}$ & norfloxacin & 187 & $\begin{array}{c}10-500 \mathrm{mg} \mathrm{L}^{-1} \\
\text { (optimal: } 10 \mathrm{mg} \\
\mathrm{L}^{-1} \text { )/ } \\
0.5 \mathrm{~g} \mathrm{~L}^{-1}\end{array}$ & Synthetic, $\mathrm{pH}=8$ & $\begin{array}{c}99.4 \% \text { (in } 30 \mathrm{~s}) / \\
\text { equilibrium time: } \\
1 \mathrm{~min}\end{array}$ & $824 \mathrm{mg} \mathrm{g}^{-1}$ & [69] \\
\hline $\begin{array}{l}\text { Multi-layer } \\
\mathrm{Ti}_{3} \mathrm{C}_{2} \mathrm{~T}_{\mathrm{x}}\end{array}$ & ciprofloxacin & -- & $\begin{array}{l}10 \mathrm{mg} \mathrm{L}^{-1} / \\
0.4 \mathrm{~g} \mathrm{~L}^{-1}\end{array}$ & $\begin{array}{l}\text { Synthetic, } \mathrm{pH}=5.5 \text {, } \\
\text { temperature: } 25^{\circ} \mathrm{C}\end{array}$ & $\begin{array}{l}>80 \% \text { (in } 30 \mathrm{~s} \text { )/ } \\
\text { equilibrium time: } \\
\text { few minutes }\end{array}$ & $208 \mathrm{mg} \mathrm{g}^{-1}$ & [70] \\
\hline \multicolumn{8}{|c|}{ Binary and ternary nanocomposites } \\
\hline Material & Pollutant & $\begin{array}{c}\text { Specific } \\
\text { area } / \mathrm{m}^{2} \\
\mathrm{~g}^{-1}\end{array}$ & $\begin{array}{l}\text { Concentration } \\
\text { (pollutant/adsorbent) }\end{array}$ & $\begin{array}{l}\text { Wastewater } \\
\text { characteristics }\end{array}$ & $\begin{array}{c}\text { Optimal } \\
\text { adsorption } \\
\text { characteristics }\end{array}$ & $\begin{array}{c}\text { Maximum } \\
\text { adsorption } \\
\text { capacity }\end{array}$ & Ref. \\
\hline $\mathrm{rGO} / \mathrm{Fe}_{3} \mathrm{O}_{4}$ & $\begin{array}{l}\text { sulfonamide } \\
\text { antibi- } \\
\text { otics }\end{array}$ & -- & $\begin{array}{c}\text { trace amounts/ } \\
0.5-3 \mathrm{~g} \mathrm{~L}^{-1} \\
\text { (optimal: } 2 \mathrm{~g} \mathrm{~L}^{-1} \text { ) }\end{array}$ & Tap water, sewage & $\begin{array}{c}\text { Fast uptake } \\
\text { within } 10 \mathrm{~min} / \\
\text { equilibrium time: } \\
15 \mathrm{~min}\end{array}$ & -- & [71] \\
\hline $\mathrm{GO} / \mathrm{Fe}_{3} \mathrm{O}_{4}$ & tetracycline & 249 & $\begin{array}{c}30 \text { and } 50 \mathrm{mg} \mathrm{L}^{-1} \\
\text { (optimal: } 50 \mathrm{mg} \\
\left.\mathrm{L}^{-1}\right) / \\
9.6 \mathrm{~g} \mathrm{~L}^{-1}\end{array}$ & $\begin{array}{c}\text { Synthetic, } \mathrm{pH}= \\
\text { 2-11, temperature: } \\
25{ }^{\circ} \mathrm{C}\end{array}$ & $\begin{array}{c}\text { Fast uptake } \\
\text { within } 20 \mathrm{~min} / \\
\text { equilibrium time: } \\
10 \mathrm{~h}\end{array}$ & $212 \mathrm{mg} \mathrm{g}^{-1}$ & [72] \\
\hline $\begin{array}{l}\mathrm{GO} / \mathrm{Fe}_{3} \mathrm{O}_{4} \\
\text { (suspen- } \\
\text { sions) }\end{array}$ & chlorpheniram & nine221 & $\begin{array}{c}120 \mathrm{mg} \mathrm{L}^{-1} / \\
--\end{array}$ & Synthetic, $\mathrm{pH}=6$ & $\begin{array}{c}\text { Fast uptake } \\
\text { within } 5 \mathrm{~min} / \\
\text { equilibrium time: } \\
60 \mathrm{~min}\end{array}$ & $300 \mathrm{mg} \mathrm{g}^{-1}$ & [73] \\
\hline
\end{tabular}


Table 1. Cont.

\begin{tabular}{|c|c|c|c|c|c|c|c|}
\hline \multicolumn{8}{|c|}{ Binary and ternary nanocomposites } \\
\hline $\begin{array}{c}\mathrm{MoS}_{2} / \mathrm{GO} / \\
\mathrm{Fe}_{3} \mathrm{O}_{4}\end{array}$ & $\begin{array}{l}\text { lecofloxacin, } \\
\text { paz- } \\
\text { cofloxacin, } \\
\text { gati- } \\
\text { floxacin }\end{array}$ & 135 & $\begin{array}{c}\text { trace amounts/ } \\
0.05-0.25 \mathrm{~g} \mathrm{~L}^{-1} \\
\text { (optimal: } 0.2 \mathrm{~g} \\
\mathrm{~L}^{-1} \text { ) }\end{array}$ & $\begin{array}{c}\text { Synthetic, } \mathrm{pH}= \\
0.5-4\end{array}$ & $\begin{array}{c}\text { Fast uptake } \\
\text { within } 2 \text { min/ } \\
\text { equilibrium time: } \\
4 \text { min }\end{array}$ & $5 \mathrm{mg} \mathrm{g}^{-1}$ & [74] \\
\hline $\begin{array}{c}\mathrm{rGO} / \mathrm{Ag} / \\
\mathrm{Fe}_{3} \mathrm{O}_{4}\end{array}$ & $\begin{array}{l}\text { acetaminophen, } \\
\text { ibupro- } \\
\text { fen, } \\
\text { naproxen }\end{array}$ & -- & $0.1 \mathrm{~g} \mathrm{~L}^{-1}$ & $\begin{array}{c}\text { Synthetic, } \mathrm{pH}= \\
4-10 \text {, temperature: } \\
25{ }^{\circ} \mathrm{C}\end{array}$ & $\begin{array}{l}>99 \% \text { of } \\
\text { acetaminophen } \\
\text { (in } 1 \\
\text { h)/equilibrium } \\
\text { time: } 6 \mathrm{~h}\end{array}$ & --- & [75] \\
\hline$\underset{\mathrm{MoS}_{2} / \text { biochar }}{\mathrm{g}-}$ & tetracycline & 176.8 & $\begin{array}{l}100 \mathrm{mg} \mathrm{L}^{-1} / \\
0.4 \mathrm{~g} \mathrm{~mL}^{-1}\end{array}$ & $\begin{array}{c}\text { Synthetic, } \mathrm{pH}= \\
\text { 2-11, temperature: } \\
25{ }^{\circ} \mathrm{C}\end{array}$ & $\begin{array}{l}>80 \%(\text { in } 4 \mathrm{~h}) / \\
\text { equilibrium time: } \\
15 \mathrm{~h}\end{array}$ & $249 \mathrm{mg} \mathrm{g}^{-1}$ & [76] \\
\hline chitin/GO & ciprofloxacin & --- & $\begin{array}{c}4-850 \mathrm{mg} \mathrm{L}^{-1} / \\
5 \mathrm{~g} \mathrm{~L}^{-1}\end{array}$ & $\begin{array}{l}\text { Synthetic, } \mathrm{pH}=6.3 \text {, } \\
\text { temperature: } 25^{\circ} \mathrm{C}\end{array}$ & $\begin{array}{c}\text { Fast uptake } \\
\text { within } 100 \mathrm{~min} / \\
\text { equilibrium time: } \\
6 \mathrm{~h}\end{array}$ & $270 \mathrm{mg} \mathrm{g}^{-1}$ & [77] \\
\hline
\end{tabular}

Table 2. 2D nanomaterials reported for the degradation of pharmaceuticals in wastewater via photocatalytic processes.

\begin{tabular}{|c|c|c|c|c|c|c|c|c|}
\hline \multicolumn{9}{|c|}{ Graphitic Carbon Nitride-Based Materials } \\
\hline Material & $\begin{array}{c}\text { Band } \\
\text { gap/eV }\end{array}$ & Pollutant & $\begin{array}{c}\text { Specific } \\
\text { area } / \mathrm{m}^{2} \\
\mathrm{~g}^{-1}\end{array}$ & $\begin{array}{l}\text { Concentration } \\
\text { (pollutant/catalyst) }\end{array}$ & $\begin{array}{c}\text { Wastewater } \\
\text { characteristics }\end{array}$ & $\begin{array}{l}\text { Maximum } \\
\text { degrada- } \\
\text { tion }\end{array}$ & $\begin{array}{l}\text { Degradation } \\
\text { rate } \\
/ \frac{m g \text { pollutant }}{\text { g catalyst }- \text { min }}\end{array}$ & Ref. \\
\hline $\begin{array}{l}\mathrm{MCU}- \\
\mathrm{C}_{3} \mathrm{~N}_{4}\end{array}$ & 2.79 & $\begin{array}{l}\text { tetracycline, } \\
\text { ciprofloxacin }\end{array}$ & 122.53 & $\begin{array}{l}10 \mathrm{mg} \mathrm{L}^{-1} / \\
0.7 \mathrm{~g} \mathrm{~L}^{-1}\end{array}$ & Synthetic & $\begin{array}{l}81.60 \% \text { of } \\
\text { tetracycline } \\
\text { (in } 80 \mathrm{~min} \text { ) } \\
65.80 \% \text { of } \\
\text { ciprofloxacin } \\
\text { (in } 90 \mathrm{~min} \text { ) }\end{array}$ & $\begin{array}{l}14.57 \\
10.44\end{array}$ & [86] \\
\hline $\mathrm{Cv}-\mathrm{CNNs}$ & 2.83 & sulfadiazine & 77.72 & $\begin{array}{l}10 \mathrm{mg} \mathrm{L}^{-1} / \\
0.02 \mathrm{~g} \mathrm{~L}^{-1}\end{array}$ & $\begin{array}{c}\text { Synthetic, } \\
\text { temperature: } \\
25{ }^{\circ} \mathrm{C}\end{array}$ & $\begin{array}{c}100 \% \text { (in } 90 \\
\text { min) }\end{array}$ & 555.56 & [87] \\
\hline $\begin{array}{l}\text { OCN-24- } \\
550\end{array}$ & 2.54 & oxytetracycline & 126 & $\begin{array}{c}20 \mathrm{mg} \mathrm{L}^{-1} / \\
1 \mathrm{~g} \mathrm{~L}^{-1}\end{array}$ & Synthetic & $\begin{array}{l}85.76 \% \text { (in } \\
120 \mathrm{~min})\end{array}$ & 14.29 & [89] \\
\hline $\mathrm{KMCN}(0.05)$ & 2.33 & tetracycline & 50.19 & $\begin{array}{c}20 \mathrm{mg} \mathrm{L}^{-1} / \\
1 \mathrm{~g} \mathrm{~L}^{-1}\end{array}$ & $\begin{array}{c}\text { Synthetic, } \\
\text { temperature: } \\
\text { ambient }\end{array}$ & $\begin{array}{l}85.13 \% \text { (in } \\
60 \mathrm{~min})\end{array}$ & 28.38 & [90] \\
\hline $\mathrm{Ti}_{3} \mathrm{C}_{2} \mathrm{~T}_{\mathrm{x}} / \mathrm{C}_{3} \mathrm{~N}_{4}$ & -- & tetracycline & 37.20 & $\begin{array}{c}20 \mathrm{mg} \mathrm{L}^{-1} / \\
0.2 \mathrm{~g} \mathrm{~L}^{-1}\end{array}$ & Synthetic & $\begin{array}{c}77 \% \text { (in } 60 \\
\min )\end{array}$ & 128.33 & [91] \\
\hline \multicolumn{9}{|c|}{ Bismuth oxyhalides-based materials } \\
\hline Material & $\begin{array}{c}\text { Band } \\
\text { gap/eV }\end{array}$ & Pollutant & $\begin{array}{l}\text { Specific } \\
\text { area } / \mathrm{m}^{2} \\
\mathrm{~g}^{-1}\end{array}$ & $\begin{array}{l}\text { Concentration } \\
\text { (pollutant/catalyst) }\end{array}$ & $\begin{array}{l}\text { Wastewater } \\
\text { characteristic }\end{array}$ & $\begin{array}{l}\text { Maximum } \\
\text { degrada- } \\
\text { tion }\end{array}$ & $\begin{array}{l}\text { Degradation } \\
\text { rate } \\
/ \frac{m g \text { pollutant }}{g \text { catalyst }-\mathrm{min}}\end{array}$ & Ref. \\
\hline Cyst-BiOBr & 2.3 & cefazolin & 11.38 & $\begin{array}{l}10 \mathrm{mg} \mathrm{L}^{-1} / \\
0.2 \mathrm{~g} \mathrm{~L}^{-1}\end{array}$ & $\begin{array}{c}\text { Synthetic, } \\
\text { pH = 6.7,tem- } \\
\text { perature: } 20 \\
{ }^{\circ} \mathrm{C}\end{array}$ & $\begin{array}{c}87 \% \text { (in } 180 \\
\min )\end{array}$ & 24.17 & [97] \\
\hline $\mathrm{Bi}_{24} \mathrm{O}_{31} \mathrm{Br}_{10}$ & 2.3 & tetracycline & 8.57 & $\begin{array}{l}10 \mathrm{mg} \mathrm{L}^{-1} / \\
0.34 \mathrm{~g} \mathrm{~L}^{-1}\end{array}$ & $\begin{array}{l}\text { Synthetic, } \\
\text { temperature: } \\
\text { ambient }\end{array}$ & $\begin{array}{l}95 \%(\text { in } 90 \\
\min )\end{array}$ & 31.05 & [98] \\
\hline
\end{tabular}


Table 2. Cont.

\begin{tabular}{|c|c|c|c|c|c|c|c|c|}
\hline \multicolumn{9}{|c|}{ Bismuth oxyhalides-based materials } \\
\hline $\mathrm{BiOCl}_{\mathrm{x}} \mathrm{I}_{\mathrm{y}}$ & 2.12 & acetaminophen & 34.93 & $\begin{array}{c}20 \mathrm{mg} \mathrm{L}^{-1} / \\
0.6 \mathrm{~g} \mathrm{~L}^{-1}\end{array}$ & $\begin{array}{c}\text { Synthetic, } \\
\mathrm{pH}=7.36, \\
\text { temperature: } \\
25^{\circ} \mathrm{C}\end{array}$ & $\begin{array}{c}80 \% \text { (in } 180 \\
\min )\end{array}$ & 14.81 & [99] \\
\hline $\mathrm{Bi}_{5} \mathrm{O}_{7} \mathrm{Br} / \mathrm{BiOBr}$ & -- & carbamazepine & -- & $\begin{array}{l}10 \mathrm{mg} \mathrm{L}^{-1} / \\
0.5 \mathrm{~g} \mathrm{~L}^{-1}\end{array}$ & $\begin{array}{c}\text { Synthetic, } \\
\text { temperature: } \\
25{ }^{\circ} \mathrm{C}\end{array}$ & $\begin{array}{l}92 \% \text { (in } 90 \\
\text { min) }\end{array}$ & 20.44 & [100] \\
\hline $\mathrm{Bi} / \mathrm{C} / \mathrm{BiOCl}$ & -- & tetracycline & 57.80 & $\begin{array}{l}10 \mathrm{mg} \mathrm{L}^{-1} / \\
0.2 \mathrm{~g} \mathrm{~L}^{-1}\end{array}$ & $\begin{array}{l}\text { Synthetic, } \\
\text { temperature: } \\
25^{\circ} \mathrm{C}\end{array}$ & $\begin{array}{l}80 \% \text { (in } 15 \\
\text { min) }\end{array}$ & 266.67 & [101] \\
\hline $\mathrm{Bi}_{4} \mathrm{Ti}_{3} \mathrm{O}_{12} / \mathrm{BiOB}$ & $3 r---$ & $\begin{array}{l}\text { ciprofloxacin, } \\
\text { tetracycline }\end{array}$ & -- & $20 \mathrm{mg} \mathrm{L}^{-1} /$ & $\begin{array}{c}\text { Synthetic, } \\
\text { temperature: } \\
\text { ambient }\end{array}$ & $\begin{array}{l}96 \% \text { of } \\
\text { ciprofloxacin } \\
\text { (in } 210 \\
\text { min) } 97 \% \text { of } \\
\text { tetracycline } \\
\text { (in } 210 \mathrm{~min} \text { ) }\end{array}$ & --- & [102] \\
\hline \multicolumn{9}{|c|}{$\mathrm{TiO}_{2}$-based materials } \\
\hline Material & $\begin{array}{l}\text { Band } \\
\text { gap/ } \\
\mathrm{eV}\end{array}$ & Pollutant & $\begin{array}{l}\text { Specific } \\
\text { area } / \mathrm{m}^{2} \\
\mathrm{~g}^{-1}\end{array}$ & $\begin{array}{l}\text { Concentration } \\
\text { (pollutant/catalyst) }\end{array}$ & $\begin{array}{l}\text { Wastewater } \\
\text { characteristic }\end{array}$ & $\begin{array}{l}\text { Maximum } \\
\text { degrada- } \\
\text { tion }\end{array}$ & $\begin{array}{l}\text { Degradation } \\
\text { rate } \\
/ \frac{m g \text { pollutant }}{\text { g catalyst }-\mathrm{min}}\end{array}$ & Ref. \\
\hline $\mathrm{TiO}_{2}-\mathrm{BN}$ & --- & ibuprofen & 49.60 & $\begin{array}{c}5 \mathrm{mg} \mathrm{L}^{-1} / \\
0.2 \mathrm{~g} \mathrm{~L}^{-1}\end{array}$ & Synthetic & $\begin{array}{l}100 \% \text { (in } \\
120 \mathrm{~min})\end{array}$ & 20.83 & [104] \\
\hline $\begin{array}{l}\mathrm{CF} / \mathrm{TiO}_{2} / \\
\mathrm{Bi}_{2} \mathrm{WO}_{6}\end{array}$ & --- & tetracycline & -- & $\begin{array}{l}10 \mathrm{mg} \mathrm{L}^{-1} / \\
3 \mathrm{~g} \mathrm{~L}^{-1}\end{array}$ & $\begin{array}{c}\text { Synthetic, } \\
\text { temperature: } \\
20{ }^{\circ} \mathrm{C}\end{array}$ & $\begin{array}{l}95.10 \% \text { (in } \\
60 \mathrm{~min})\end{array}$ & 5.28 & [105] \\
\hline $\begin{array}{l}\mathrm{Ni}(\mathrm{OH})_{2-}^{-} \\
\mathrm{TiO}_{2}\end{array}$ & -- & tetracycline & 96.60 & $\begin{array}{c}100 \mathrm{mg} \mathrm{L}^{-1} / \\
10 \mathrm{~g} \mathrm{~L}^{-1}\end{array}$ & Synthetic & $\begin{array}{c}74 \% \text { (in } 120 \\
\text { min) }\end{array}$ & 6.17 & [106] \\
\hline
\end{tabular}

Table 3. 2D nanomaterials reported for the degradation of pharmaceuticals in wastewater via redox and electrochemical processes.

\begin{tabular}{|c|c|c|c|c|c|c|}
\hline \multicolumn{7}{|c|}{ Peroxymonosulfate Activation } \\
\hline Material & Pollutant & $\begin{array}{c}\text { Specific } \\
\text { area } / \mathrm{m}^{2} \mathrm{~g}^{-1}\end{array}$ & $\begin{array}{c}\text { Concentration } \\
\text { (pollutant/catalyst) }\end{array}$ & $\begin{array}{c}\text { Wastewater } \\
\text { characteristics }\end{array}$ & $\begin{array}{c}\text { Maximum } \\
\text { degradation }\end{array}$ & Ref. \\
\hline h- $\mathrm{Co}(\mathrm{OH})_{2}$ & ibuprofen & 132.36 & $\begin{array}{l}10 \mu \mathrm{mol} \mathrm{L}^{-1} / \\
0.2 \mathrm{~g} \mathrm{~L}^{-1}\end{array}$ & $\begin{array}{c}0.2 \mathrm{mmol} \mathrm{L}{ }^{-1} \text { PMS, } \\
\mathrm{pH}=3-11 \text { (optimal: } \\
7 \text { ), } \\
\text { room temperature }\end{array}$ & 98.6\% (in $10 \mathrm{~min}$ ) & [108] \\
\hline $\begin{array}{c}\alpha- \\
\mathrm{Fe}_{2} \mathrm{O}_{3} / \text { Mxene }\end{array}$ & salicylic acid & 37.2 & $\begin{array}{c}\text { 10-100 mg L } \\
\text { (optimal: } 20 \mathrm{mg} \\
\left.\mathrm{L}^{-1}\right) / \\
0.1-1 \mathrm{~g} \mathrm{~L}^{-1} \\
\text { (optimal: } 0.2 \mathrm{~g} \mathrm{~L}^{-1} \text { ) }\end{array}$ & $\begin{array}{c}0.1-0.8 \mathrm{~g} \mathrm{~L}^{-1} \mathrm{PMS} \\
\left.\text { (optimal: } 0.2 \mathrm{~g} \mathrm{~L}^{-1}\right) \\
\text { pH }=3-9 \text { (optimal: } 7 \text { ), } \\
\text { temperature: } 25^{\circ} \mathrm{C}\end{array}$ & 96.7\% (in $120 \mathrm{~min}$ ) & [109] \\
\hline $\mathrm{Cu}-\mathrm{Mo}_{2} \mathrm{C}$ & Tetracycline $^{1}$ & - & $\begin{array}{c}\text { 10-50 ppm } \\
\text { (optimal: } 40 \mathrm{ppm} \text { )/ } \\
0.05-0.40 \mathrm{~g} \mathrm{~L}^{-1} \\
\text { (optimal: } 0.2 \mathrm{~g} \mathrm{~L}^{-1} \text { ) }\end{array}$ & $\begin{array}{c}\text { 0-0.5 g L }{ }^{-1} \mathrm{PMS} \\
\text { (optimal: } 0.3 \mathrm{~g} \mathrm{~L}^{-1} \text { ), } \\
\mathrm{pH}=3-11 \text { (optimal: } \\
\text { 5), } \\
\text { temperature: } 15-45 \\
{ }^{\circ} \mathrm{C}\left(\text { optimal: } 25^{\circ} \mathrm{C}\right)^{2}\end{array}$ & 100\% (in $20 \mathrm{~min}$ ) & [110] \\
\hline
\end{tabular}


Table 3. Cont.

\begin{tabular}{|c|c|c|c|c|c|c|}
\hline \multicolumn{7}{|c|}{ Fenton and Fenton-like reactions } \\
\hline Material & Pollutant & $\begin{array}{c}\text { Specific } \\
\text { area } / \mathrm{m}^{2} \mathrm{~g}^{-1}\end{array}$ & $\begin{array}{c}\text { Concentration } \\
\text { (pollutant/catalyst) }\end{array}$ & $\begin{array}{c}\text { Wastewater } \\
\text { characteristics }\end{array}$ & $\begin{array}{c}\text { Maximum } \\
\text { degradation }\end{array}$ & Ref. \\
\hline CoFe-ONSs & tetracycline & 144.1 & $\begin{array}{c}40-70 \mathrm{mg} \mathrm{L}-1 \\
\text { (optimal: } 50 \mathrm{mg} \\
\mathrm{L}^{-1} \text { )/ } \\
0.2-1.2 \mathrm{~g} \mathrm{~L}^{-1} \\
\text { (optimal: } 0.3 \mathrm{~g} \mathrm{~L}^{-1} \text { ) }\end{array}$ & $\begin{array}{c}\text { 5-40 mM H} \mathrm{m}_{2} \mathrm{O}_{2} \\
\text { (optimal: } 20 \mathrm{mM} \text { ), } \\
\mathrm{pH}=3-8 \text { (optimal: } 7 \text { ), } \\
\text { temperature: } 15-35 \\
\left.{ }^{\circ} \mathrm{C} \text { (optimal: } 25^{\circ} \mathrm{C}\right)^{3}\end{array}$ & $\sim 83.5 \%$ (in $50 \mathrm{~min}$ ) & [111] \\
\hline $\mathrm{Fe}_{3}(\mathrm{HITP})_{2}$ & Tetracycline $^{4}$ & 260.2 & $\begin{array}{c}20 \mathrm{mg} \mathrm{L}^{-1 /} \\
0.1-0.4 \mathrm{~g} \mathrm{~L}^{-1} \\
\text { (optimal: } 0.4 \mathrm{~g} \mathrm{~L}^{-1} \text { ) }\end{array}$ & $\begin{array}{c}4-40 \mathrm{mM} \mathrm{H} \mathrm{O}_{2} \\
\text { (optimal: } 20 \mathrm{mM} \text { ), } \\
\text { pH = 3-9 (optimal: } \\
4.5 \text { ), } \\
\text { room temperature, } \\
\text { under visible light } \\
\text { illumination }\end{array}$ & 96.7\% (in $30 \mathrm{~min}$ ) & [112] \\
\hline \multicolumn{7}{|c|}{ Electrochemical processes } \\
\hline Material & Pollutant & $\begin{array}{c}\text { Specific } \\
\text { area } / \mathrm{m}^{2} \mathrm{~g}^{-1}\end{array}$ & $\begin{array}{l}\text { Concentration } \\
\text { (pollutant) }\end{array}$ & $\begin{array}{c}\text { Wastewater } \\
\text { characteristics }\end{array}$ & $\begin{array}{c}\text { Maximum } \\
\text { degradation }\end{array}$ & Ref. \\
\hline $\begin{array}{l}\mathrm{CF} / \mathrm{RGO}_{-} \\
\mathrm{Ce} / \mathrm{WO}_{3}\end{array}$ & ciprofloxacin & 69.71 & $50 \mathrm{mg} \mathrm{L}^{-1}$ & $\begin{array}{c}0.05 \mathrm{~mol} \mathrm{~L}-1 \mathrm{Na}_{2} \mathrm{SO}_{4} \\
0.05-0.30 \mathrm{mmol} \mathrm{L} \\
\mathrm{FeSO}_{4} \cdot 7 \mathrm{H}_{2} \mathrm{O} \\
\text { (optimal: } 0.1 \mathrm{mmol} \\
\mathrm{L}^{-1} \text { ), } \\
\mathrm{pH}=3.0, \\
\text { applied current: } 400 \\
\mathrm{~mA} \\
\text { room temperature }\end{array}$ & $\sim 100 \%$ (in $60 \mathrm{~min}$ ) & [113] \\
\hline $\begin{array}{l}\mathrm{TiO}_{2} \mathrm{NTs}_{\mathrm{T}} / \mathrm{g}- \\
\mathrm{C}_{3} \mathrm{~N}_{4}\end{array}$ & Tetracycline $^{5}$ & - & $10 \mathrm{mg} \mathrm{L}^{-1}$ & $\begin{array}{c}0.1 \mathrm{~mol} \mathrm{~L}^{-1} \mathrm{Na}_{2} \mathrm{SO}_{4} \\
\text { applied voltage: } \\
0.2-2.5 \mathrm{~V} \text { vs. } \\
\mathrm{Ag} / \mathrm{AgCl} \text { (optimal: } \\
1.0 \mathrm{~V}) \\
\text { under solar light } \\
\text { illumination } 6\end{array}$ & 95\% (in $60 \mathrm{~min}$ ) & [114] \\
\hline $\begin{array}{c}\mathrm{Ti} / \mathrm{TiO}_{2} \mathrm{NTs} / \\
\mathrm{NiO} @ \mathrm{C} / \mathrm{PbO}_{2}\end{array}$ & salicylic acid & - & $\begin{array}{c}\text { 10-90 mg L }{ }^{-1} \\
\text { (optimal: } 30 \mathrm{mg} \\
\mathrm{L}^{-1} \text { ) }\end{array}$ & $\begin{array}{c}0.025-0.3 \text { mol L } \\
\mathrm{Na}_{2} \mathrm{SO}_{4} \text { (optimal: } \\
\left.0.05-0.1 \mathrm{~mol} \mathrm{~L}^{-1}\right) \\
\mathrm{pH}=3-11 \text { (optimal: } \\
3-5 \text { ), } \\
\text { applied current: } \\
\text { 30-120 mA cm }{ }^{-2} \\
\text { (optimal: } 70 \mathrm{~mA} \\
\mathrm{~cm}^{-2} \text { ) }\end{array}$ & 96.29\% (in $180 \mathrm{~min}$ ) & [115] \\
\hline
\end{tabular}

${ }^{1}$. Additionally, other organics were almost completely degraded in about $60 \mathrm{~min} .{ }^{2}$. Additionally, the effects on the degradation rate of different anions, cations and natural water sources were investigated. No significant drawbacks were observed, reaching complete or almost complete degradation in about $60 \mathrm{~min} .{ }^{3}$. Additionally, the effects on the degradation rate of different anions and natural water sources were investigated. Suppression of tetracycline degradation was observed in $50 \mathrm{~min}$, probably due to the consumption of active species by the added chemicals. ${ }^{4}$. Additionally, other organics were highly degraded in about 45 min. ${ }^{5}$. Additionally, other organics were highly degraded in about $60 \mathrm{~min} .{ }^{6}$. Additionally, the effect on the degradation rate of a natural water source was investigated. No significant drawbacks were observed, reaching $80 \%$ of degradation in about $60 \mathrm{~min}$.

Although large scale application of 2D nanomaterials for the removal of pollutants in wastewater is highly desired, most of the studies to date wereperformed at laboratory scale. Moreover, several challenges need to be addressed to achieve full-scale treatment systems, including large-scale fabrication, devices and automatization design, regeneration systems, and management of secondary residues (when produced). In this regard, the potential 
up-scaling must be considered when developing novel synthesis routes. For instance, it has been identified that synthesis routes such as liquid-phase oxidation, chemical vapor deposition, and oxidative exfoliation reduction are well suited for large scale of graphene, based upon environmental, economic, and social indicators [116]. In the case of MXenes, Naguib et al. reported a generic method for large-scale delamination of Mxenes $\left(\mathrm{V}_{2} \mathrm{CT}_{\mathrm{x}}\right.$ and $\mathrm{Ti}_{3} \mathrm{CNT}_{\mathrm{x}}$ ) using tetrabutylammonium hydroxide (TBAOH), choline hydroxide, or n-butylamine as an organic base. The authors reported a successful up-scaling of the process from few milliliters to a liter batch without significant changes of MXenes surface chemistry and overall quality [117]. Despite these recent reports, large scale production of 2D nanomaterials remains in its infancy and further research is required to take the processes to pilot scale before full-scale applications are feasible. In this regard, the study of alternative methods that could accelerate the transition from batch experiments to continuous production is key for the success of the methods revised in this work in the short term.

2D nanomaterials have been demonstrated to be well suited to degrade and reduce pharmaceutical pollutants in wastewater. Although, despite extensive research conducted, they still encounter several challenges to be addressed in the future:

- It is critical to replace toxic reagents during the synthesis of these materials (e.g., cyanide and hydrazine), which turn into secondary residues at the end of the fabrication process. In this regard, several studies highlight the importance of green synthesis methods such as the replacement of $\mathrm{HF}$, an etchant agent widely used during $\mathrm{Ti}_{3} \mathrm{C}_{2} \mathrm{~T}_{\mathrm{x}}$ MXene synthesis, by less toxic chemicals. For instance, Limbu et al. reported a green protocol for the room temperature synthesis of reduced $\mathrm{Ti}_{3} \mathrm{C}_{2} \mathrm{~T}_{\mathrm{x}}$ MXene via a simple L-ascorbic acid treatment [118].

- Toxicity studies on humans and environmental impact assessments need to be addressed, in the light of studies performed on graphene, GO, and rGO reporting that these materials can elicit toxic effects both in-vitro and in-vivo [119]. Furthermore, life cycle analyses should be considered in the development of every so-called sustainable material to establish the real impact of its fabrication and use on the environment [120].

- More research needs to be conducted on the regeneration and reuse of 2D nanomaterials for wastewater treatment to assure and improve sustainability. Moreover, a material with a high selectivity for the target pollutant is required for real wastewater applications. Real wastewaters contain different chemicals like organic and inorganic molecules, as well as counter ions, which can lead to a reduced efficiency than that reported at the laboratory scale employing one-component solutions.

Author Contributions: Conceptualization, M.C.-L. and S.G.-P.; formal analysis, M.C.-L., A.R. and S.G.-P.; investigation, M.C.-L., A.R. and S.G.-P.; writing-original draft preparation, M.C.-L., A.R. and S.G.-P.; writing-review and editing, M.C.-L., A.R. and S.G.-P. All authors have read and agreed to the published version of the manuscript.

Funding: This research received no external funding.

Institutional Review Board Statement: Not applicable.

Informed Consent Statement: Not applicable.

Conflicts of Interest: The authors declare no conflict of interest.

\section{References}

1. Ghosh, A.; Nayak, A.K.; Pal, A. Nano-Particle-Mediated Wastewater Treatment: A Review. Curr. Pollut. Rep. 2017, 3, 17-30. [CrossRef]

2. Zunita, M. Graphene oxide-based nanofiltration for $\mathrm{Hg}$ removal from wastewater: A mini review. Membranes 2021, 11, 269. [CrossRef]

3. Kommu, A.; Singh, J.K. A review on graphene-based materials for removal of toxic pollutants from wastewater. Soft Mater. 2020, 18, 297-322. [CrossRef] 
4. Sirés, I.; Brillas, E.; Oturan, M.A.; Rodrigo, M.A.; Panizza, M. Electrochemical advanced oxidation processes: Today and tomorrow. A review. Environ. Sci. Pollut. Res. 2014, 21, 8336-8367. [CrossRef] [PubMed]

5. Ibrahim, Y.; Kassab, A.; Eid, K.; Abdullah, A.M.; Ozoemena, K.I.; Elzatahry, A. Unveiling fabrication and environmental remediation of mxene-based nanoarchitectures in toxic metals removal from wastewater: Strategy and mechanism. Nanomaterials 2020, 10, 885. [CrossRef] [PubMed]

6. Chen, H.; Jing, L.; Teng, Y.; Wang, J. Multimedia fate modeling and risk assessment of antibiotics in a water-scarce megacity. J. Hazard. Mater. 2018, 348, 75-83. [CrossRef]

7. Aus der Beek, T.; Weber, F.A.; Bergmann, A.; Hickmann, S.; Ebert, I.; Hein, A.; Küster, A. Pharmaceuticals in the environmentGlobal occurrences and perspectives. Environ. Toxicol. Chem. 2016, 35, 823-835. [CrossRef]

8. Liu, J.L.; Wong, M.H. Pharmaceuticals and personal care products (PPCPs): A review on environmental contamination in China. Environ. Int. 2013, 59, 208-224. [CrossRef]

9. Lindsey, M.E.; Meyer, M.; Thurman, E.M. Analysis of Trace Levels of Sulfonamide and Tetracycline Antimicrobials in Groundwater and Surface Water Using Solid-Phase Extraction and Liquid Chromatography/Mass Spectrometry. Anal. Chem. 2001, 73, 46404646. [CrossRef]

10. Santos, J.L.; Aparicio, I.; Callejón, M.; Alonso, E. Occurrence of pharmaceutically active compounds during 1-year period in wastewaters from four wastewater treatment plants in Seville (Spain). J. Hazard. Mater. 2009, 164, 1509-1516. [CrossRef]

11. Luo, Y.; Guo, W.; Ngo, H.H.; Nghiem, L.D.; Hai, F.I.; Zhang, J.; Liang, S.; Wang, X.C. A review on the occurrence of micropollutants in the aquatic environment and their fate and removal during wastewater treatment. Sci. Total Environ. 2014, 473-474, 619-641. [CrossRef] [PubMed]

12. Monteil, H.; Péchaud, Y.; Oturan, N.; Oturan, M.A. A review on efficiency and cost effectiveness of electro- and bio-electro-Fenton processes: Application to the treatment of pharmaceutical pollutants in water. Chem. Eng. J. 2019, 376, 119577. [CrossRef]

13. Kharel, S.; Stapf, M.; Miehe, U.; Ekblad, M.; Cimbritz, M.; Falås, P.; Nilsson, J.; Sehlén, R.; Bester, K. Ozone dose dependent formation and removal of ozonation products of pharmaceuticals in pilot and full-scale municipal wastewater treatment plants. Sci. Total Environ. 2020, 731, 139064. [CrossRef] [PubMed]

14. Morris, D.; Harris, S.; Morris, C.; Commins, E.; Cormican, M. Hospital Effluent: Impact on the Microbial Environment and Risk to Human Health; Report No. 162; Environmental Protection Agency: Wexford, Ireland, 2016.

15. Zeng, M.; Chen, M.; Huang, D.; Lei, S.; Zhang, X.; Wang, L.; Cheng, Z. Engineered two-dimensional nanomaterials: An emerging paradigm for water purification and monitoring. Mater. Horiz. 2021, 8, 758-802. [CrossRef]

16. Ihsanullah, I. Boron nitride-based materials for water purification: Progress and outlook. Chemosphere 2021, 263, 127970. [CrossRef]

17. Yang, Y.; Wu, M.; Zhu, X.; Xu, H.; Ma, S.; Zhi, Y.; Xia, H.; Liu, X.; Pan, J.; Tang, J.-Y.; et al. 2020 Roadmap on two-dimensional nanomaterials for environmental catalysis. Chin. Chem. Lett. 2019, 30, 2065-2088. [CrossRef]

18. Liu, Y.; Zeng, X.; Hu, X.; Hu, J.; Zhang, X. Two-dimensional nanomaterials for photocatalytic water disinfection: Recent progress and future challenges. J. Chem. Technol. Biotechnol. 2019, 94, 22-37. [CrossRef]

19. Jeon, M.; Jun, B.M.; Kim, S.; Jang, M.; Park, C.M.; Snyder, S.A.; Yoon, Y. A review on MXene-based nanomaterials as adsorbents in aqueous solution. Chemosphere 2020, 261, 127781. [CrossRef]

20. Velusamy, S.; Roy, A.; Sundaram, S.; Kumar Mallick, T. A Review on Heavy Metal Ions and Containing Dyes Removal Through Graphene Oxide-Based Adsorption Strategies for Textile Wastewater Treatment. Chem. Rec. 2021, 21, 1570-1610. [CrossRef]

21. Faysal Hossain, M.D.; Akther, N.; Zhou, Y. Recent advancements in graphene adsorbents for wastewater treatment: Current status and challenges. Chin. Chem. Lett. 2020, 31, 2525-2538. [CrossRef]

22. Jun, B.M.; Kim, S.; Heo, J.; Park, C.M.; Her, N.; Jang, M.; Huang, Y.; Han, J.; Yoon, Y. Review of MXenes as new nanomaterials for energy storage/delivery and selected environmental applications. Nano Res. 2019, 12, 471-487. [CrossRef]

23. Yaqub, A.; Shafiq, Q.; Khan, A.R.; Husnain, S.M.; Shahzad, F. Recent advances in the adsorptive remediation of wastewater using two-dimensional transition metal carbides (MXenes): A review. New J. Chem. 2021, 45, 9721-9742. [CrossRef]

24. Zhang, S.; Gu, P.; Ma, R.; Luo, C.; Wen, T.; Zhao, G.; Cheng, W.; Wang, X. Recent developments in fabrication and structure regulation of visible-light-driven $\mathrm{g}-\mathrm{C}_{3} \mathrm{~N}_{4}$-based photocatalysts towards water purification: A critical review. Catal. Today 2019, 335, 65-77. [CrossRef]

25. Lopes, J.L.; Martins, M.J.; Nogueira, H.I.S.; Estrada, A.C.; Trindade, T. Carbon-based heterogeneous photocatalysts for water cleaning technologies: A review. Environ. Chem. Lett. 2021, 19, 643-668. [CrossRef]

26. Antonopoulou, M.; Kosma, C.; Albanis, T.; Konstantinou, I. An overview of homogeneous and heterogeneous photocatalysis applications for the removal of pharmaceutical compounds from real or synthetic hospital wastewaters under lab or pilot scale. Sci. Total Environ. 2021, 765, 144163. [CrossRef]

27. Ren, G.; Han, H.; Wang, Y.; Liu, S.; Zhao, J.; Meng, X.; Li, Z. Recent advances of photocatalytic application in water treatment: A review. Nanomaterials 2021, 11, 1804. [CrossRef]

28. Shurbaji, S.; Huong, P.T.; Altahtamouni, T.M. Review on the visible light photocatalysis for the decomposition of ciprofloxacin, norfloxacin, tetracyclines, and sulfonamides antibiotics in wastewater. Catalysts 2021, 11, 437. [CrossRef]

29. Atalay, S.; Ersöz, G. Advanced Oxidation Processes. In Novel Catalysts in Advanced Oxidation of Organic Pollutants; Springer: Cham, Switzerland, 2016; ISBN 9781789848908.

30. Chen, G.; Yu, Y.; Liang, L.; Duan, X.; Li, R.; Lu, X.; Yan, B.; Li, N.; Wang, S. Remediation of antibiotic wastewater by coupled photocatalytic and persulfate oxidation system: A critical review. J. Hazard. Mater. 2021, 408, 124461. [CrossRef] 
31. Liu, Y.; Zhao, Y.; Wang, J. Fenton/Fenton-like processes with in-situ production of hydrogen peroxide/hydroxyl radical for degradation of emerging contaminants: Advances and prospects. J. Hazard. Mater. 2021, 404, 124191. [CrossRef]

32. Wang, J.; Zhuan, R. Degradation of antibiotics by advanced oxidation processes: An overview. Sci. Total Environ. 2020, 701, 135023. [CrossRef]

33. Zhang, J.; Zhou, Y.; Yao, B.; Yang, J.; Zhi, D. Current progress in electrochemical anodic-oxidation of pharmaceuticals: Mechanisms, influencing factors, and new technique. J. Hazard. Mater. 2021, 418, 126313. [CrossRef]

34. Bampos, G.; Petala, A.; Frontistis, Z. Recent Trends in Pharmaceuticals Removal from Water Using Electrochemical Oxidation Processes. Environments 2021, 8, 85. [CrossRef]

35. Dao, K.C.; Yang, C.-C.; Chen, K.-F.; Tsai, Y.-P. Recent Trends in Removal Pharmaceuticals and Personal Care Products by Electrochemical Oxidation and Combined Systems. Water 2020, 12, 1043. [CrossRef]

36. Liu, L.; Chen, Z.; Zhang, J.; Shan, D.; Wu, Y.; Bai, L.; Wang, B. Treatment of industrial dye wastewater and pharmaceutical residue wastewater by advanced oxidation processes and its combination with nanocatalysts: A review. J. Water Process Eng. 2021, 42, 102122. [CrossRef]

37. Novoselov, K.S.; Geim, A.K.; Morozov, S.V.; Jiang, D.; Zhang, Y.; Dubonos, S.V.; Grigorieva, I.V.; Firsov, A.A. Electric Field Effect in Atomically Thin Carbon Films. Science 2004, 306, 666-669. [CrossRef] [PubMed]

38. Marcano, D.C.; Kosynkin, D.V.; Berlin, J.M.; Sinitskii, A.; Sun, Z.; Slesarev, A.; Alemany, L.B.; Lu, W.; Tour, J.M. Improved Synthesis of Graphene Oxide. ACS Nano 2010, 4, 4806-4814. [CrossRef] [PubMed]

39. Manzeli, S.; Ovchinnikov, D.; Pasquier, D.; Yazyev, O.V.; Kis, A. 2D transition metal dichalcogenides. Nat. Rev. Mater. 2017, 2, 17033. [CrossRef]

40. Rosenkranz, A.; Costa, H.L.; Baykara, M.Z.; Martini, A. Synergetic effects of surface texturing and solid lubricants to tailor friction and wear-A review. Tribol. Int. 2021, 155, 106792. [CrossRef]

41. Anasori, B.; Lukatskaya, M.R.; Gogotsi, Y. 2D metal carbides and nitrides (MXenes) for energy storage. Nat. Rev. Mater. 2017, 2, 16098. [CrossRef]

42. Naguib, M.; Barsoum, M.W.; Gogotsi, Y. Ten Years of Progress in the Synthesis and Development of MXenes. Adv. Mater. 2021, 2103393, 1-10. [CrossRef]

43. Wyatt, B.C.; Rosenkranz, A.; Anasori, B. 2D MXenes: Tunable Mechanical and Tribological Properties. Adv. Mater. 2021, 33, 2007973. [CrossRef] [PubMed]

44. Ihsanullah, I. MXenes (two-dimensional metal carbides) as emerging nanomaterials for water purification: Progress, challenges and prospects. Chem. Eng. J. 2020, 388, 124340. [CrossRef]

45. Rasool, K.; Pandey, R.P.; Rasheed, P.A.; Buczek, S.; Gogotsi, Y.; Mahmoud, K.A. Water treatment and environmental remediation applications of two-dimensional metal carbides (MXenes). Mater. Today 2019, 30, 80-102. [CrossRef]

46. Dervin, S.; Dionysiou, D.D.; Pillai, S.C. 2D nanostructures for water purification: Graphene and beyond. Nanoscale 2016, 8, 15115-15131. [CrossRef] [PubMed]

47. Minale, M.; Gu, Z.; Guadie, A.; Kabtamu, D.M.; Li, Y.; Wang, X. Application of graphene-based materials for removal of tetracyclines using adsorption and photocatalytic-degradation: A review. J. Environ. Manag. 2020, 276, 111310. [CrossRef]

48. Li, M.; Liu, Y.; Zeng, G.; Liu, N.; Liu, S. Graphene and graphene-based nanocomposites used for antibiotics removal in water treatment: A review. Chemosphere 2019, 226, 360-380. [CrossRef]

49. Lu, L.; Yang, Q.; Xu, Q.; Sun, Y.; Tang, S.; Tang, X.; Liang, H.; Yu, Y. Two-dimensional materials beyond graphene for the detection and removal of antibiotics: A critical review. Crit. Rev. Environ. Sci. Technol. 2021, 51, 1-32. [CrossRef]

50. Yang, X.; Chen, Z.; Zhao, W.; Liu, C.; Qian, X.; Zhang, M.; Wei, G.; Khan, E.; Hau Ng, Y.; Sik Ok, Y. Recent advances in photodegradation of antibiotic residues in water. Chem. Eng. J. 2021, 405, 126806. [CrossRef]

51. Jakubczak, M.; Szuplewska, A.; Rozmysłowska-Wojciechowska, A.; Rosenkranz, A.; Jastrzębska, A.M. Novel 2D MBenesSynthesis, Structure, and Biotechnological Potential. Adv. Funct. Mater. 2021, 31, 2103048. [CrossRef]

52. Papageorgiou, D.G.; Kinloch, I.A.; Young, R.J. Mechanical properties of graphene and graphene-based nanocomposites. Prog. Mater. Sci. 2017, 90, 75-127. [CrossRef]

53. Compton, O.C.; Cranford, S.W.; Putz, K.W.; An, Z.; Brinson, L.C.; Buehler, M.J.; Nguyen, S.T. Tuning the Mechanical Properties of Graphene Oxide Paper and Its Associated Polymer Nanocomposites by Controlling Cooperative Intersheet Hydrogen Bonding. ACS Nano 2012, 6, 2008-2019. [CrossRef] [PubMed]

54. Wu, Z.; Shang, T.; Deng, Y.; Tao, Y.; Yang, Q. The Assembly of MXenes from 2D to 3D. Adv. Sci. 2020, 7, 1903077. [CrossRef]

55. Quero, F.; Rosenkranz, A. Mechanical Performance of Binary and Ternary Hybrid MXene/Nanocellulose Hydro- and Aerogels-A Critical Review. Adv. Mater. Interfaces 2021, 8, 2100952. [CrossRef]

56. Ye, S.; Yan, M.; Tan, X.; Liang, J.; Zeng, G.; Wu, H.; Song, B.; Zhou, C.; Yang, Y.; Wang, H. Facile assembled biochar-based nanocomposite with improved graphitization for efficient photocatalytic activity driven by visible light. Appl. Catal. B Environ. 2019, 250, 78-88. [CrossRef]

57. Rosales, M.; Garcia, A.; Fuenzalida, V.M.; Espinoza-González, R.; Song, G.; Wang, B.; Yu, J.; Gracia, F.; Rosenkranz, A. Unprecedented arsenic photo-oxidation behavior of few- and multi-layer $\mathrm{Ti}_{3} \mathrm{C}_{2} \mathrm{~T}_{\mathrm{x}}$ nano-sheets. Appl. Mater. Today 2020, $20,100769$. [CrossRef]

58. Chaves, A.; Azadani, J.G.; Alsalman, H.; da Costa, D.R.; Frisenda, R.; Chaves, A.J.; Song, S.H.; Kim, Y.D.; He, D.; Zhou, J.; et al. Bandgap engineering of two-dimensional semiconductor materials. Jpn. 2D Mater. Appl. 2020, 4, 29. [CrossRef] 
59. Lu, J.; Wu, J.; Carvalho, A.; Ziletti, A.; Liu, H.; Tan, J.; Chen, Y.; Castro Neto, A.H.; Özyilmaz, B.; Sow, C.H. Bandgap Engineering of Phosphorene by Laser Oxidation toward Functional 2D Materials. ACS Nano 2015, 9, 10411-10421. [CrossRef]

60. Ba, K.; Jiang, W.; Cheng, J.; Bao, J.; Xuan, N.; Sun, Y.; Liu, B.; Xie, A.; Wu, S.; Sun, Z. Chemical and Bandgap Engineering in Monolayer Hexagonal Boron Nitride. Sci. Rep. 2017, 7, 45584. [CrossRef]

61. Zhao, P.; Jian, M.; Zhang, Q.; Xu, R.; Liu, R.; Zhang, X.; Liu, H. A new paradigm of ultrathin 2D nanomaterial adsorbents in aqueous media: Graphene and GO, MoS 2 , MXenes, and 2D MOFs. J. Mater. Chem. A 2019, 7, 16598-16621. [CrossRef]

62. Zhang, Y.; Yin, Z.; Dai, C.; Zhou, X.; Chen, W. Interfacial thermodynamics and kinetics of sorption of diclofenac on prepared high performance flower-like $\mathrm{MoS}_{2}$. J. Colloid Interface Sci. 2016, 481, 210-219. [CrossRef]

63. Liu, G.; Zhang, Z.; Yan, C.; Wang, Y.; Ma, X.; Gao, P.; Feng, Y. Adsorption of estrone with few-layered boron nitride nanosheets: Kinetics, thermodynamics and mechanism. Chemosphere 2018, 207, 534-542. [CrossRef] [PubMed]

64. Chao, Y.; Zhang, J.; Li, H.; Wu, P.; Li, X.; Chang, H.; He, J.; Wu, H.; Li, H.; Zhu, W. Synthesis of boron nitride nanosheets with $\mathrm{N}$-defects for efficient tetracycline antibiotics adsorptive removal. Chem. Eng. J. 2020, 387, 124138. [CrossRef]

65. Chao, Y.; Tang, B.; Luo, J.; Wu, P.; Tao, D.; Chang, H.; Chu, X.; Huang, Y.; Li, H.; Zhu, W. Hierarchical porous boron nitride with boron vacancies for improved adsorption performance to antibiotics. J. Colloid Interface Sci. 2021, 584, 154-163. [CrossRef] [PubMed]

66. Tian, C.; Zhao, H.; Sun, H.; Xiao, K.; Keung Wong, P. Enhanced adsorption and photocatalytic activities of ultrathin graphitic carbon nitride nanosheets: Kinetics and mechanism. Chem. Eng. J. 2020, 381, 122760. [CrossRef]

67. Zhao, S.; Li, S.; Zhao, Z.; Su, Y.; Long, Y.; Zheng, Z.; Cui, D.; Liu, Y.; Wang, C.; Zhang, X.; et al. Microwave-assisted hydrothermal assembly of 2D copper-porphyrin metal-organic frameworks for the removal of dyes and antibiotics from water. Environ. Sci. Pollut. Res. 2020, 27, 39186-39197. [CrossRef]

68. Tang, Y.; Huang, H.; Xue, W.; Chang, Y.; Li, Y.; Guo, X.; Zhong, C. Rigidifying induced fluorescence enhancement in 2D porous covalent triazine framework nanosheets for the simultaneously luminous detection and adsorption removal of antibiotics. Chem. Eng. J. 2020, 384, 123382. [CrossRef]

69. Jiang, W.; Cui, W.; Liang, R.; Qiu, J. Zwitterionic surface charge regulation in ionic covalent organic nanosheets: Synergistic adsorption of fluoroquinolone antibiotics. Chem. Eng. J. 2021, 417, 128034. [CrossRef]

70. Ghani, A.A.; Shahzad, A.; Moztahida, M.; Tahir, K.; Jeon, H.; Kim, B.; Lee, D.S. Adsorption and electrochemical regeneration of intercalated $\mathrm{Ti}_{3} \mathrm{C}_{2} \mathrm{~T}_{\mathrm{x}}$ MXene for the removal of ciprofloxacin from wastewater. Chem. Eng. J. 2021, 421, 127780. [CrossRef]

71. Wu, J.; Zhao, H.; Chen, R.; Pham-Huy, C.; Hui, X.; He, H. Adsorptive removal of trace sulfonamide antibiotics by water-dispersible magnetic reduced graphene oxide-ferrite hybrids from wastewater. J. Chromatogr. B 2016, 1029-1030, 106-112. [CrossRef]

72. Li, M.; Liu, Y.; Zeng, G.; Liu, S.; Hu, X.; Shu, D.; Jiang, L.; Tan, X.; Cai, X.; Yan, Z. Tetracycline absorbed onto nitrilotriacetic acid-functionalized magnetic graphene oxide: Influencing factors and uptake mechanism. J. Colloid Interface Sci. 2017, 485, 269-279. [CrossRef]

73. Li, C.; Chen, C.-H.; Chen, W. Different influences of nanopore dimension and $\mathrm{pH}$ between chlorpheniramine adsorptions on graphene oxide-iron oxide suspension and particle. Chem. Eng. J. 2017, 307, 447-455. [CrossRef]

74. Xiao, R.; Wang, S.; Ibrahim, M.H.; Abdu, H.I.; Shan, D.; Chen, J.; Lu, X. Three-dimensional hierarchical frameworks based on molybdenum disulfide-graphene oxide-supported magnetic nanoparticles for enrichment fluoroquinolone antibiotics in water. J. Chromatogr. A 2019, 1593, 1-8. [CrossRef]

75. Park, C.M.; Heo, J.; Wang, D.; Su, C.; Yoon, Y. Heterogeneous activation of persulfate by reduced graphene oxide-elemental silver/magnetite nanohybrids for the oxidative degradation of pharmaceuticals and endocrine disrupting compounds in water. Appl. Catal. B Environ. 2018, 225, 91-99. [CrossRef]

76. Zeng, Z.; Ye, S.; Wu, H.; Xiao, R.; Zeng, G.; Liang, J.; Zhang, C.; Yu, J.; Fang, Y.; Song, B. Research on the sustainable efficacy of g-MoS 2 decorated biochar nanocomposites for removing tetracycline hydrochloride from antibiotic-polluted aqueous solution. Sci. Total Environ. 2019, 648, 206-217. [CrossRef] [PubMed]

77. González, J.A.; Bafico, J.G.; Villanueva, M.E.; Giorgieri, S.A.; Copello, G.J. Continuous flow adsorption of ciprofloxacin by using a nanostructured chitin/graphene oxide hybrid material. Carbohydr. Polym. 2018, 188, 213-220. [CrossRef]

78. Shahzad, A.; Nawaz, M.; Moztahida, M.; Jang, J.; Tahir, K.; Kim, J.; Lim, Y.; Vassiliadis, V.S.; Woo, S.H.; Lee, D.S. Ti 3 C $_{2} \mathrm{~T}_{\mathrm{x}}$ MXene core-shell spheres for ultrahigh removal of mercuric ions. Chem. Eng. J. 2019, 368, 400-408. [CrossRef]

79. Khan, A.R.; Husnain, S.M.; Shahzad, F.; Mujtaba-ul-Hassan, S.; Mehmood, M.; Ahmad, J.; Mehran, M.T.; Rahman, S. Twodimensional transition metal carbide $\left(\mathrm{Ti}_{3} \mathrm{C}_{2} \mathrm{~T}_{\mathrm{x}}\right)$ as an efficient adsorbent to remove cesium $\left(\mathrm{Cs}^{+}\right)$. Dalt. Trans. 2019, 48, 11803-11812. [CrossRef] [PubMed]

80. Zhang, K.; Li, H.; Xu, X.; Yu, H. Synthesis of reduced graphene oxide/NiO nanocomposites for the removal of $\mathrm{Cr}(\mathrm{VI}) \mathrm{from}$ aqueous water by adsorption. Microporous Mesoporous Mater. 2018, 255, 7-14. [CrossRef]

81. Teoh, W.Y.; Scott, J.A.; Amal, R. Progress in Heterogeneous Photocatalysis: From Classical Radical Chemistry to Engineering Nanomaterials and Solar Reactors. J. Phys. Chem. Lett. 2012, 3, 629-639. [CrossRef]

82. Tahir, M.; Tasleem, S.; Tahir, B. Recent development in band engineering of binary semiconductor materials for solar driven photocatalytic hydrogen production. Int. J. Hydrogen Energy 2020, 45, 15985-16038. [CrossRef]

83. Zhao, Z.; Sun, Y.; Dong, F. Graphitic carbon nitride based nanocomposites: A review. Nanoscale 2015, 7, 15-37. [CrossRef] [PubMed] 
84. Wang, X.; Maeda, K.; Thomas, A.; Takanabe, K.; Xin, G.; Carlsson, J.M.; Domen, K.; Antonietti, M. A metal-free polymeric photocatalyst for hydrogen production from water under visible light. Nat. Mater. 2009, 8, 76-80. [CrossRef] [PubMed]

85. Wang, X.L.; Yang, H.G. Facile fabrication of high-yield graphitic carbon nitride with a large surface area using bifunctional urea for enhanced photocatalytic performance. Appl. Catal. B Environ. 2017, 205, 624-630. [CrossRef]

86. Shi, Y.; Huang, J.; Zeng, G.; Cheng, W.; Yu, H.; Gu, Y.; Shi, L.; Yi, K. Stable, metal-free, visible-light-driven photocatalyst for efficient removal of pollutants: Mechanism of action. J. Colloid Interface Sci. 2018, 531, 433-443. [CrossRef] [PubMed]

87. Liu, M.; Zhang, D.; Han, J.; Liu, C.; Ding, Y.; Wang, Z.; Wang, A. Adsorption enhanced photocatalytic degradation sulfadiazine antibiotic using porous carbon nitride nanosheets with carbon vacancies. Chem. Eng. J. 2020, 382, 123017. [CrossRef]

88. Jian, J.; Jiang, G.; van de Krol, R.; Wei, B.; Wang, H. Recent advances in rational engineering of multinary semiconductors for photoelectrochemical hydrogen generation. Nano Energy 2018, 51, 457-480. [CrossRef]

89. Guo, H.; Niu, C.-G.; Feng, C.-Y.; Liang, C.; Zhang, L.; Wen, X.-J.; Yang, Y.; Liu, H.-Y.; Li, L.; Lin, L.-S. Steering exciton dissociation and charge migration in green synthetic oxygen-substituted ultrathin porous graphitic carbon nitride for boosted photocatalytic reactive oxygen species generation. Chem. Eng. J. 2020, 385, 123919. [CrossRef]

90. Wang, W.; Xu, P.; Chen, M.; Zeng, G.; Zhang, C.; Zhou, C.; Yang, Y.; Huang, D.; Lai, C.; Cheng, M.; et al. Alkali Metal-Assisted Synthesis of Graphite Carbon Nitride with Tunable Band-Gap for Enhanced Visible-Light-Driven Photocatalytic Performance. ACS Sustain. Chem. Eng. 2018, 6, 15503-15516. [CrossRef]

91. Yi, X.; Yuan, J.; Tang, H.; Du, Y.; Hassan, B.; Yin, K.; Chen, Y.; Liu, X. Embedding few-layer $\mathrm{Ti}_{3} \mathrm{C}_{2} \mathrm{~T}_{\mathrm{x}}$ into alkalized g-C3N4 nanosheets for efficient photocatalytic degradation. J. Colloid Interface Sci. 2020, 571, 297-306. [CrossRef]

92. Ahern, J.C.; Fairchild, R.; Thomas, J.S.; Carr, J.; Patterson, H.H. Characterization of BiOX compounds as photocatalysts for the degradation of pharmaceuticals in water. Appl. Catal. B Environ. 2015, 179, 229-238. [CrossRef]

93. Sharma, K.; Dutta, V.; Sharma, S.; Raizada, P.; Hosseini-Bandegharaei, A.; Thakur, P.; Singh, P. Recent advances in enhanced photocatalytic activity of bismuth oxyhalides for efficient photocatalysis of organic pollutants in water: A review. J. Ind. Eng. Chem. 2019, 78, 1-20. [CrossRef]

94. Tang, L.; Lv, Z.; Xue, Y.; Xu, L.; Qiu, W.; Zheng, C.; Chen, W.; Wu, M. MIL-53(Fe) incorporated in the lamellar BiOBr: Promoting the visible-light catalytic capability on the degradation of rhodamine B and carbamazepine. Chem. Eng. J. 2019, 374, 975-982. [CrossRef]

95. Gao, X.; Peng, W.; Tang, G.; Guo, Q.; Luo, Y. Highly efficient and visible-light-driven BiOCl for photocatalytic degradation of carbamazepine. J. Alloys Compd. 2018, 757, 455-465. [CrossRef]

96. Xu, J.; Wang, Y.; Niu, J.; Chen, M. Facile construction of BiOBr/BiOCOOH p-n heterojunction photocatalysts with improved visible-light-driven photocatalytic performance. Sep. Purif. Technol. 2019, 225, 24-32. [CrossRef]

97. Chen, Y.; Tian, H.; Zhu, W.; Zhang, X.; Li, R.; Chen, C.; Huang, Y. L-Cysteine directing synthesis of BiOBr nanosheets for efficient cefazolin photodegradation: The pivotal role of thiol. J. Hazard. Mater. 2021, 414, 125544. [CrossRef] [PubMed]

98. Wang, C.-Y.; Zhang, X.; Qiu, H.-B.; Huang, G.-X.; Yu, H.-Q. $\mathrm{Bi}_{24} \mathrm{O}_{31} \mathrm{Br}_{10}$ nanosheets with controllable thickness for visible-lightdriven catalytic degradation of tetracycline hydrochloride. Appl. Catal. B Environ. 2017, 205, 615-623. [CrossRef]

99. Wang, X.; Bi, W.; Zhai, P.; Wang, X.; Li, H.; Mailhot, G.; Dong, W. Adsorption and photocatalytic degradation of pharmaceuticals by BiOClxI $\mathrm{y}_{\mathrm{y}}$ nanospheres in aqueous solution. Appl. Surf. Sci. 2016, 360, 240-251. [CrossRef]

100. Zhang, L.; Yue, X.; Liu, J.; Feng, J.; Zhang, X.; Zhang, C.; Li, R.; Fan, C. Facile synthesis of $\mathrm{Bi}_{5} \mathrm{O}_{7} \mathrm{Br} / \mathrm{BiOBr} 2 \mathrm{D} / 3 \mathrm{D}$ heterojunction as efficient visible-light-driven photocatalyst for pharmaceutical organic degradation. Sep. Purif. Technol. 2020, $231,115917$. [CrossRef]

101. Li, H.; Long, B.; Ye, K.-H.; Cai, Y.; He, X.; Lan, Y.; Yang, Z.; Ji, H. A recyclable photocatalytic tea-bag-like device model based on ultrathin $\mathrm{Bi} / \mathrm{C} / \mathrm{BiOX}(\mathrm{X}=\mathrm{Cl}, \mathrm{Br})$ nanosheets. Appl. Surf. Sci. 2020, 515, 145967. [CrossRef]

102. Shen, G.; Pu, Y.; Sun, R.; Shi, Y.; Cui, Y.; Jing, P. Enhanced visible light photocatalytic performance of a novel heterostructured $\mathrm{Bi}_{4} \mathrm{Ti}_{3} \mathrm{O}_{12} / \mathrm{BiOBr}$ photocatalyst. New J. Chem. 2019, 43, 12932-12940. [CrossRef]

103. Sivula, K.; van de Krol, R. Semiconducting materials for photoelectrochemical energy conversion. Nat. Rev. Mater. 2016, 1, 15010. [CrossRef]

104. Xu, P.; Shen, X.; Luo, L.; Shi, Z.; Liu, Z.; Chen, Z.; Zhu, M.; Zhang, L. Preparation of $\mathrm{TiO}_{2} / \mathrm{Bi}_{2} \mathrm{~W}_{6}$ nanostructured heterojunctions on carbon fibers as a weaveable visible-light photocatalyst/photoelectrode. Environ. Sci. Nano 2018, 5, 327-337. [CrossRef]

105. Leong, S.; Li, D.; Hapgood, K.; Zhang, X.; Wang, H. Ni(OH $)_{2}$ decorated rutile $\mathrm{TiO}_{2}$ for efficient removal of tetracycline from wastewater. Appl. Catal. B Environ. 2016, 198, 224-233. [CrossRef]

106. Lin, L.; Jiang, W.; Nasr, M.; Bechelany, M.; Miele, P.; Wang, H.; Xu, P. Enhanced visible light photocatalysis by TiO ${ }_{2}-\mathrm{BN}$ enabled electrospinning of nanofibers for pharmaceutical degradation and wastewater treatment. Photochem. Photobiol. Sci. 2019, 18, 2921-2930. [CrossRef]

107. Taoufik, N.; Boumya, W.; Achak, M.; Sillanpää, M.; Barka, N. Comparative overview of advanced oxidation processes and biological approaches for the removal pharmaceuticals. J. Environ. Manag. 2021, 288, 112404. [CrossRef]

108. Ma, M.; Chen, L.; Zhao, J.; Liu, W.; Ji, H. Efficient activation of peroxymonosulfate by hollow cobalt hydroxide for degradation of ibuprofen and theoretical study. Chin. Chem. Lett. 2019, 30, 2191-2195. [CrossRef]

109. Ding, M.; Chen, W.; Xu, H.; Shen, Z.; Lin, T.; Hu, K.; Lu, C.h.; Xie, Z. Novel $\alpha-\mathrm{Fe}_{2} \mathrm{O}_{3} / \mathrm{MXene}$ nanocomposite as heterogeneous activator of peroxymonosulfate for the degradation of salicylic acid. J. Hazard. Mater. 2020, 382, 121064. [CrossRef] 
110. Yang, L.; Chen, H.; Jia, F.; Peng, W.; Tian, X.; Xia, L.; Wu, X.; Song, S. Emerging Hexagonal Mo 2 C Nanosheet with (002) Facet Exposure and $\mathrm{Cu}$ Incorporation for Peroxymonosulfate Activation Toward Antibiotic Degradation. ACS Appl. Mater. Interfaces 2021, 13, 14342-14354. [CrossRef]

111. Nie, M.; Li, Y.; Li, L.; He, J.; Hong, P.; Zhang, K.; Cai, X.; Kong, L.; Liu, J. Ultrathin iron-cobalt oxide nanosheets with enhanced $\mathrm{H}_{2} \mathrm{O}_{2}$ activation performance for efficient degradation of tetracycline. Appl. Surf. Sci. 2021, 535, 147655. [CrossRef]

112. Xing, D.; Cui, Z.; Liu, Y.; Wang, Z.; Wang, P.; Zheng, Z.; Cheng, H.; Dai, Y.; Huang, B. Two-dimensional $\pi-d$ conjugated metalorganic framework $\mathrm{Fe}_{3}$ (hexaiminotriphenylene) ${ }_{2}$ as a photo-Fenton like catalyst for highly efficient degradation of antibiotics. Appl. Catal. B Environ. 2021, 290, 120029. [CrossRef]

113. Mi, X.; Han, J.; Sun, Y.; Li, Y.; Hu, W.; Zhan, S. Enhanced catalytic degradation by using RGO-Ce/WO 3 nanosheets modified CF as electro-Fenton cathode: Influence factors, reaction mechanism and pathways. J. Hazard. Mater. 2019, 367, 365-374. [CrossRef]

114. Tang, H.; Shang, Q.; Tang, Y.; Yi, X.; Wei, Y.; Yin, K.; Liu, M.; Liu, C. Static and continuous flow photoelectrocatalytic treatment of antibiotic wastewater over mesh of $\mathrm{TiO}_{2}$ nanotubes implanted with $\mathrm{g}-\mathrm{C}_{3} \mathrm{~N}_{4}$ nanosheets. J. Hazard. Mater. 2020, $384,121248$. [CrossRef]

115. Wang, J.; Xu, M.; Liang, X.; Zhang, Y.; Yang, D.; Pan, L.; Fang, W.; Zhu, C.; Wang, F. Development of a novel 2D Ni-MOF derived NiO@C nanosheet arrays modified Ti/TiO2NTs $/ \mathrm{PbO}_{2}$ electrode for efficient electrochemical degradation of salicylic acid wastewater. Sep. Purif. Technol. 2021, 263, 118368. [CrossRef]

116. Lee, X.J.; Hiew, B.Y.Z.; Lai, K.C.; Lee, L.Y.; Gan, S.; Thangalazhy-Gopakumar, S.; Rigby, S. Review on graphene and its derivatives: Synthesis methods and potential industrial implementation. J. Taiwan Inst. Chem. Eng. 2019, 98, 163-180. [CrossRef]

117. Naguib, M.; Unocic, R.R.; Armstrong, B.L.; Nanda, J. Large-scale delamination of multi-layers transition metal carbides and carbonitrides "MXenes". Dalt. Trans. 2015, 44, 9353-9358. [CrossRef]

118. Limbu, T.B.; Chitara, B.; Orlando, J.D.; Garcia Cervantes, M.Y.; Kumari, S.; Li, Q.; Tang, Y.; Yan, F. Green synthesis of reduced $\mathrm{Ti}_{3} \mathrm{C}_{2} \mathrm{~T}_{\mathrm{X}}$ MXene nanosheets with enhanced conductivity, oxidation stability, and SERS activity. J. Mater. Chem. C 2020, 8 , 4722-4731. [CrossRef]

119. Guo, X.; Mei, N. Assessment of the toxic potential of graphene family nanomaterials. J. Food Drug Anal. 2014, 22, 105-115. [CrossRef] [PubMed]

120. Cossutta, M.; Vretenar, V.; Centeno, T.A.; Kotrusz, P.; McKechnie, J.; Pickering, S.J. A comparative life cycle assessment of graphene and activated carbon in a supercapacitor application. J. Clean. Prod. 2020, 242, 118468. [CrossRef] 